UNIVERSIDADE DE SÃO PAULO

INSTITUTO DE GEOCIENNCIAS

\title{
DISTRIBUIÇÃO DE METAIS PESADOS PROVENIENTES DOS RESÍDUOS DE LODO DE ESGOTO EM AMBIENTE LACUSTRE
}

\author{
VALÉRIA GUIMARÃES
}

Orientador: Prof. Dr. Joel Barbujiani Sígolo

DISSERTAÇÃO DE MESTRADO

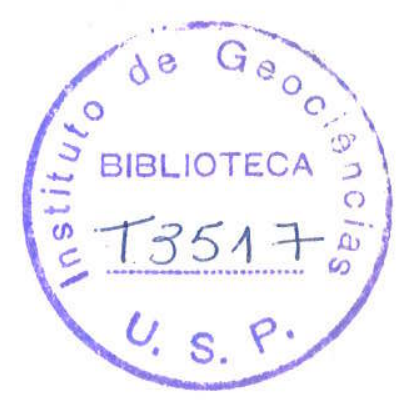

COMISSÃO JULGADORA

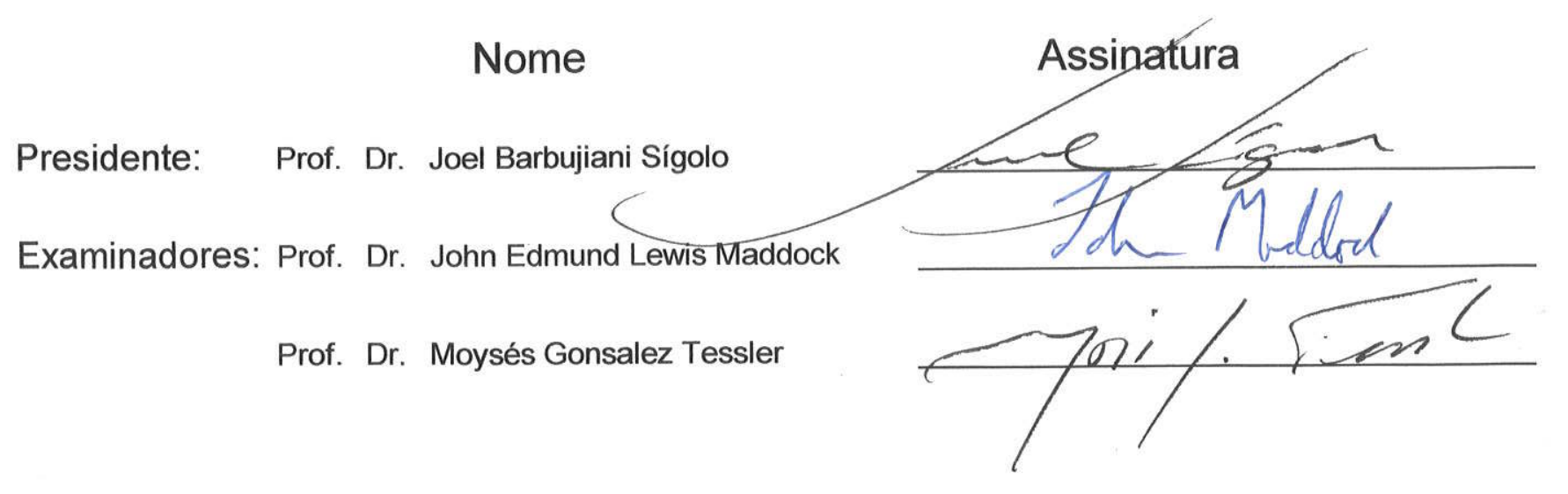

SÃO PAULO

2001 


\section{UNIVERSIDADE DE SÃO PAULO INSTITUTO DE GEOCIÊNCIAS}

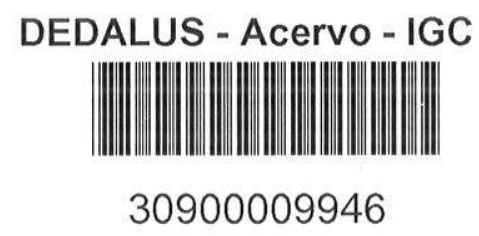

\section{DISTRIBUIÇÃO DE METAIS PESADOS PROVENIENTES DOS RESÍDUOS DE LODO DE ESGOTO EM AMBIENTE LACUSTRE}

\section{Valéria Guimarães}

\section{DISSERTAÇÃO DE MESTRADO}

Programa de Pós-Graduação em Geoquímica e Geotectônica 
"À minha avó Nair "in memorian", por acreditar em mim" 
Agradeço de coração ao meu amigo, professor e orientador Prof. Dr. Joel Barbujiani Sigolo, pela paciência, confiança, apoio e dedicação.

Agradeço em especial às seguintes instituições e pessoas que me ajudaram na viabilização e na elaboração desta dissertação:

Ao Prof. Dr. Antônio Aparecido Mozeto do Instituto de Química da Universidade Federal de São Carlos (UFSCAR), pela ajuda prestada no início desta dissertação e pelos conhecimentos transmitidos sobre o tema estudado;

Ao Prof. Dr. Moysés Gonçales Tessler do Instituto Oceonográfico (IO) da Universidade de São Paulo (USP), que me orientou nos procedimentos de coleta;

À Elaine do Laboratório de Sedimentologia do Instituto de Geociências (IGC) - USP, pela amizade e ajuda prestada no decorrer das análises granulométricas;

Ao pessoal do Laboratório de Química e ICP-AES do IGC-USP, Sandra, Marinês e Ricardo, que executaram todas as análises químicas com grande competência e eficiência;

A Lúcia Helena do CEPAS do IGC-USP, que executou parte das análises químicas totais; Ao pessoal do Laboratório de Microscopia Eletrônica de Varredura (MEV) do IGc-USP, pela realização das análises microscópicas;

Ao pessoal do Laboratório de Caracterização Tecnológica (LCT) da Faculdade de Engenharia de Minas da USP, que executaram as análises granulométricas;

Aos funcionários Ana Paula Cabonal e Magali P. F. Rizzo (Secretaria da Pós-Graduação), Rita Parisi e Pedro (Setor de Informática), Tadeu (Secretário da Pós-Graduação), José Paulo (LTA), Verônica (Laboratório de Geoquímica), Erica e Brenda (Biblioteca), pela paciência e boa vontade para comigo;

À Seção Gráfica e à Seção de Reprodução Fotográfica, que sempre foram muito atenciosos comigo;

Aos meus amigos e colegas da graduação, em especial à Lucelene Martins e à Márcia Mika, pela ajuda prestada e principalmente pela amizade cultivada durante todos estes anos de geologia;

Aos amigos da pós-graduação do Programa de Geologia e Geotectônica, em especial à Cyntia Helena, pela amizade e pelas calorosas discussões sobre o tema abordado;

Ao pessoal da Estação de Tratamento de Esgoto de Barueri (ETE), por tornarem este trabalho possivel;

À Fundação de Amparo a Pesquisa do Estado de São Paulo (FAPESP) pelo financiamento prestado, pois sem este seria impossivel a realização desta pesquisa;

Ao Programa de Pós-Graduação em Geoquímica e Geotectônica e ao Departamento de Geologia Sedimentar e Ambiental (DGSA) do IGc da USP, que me acolheram;

Ao meu noivo Elmar, por ter feito a editoração desta dissertação, por sempre estar disponivel quando precisei e pela extrema paciência;

Aos meus pais (Elcio e Thereza), à minha irmã Kátia e à minha sobrinha Amanda, sempre presentes, solidários e dedicados para comigo. Ao meu irmão Marcelo, pela atençấo, boa vontade e ajuda prestada;

Aos meus sogros (Doracir e Zezá), à minha cunhada Cristina e às minhas sobrinhas Ana Paula e Ana Cláudia, por me incentivarem;

A minha tia Sinhá, por ter me acolhido e por ter tido paciência suficiente, principalmente no decorrer do termino desta pesquisa;

A minha amiga Kátia e ao Eduardo, por terem me ajudado na impressão desta dissertação $e$ por sempre estarem ao meu lado me ajudando.

A minha amiga Gislaine, por tudo.

Meu muito obrigado! 


\section{INDICE}

ÍNDICE DE FIGURAS

iv

ÍNDICE DE TABELAS

vii

ÍNDICE DE QUADROS $x$

RESUMO $x i$

ABSTRACT xiii

1 - INTRODUÇÃO 1

1.1 - Objetivos 2

2 - METAIS PESADOS 3

2.1 - Metais Pesados em Sistemas Naturais 3

2.1.1 Toxicidade dos Metais Pesados em Ambientes Naturais 4

2.2 - Metais Pesados em Sistemas Lacustres 5

2.2.1 Geoquímica dos Metais Pesados em Sistemas Lacustres ___ 6

2.2.1.l Efeitos do pH e Eh no comportamento geoquímico dos metais

2.2.1.1.1 Comportamento geoquímico do Cobre, Cromo, Níquel e Zinco em função dos parâmetros físico-químicos 10

3 - CARACTERIZAÇAO DA ÁREA DE ESTUDO 13

3.1 - Localização 13

3.2 - Clima 16

3.2 .1 Temperatura

3.2.2 Pluviosidade 16

3.3 - Geomorfologia __ 17

$3.4-$ Solos 17

3.5 - Geologia 18

3.6 - Hidrologia 20

3.6.1 Águas Superficiais 20

3.6.2 Águas Subterrâneas________ 21

4- MATERLAIS E MÉTODOS 22

4.1 - Trabalho de Campo _ 22

4.1.1 Reconhecimento Inicial $\quad 22$

4.1.2 Mapeamento e Batimetria do Lago ___ 23

4.1.3 Obtenção de Coordenadas Geográficas___ 23

4.1.4 Amostragem _ـ 24 
4.1.4.1 Amostragem do sedimento de fundo 25

4.1.4.2 Amostragem da água da interface e do sedimento particulado em suspensão

4.1.5 Obtenção de Parâmetros Físico-Químicos no Sedimento de Fundo e na Água da Interface

4.1.5.1 Medidas de pH e Eh no sedimento de fundo

4.1.5.2 Medidas de pH e Eh na água da interface

4.2 - Trabalho de Laboratório 33

4.2.1 Análises Realizadas nas Amostras de Sedimento de Fundo

4.2.1.1 Análises sedimentares

4.2.1.1.1 Análise macroscópica

4.2.1.1.2 Dosagem do teor de umidade 34

4.2.1.1.3 Dosagem do conteúdo de matéria orgânica 34

4.2.1.1.4 Análises granulométricas 34

4.2.1.2 Análises químicas totais 34

4.2.1.2.1 Espectrometria de emissão atômica (ICP-AES)

4.2.2 Análises Realizadas nas Amostras de Água da Interface

4.2.2.1 Análises químicas

4.2.2.1.1 Espectrometria de absorção atômica (AAS)

4.2.2.1.2 Cromatografia de íons

4.2.3 Análises Realizadas nas Amostras de Sedimento Particulado em Suspensão

4.2.3.1 Microscopia eletrônica de varredura com energy dispersive spectrum (MEV/EDS)

\section{3 - Tratamento dos Dados}

4.3.1 Tratamento dos dados obtidos nas análises granulométricas _ـ_ 38

4.3.2 Tratamento dos Dados Obtidos nas Análises Químicas _ $\quad 38$

4.3.3 Verificação do Grau de Contaminação dos Metais Pesados__ 39

4.3.3.1 Fator de Contaminação

4.3.3.2 Índice de Geoacumulação

\section{1 - Sedimento de Fundo}

5.1.1 Caracterização Macroscópica

5.1.2 Teor de Umidade

5.1.3 Matéria Orgânica

5.1.4 Granulometria

5.1.5 pH e Eh

$\begin{array}{ll} & 52\end{array}$

5.1.6 Análises Químicas Totais _ 59

5.1.6.1 Elementos Maiores $\square 59$

5.1.6.2 Elementos Menores _____ 65

5.2 - Água da Interface _ 87

$\begin{array}{ll}5.2 .1 \mathrm{pH} \text { e Eh } & 87\end{array}$

5.2.2 Análises Químicas Totais_____ 91

5.3 - Sedimento Particulado em Suspensão _ـ 95 
6.1 - Sedimento de Fundo 98

6.2 - Água da Interface 102

6.3 - Sedimento Particulado em Suspensão 102

7 - CONCLUSÕES 104

8 - REFERÊNCIAS BIBLIOGRÁFICAS 107 


\section{ÍNDICE DE FIGURAS}

Figura 1 - Típica adsorção e precipitação de metais pesados na forma aniônica e catiônica, em função do $\mathrm{pH}$.

Figura 2 - Tendência de solubilização de metais pesados em relação ao $\mathrm{pH}$ e Eh. A) Minerais controladores da solubilidade de metais. B) Tendência de aumento da solubilidade.

Figura 3 - Diagrama de Eh-pH da precipitação do Cr na forma de óxidos/hidróxidos.

Figura 4 - Diagrama de Eh-pH da precipitação de $\mathrm{Cd}, \mathrm{Ni}$ e $\mathrm{Zn}$ na forma de sulfetos, óxidos/hidróxidos e carbonatos.

Figura 5 - Mapa de localização e principais vias de acesso da ETE de Barueri.

Figura 6 - Mapa de localização do lago de estudo.

Figura 7 - Mapa geológico da ETE de Barueri e de seus arredores.

Figura 8 - Mapa de contorno do lago com a localização dos pontos batimétricos e perfis A-B e C-D referentes a profundidade deste ambiente.

Figura 9 - Em destaque, malha de amostragem regular com as respectivas estações de coleta.

Figura $10 \mathrm{AB}$ - Coleta do sedimento com amostrador de gravidade modelo Kajak-Brinkhust Modificado. A) Inserção do coletor na água, visando a coleta do sedimento.

Figura $11 \mathrm{ABC}$ - Procedimento de coleta do sedimento de fundo, a partir do emprego de tubo PVC. A) Colocação do tubo PVC na água. B) Retirada da água, recuperada juntamente com o sedimento. C) Tubo PVC sendo serrado para retirada do sedimento.

Figura $12 \mathrm{AB}$ - Filtragem da água da interface e coleta do sedimento particulado em suspensão. A) Passagem da água já filtrada no filtro 0,8 $\mu \mathrm{m}$ para a seringa, visando a filtragem em filtro 0,22 $\mu \mathrm{m}$. B) Filtragem da água em filtro $0,22 \mu \mathrm{m}$.

Figura 13 - Estocagem das amostras de sedimento de fundo, água da interface e sedimento particulado em suspensão em caixa de isopor com temperatura de $4^{\circ} \mathrm{C}$.

Figura 14 - Medidas de Eh e Ph no sedimento de Fundo. 32

Figura 15 - Organograma geral de tratamento analítico das amostras de sedimento de fundo, água da interface e sedimento particulado em suspensão.

Figura 16 AB. A) Subamostra do topo do "core" de sedimento de fundo, Sedimento Argiloso. B) Subamostra coletada em algumas estações de amostragem na porção basal do "core", Aterro.

Figura 17- Diagrama triangular da distribuição granulométrica dos Sedimentos Argilosos, Aterros e Sedimentos Aluvionares.

Figura 18 AB. A) Mapa de isovalores de $\mathrm{pH}$ dos Sedimentos Argilosos coletados no período chuvoso. B) Mapa de isovalores de $\mathrm{pH}$ dos Sedimentos Argilosos coletados no período seco. 
Figura 19 AB. A) Mapa de isovalores de Eh para os Sedimentos Argilosos coletados no período chuvoso. B) Mapa de isovalores de Eh para os Sedimentos Argilosos coletados no período seco.

Figura 20 - Comparação entre as concentrações de $\mathrm{SiO}_{2}, \mathrm{Al}_{2} \mathrm{O}_{3}$ e $\mathrm{Fe}_{2} \mathrm{O}_{3}$, obtidas no Sedimento Argiloso em dois períodos climáticos distintos......61 61

Figura 21 - Assinaturas químicas do $\mathrm{Cu}, \mathrm{Cr}, \mathrm{Zn}$ e Ni no Sedimento Argiloso, referente a coleta do periodo chuvoso.

Figura 22 - Assinaturas químicas do $\mathrm{Cu}, \mathrm{Cr}$, Zn e Ni no Sedimento Argiloso, referente a coleta do período seco.

Figura 23 - Mapa de isoconcentração química do Cu para os Sedimentos Argilosos coletados nas diferentes estações de amostragem, no período chuvoso.

Figura 24 - Mapa de isoconcentração química do Cu para os Sedimentos Argilosos coletados nas diferentes estações de amostragem, no período seco.

Figura 25 - Mapa de isoconcentração química do Cr para os Sedimentos Argilosos coletados nas diferentes estações de amostragem, no período chuvoso.

Figura 26 - Mapa de isoconcentração química do $\mathrm{Cr}$ para os Sedimentos Argilosos coletados nas diferentes estações de amostragem, no período seco

Figura 27 - Mapa de isoconcentração química do Ni para os Sedimentos Argilosos coletados nas diferentes estações de amostragem, no período chuvoso.

Figura 28 - Mapa de isoconcentração química do Ni para os Sedimentos Argilosos coletados nas diferentes estações de amostragem, no período seco.

Figura 29 - Mapa de isoconcentração química do $\mathrm{Zn}$ para os Sedimentos Argilosos coletados nas diferentes estações de amostragem, no período chuvoso.

Figura 30 - Mapa de isoconcentração química do Zn para os Sedimentos Argilosos coletados nas diferentes estações de amostragem, no período seco.

Figura 31 - Mapa de isovalores de pH para a água da interface coletada no período chuvoso.

Figura 32 - Mapa de isovalores de $\mathrm{pH}$ obtidos na água da interface coletada no período seco.

Figura 33 - Mapa de isovalores de Eh para água da interface do período chuvoso.

Figura 34 - Mapa de isovalores de Eh para água da interface do período seco.

Figura 35 - Imagem de partícula metálica (partícula brilhante, imagem do lado esquerdo) detectada no interior de uma cavidade. Imagem Split, obtida com Elétroretroespalhados e Secundários.

Figura 36 - Análise qualitativa exibindo a presença de $\mathrm{Cr}, \mathrm{Zn}, \mathrm{Ni}, \mathrm{Fe}, \mathrm{S}, \mathrm{Si}$ e Al no ponto analisado na figura 35

Figura 37 - Análise qualitativa realizada no ponto brilhante localizado na porção sudeste da figura 35 (imagem à direita), indicando a presença de $\mathrm{Cr}, \mathrm{Ni}, \mathrm{Fe}, \mathrm{Al}$, Si e S. 
Figura 38 - Análise qualitativa de outro ponto localizado na porção sudoetes da figura 35 (imagem do lado direito), indicando a presença de $\mathrm{Ce}, \mathrm{Nd}, \mathrm{Cu}$, $\mathrm{Zn}$ e Ni.

Figura 39 - Análise qualitativa de um ponto localizado na porção sudoeste da figura 35 , indicando a presença de $\mathrm{K}, \mathrm{S}, \mathrm{Al}, \mathrm{Ni}$ e $\mathrm{Fe}$. 96

Figura 40 - Análise qualitativa indicando a presença de $\mathrm{Ce}$ e Nd, Th, $\mathrm{Cu}, \mathrm{Ca}$ e $\mathrm{Mn}$. Outro ponto analisado na amostra da figura 35 .

Figura 41 - Comunidade de fitoplânctons detectados no sedimento particulado, representadas por três grupos distintos. 


\section{ÍNDICE DE TABELAS}

Tabela 1 - Mobilidade relativa dos metais pesados em função do pH e Eh. ... 10

Tabela 2 - Escala Granulométrica Alemã (Atterberg modernizada) ................ 38

Tabela 3 - Concentrações naturais de $\mathrm{Cu}, \mathrm{Cr}, \mathrm{Zn}$ e Ni em folhelhos. .............. 41

Tabela 4 - Grupos de sedimentos subamostrados no topo e base do "core" nas

diferentes estações de amostragem............................................. 44

Tabela 5 - Porcentagem dos teores de umidade dos sedimentos argilosos

(subamostras de topo $-\mathrm{t}$ ) coletados nos períodos chuvoso e seco.........46 46

Tabela 6 - Porcentagem dos teores de umidade do Aterro (subamostras de base - b) coletados nos períodos chuvoso e seco.

Tabela 7-Porcentagem dos teores de umidade do Sedimento Aluvionar (subamostras de topo - $t$ e base - b) coletados nos períodos chuvoso e seco.

Tabela 8 - Porcentagem de matéria orgânica obtida no Sedimento Argiloso

(subamostra do topo - $\mathrm{t}$ ) do período climático seco...

Tabela 9 - Porcentagem de matéria orgânica obtida no Aterro (subamostra da base - b) do período climático seco. ................................................ 49

Tabela 10 - Porcentagem de matéria orgânica obtida no Sedimento Aluvionar (subamostras do topo - $t$ e base - b) do período climático seco.

Tabela 11 - Distribuição das frações granulométricas obtidas nos sedimentos argilosos (subamostras do topo - $t$ ) do período seco.

Tabela 12 - Distribuição das frações granulométricas obtidas no Aterro (subamostra da base - b) do período seco.

Tabela 13 - Distribuição das frações granulométricas obtidas no Sedimento Aluvionar (subamostras do topo - $t$ e base - b) do período seco.

Tabela 14 - Valores de $\mathrm{pH}$ obtidos nos sedimentos argilosos (subamostra do topo $-\mathrm{t}$ ), nos períodos chuvoso e seco.

Tabela 15 - Valores de pH obtidos nos Aterros (subamostras da base - b), nos

períodos chuvoso e seco........................................................ 55

Tabela 16 - Valores de pH obtidos nos Sedimentos Aluvionares (subamostras de topo - t e base - b), nos períodos chuvoso e seco.

Tabela 17 - Valores de Eh obtidos nos sedimentos argilosos (subamostras de topo - t) coletados nos períodos chuvoso e seco.

Tabela 18 - Valores de Eh obtidos nos Aterros (subamostras da base - b) coletados nos períodos chuvoso e seco.

Tabela 19 - Valores de Eh obtidos nos Sedimentos Aluvionares (subamostras de topo - $t$ e base - b) coletados nos períodos chuvoso e seco...

Tabela 20 - Elementos maiores detectados nas amostras de Sedimento Argiloso (subamostra do topo $-\mathrm{t}$ ) do período chuvoso.

Tabela 21 - Elementos maiores detectados nas amostras de Sedimento Argiloso (subamostra do topo $-t$ ) do período seco.

Tabela 22 - Elementos maiores detectados nas amostras de Aterro (subamostra da base - b) do periodo chuvoso.

Tabela 23 - Elementos maiores detectados nas amostras de Aterro (subamostra da base - b) do período seco. 
Tabela 24 - Elementos maiores detectados nas amostras de Sedimento Aluvionar (subamostra do topo - $t$ e base $-\mathrm{b}$ ) do período chuvoso. ........6 64

Tabela 25 - Elementos maiores detectados nas amostras de Sedimento Aluvionar (subamostra do topo - $t \mathrm{t}$ da base - b) do periodo seco. .........6 64

Tabela 26 - Elementos menores detectados nas amostras de Sedimento Argiloso (subamostra do topo - $t$ ) do período chuvoso..........................66 65

Tabela 27 - Elementos menores detectados nas amostras de Sedimento Argiloso (subamostra do topo - $t$ ) do período seco.

Tabela 28 - Comparação dos valores de Cu obtido nas amostras de Sedimento Argiloso (subamostra do topo - t) com o Fator de Contaminação e lgeo deste metal para estas amostras, no período chuvoso.

Tabela 29 - Comparação dos valores de Cu obtido nas amostras de Sedimento Argiloso (subamostra do topo - $t$ ) com o Fator de Contaminação e Igeo deste metal para estas amostras, no periodo seco...........................77 77

Tabela 30 - Comparação dos valores de Cr obtido nas amostras de Sedimento Argiloso (subamostra do topo - t) com o Fator de Contaminação e Igeo deste metal para estas amostras, no período chuvoso.

Tabela 31 - Comparação dos valores de Cr obtido nas amostras de Sedimento Argiloso (subamostra do topo - t) com o Fator de Contaminação e Igeo deste metal para estas amostras, no período seco.

Tabela 32 - Comparação dos valores de Ni obtido nas amostras de Sedimento Argiloso (subamostra do topo - t) com o Fator de Contaminação e Igeo deste metal para estas amostras, no período chuvoso.

Tabela 33 - Comparação dos valores de Ni obtido nas amostras de Sedimento Argiloso (subamostra do topo - $t$ ) com o Fator de Contaminação e Igeo deste metal para estas amostras, no período seco.

Tabela 34 - Comparação dos valores de $\mathrm{Zn}$ obtido nas amostras de Sedimento Argiloso (subamostra do topo - $t$ ) com o Fator de Contaminação e Igeo deste metal para estas amostras, no período chuvoso.

Tabela 35 - Comparação dos valores de Zn obtido nas amostras de Sedimento Argiloso (subamostra do topo - $t$ ) com o Fator de Contaminação e Igeo deste metal para estas amostras, no período seco.

Tabela 36 - Elementos menores detectados nas amostras de Aterro

(subamostra da base - b) do período chuvoso.

Tabela 37 - Elementos menores detectados nas amostras de Aterro

(subamostra da base - b) do período seco.

Tabela 38 - Elementos menores detectados nas amostras de Sedimento Aluvionar (subamostras do topo - t e base - b) do período chuvoso.

Tabela 39 - Elementos menores detectados nas amostras de Sedimento Aluvionar (subamostras de topo - $\mathrm{T}$ e base - b) do período seco.

Tabela 40 - Valores de $\mathrm{pH}$ obtidos nas amostras de água da interface, nos períodos climáticos chuvoso e seco.

Tabela 41 - Valores de Eh obtidos nas amostras de água da interface coletados nos períodos climáticos chuvoso e seco.

Tabela 42 - Ânions detectados nas amostras de água da interface coletada no período chuvoso.

Tabela 43 - Ânions detectados nas amostras de água da interface coletada no período seco.

Tabela 44 - Cátions detectados nas amostras de água da interface coletadas no período chuvoso. 
Tabela 45 - Cátions detectados nas amostras de água da interface coletadas

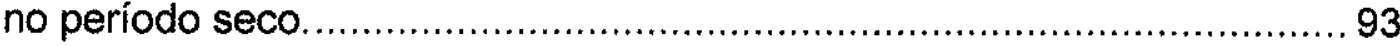




\section{ÍNDICE DE QUADROS}

Quadro 1 - Comportamento das temperaturas na região de Barueri 16

Quadro 2 - Precipitação média mensal anualizada, referentes ao período de 1916 a 1974. Dados coletados no poço pluviométrico localizado na Barragem de Edgar de Souza, município vizinho a Barueri. 


\section{RESUMO}

Nesta dissertação foi investigada a existência de Cobre (Cu), Cromo (Cr), Zinco ( $\mathrm{Zn}$ ) e Níquel (Ni), nos sedimentos de fundo, água da interface e sedimento particulado em suspensão coletados nos períodos climáticos de alta e baixa pluviosidade, em um lago localizado nas dependências da Estação de Tratamento de Esgotos de Barueri (ETE). Tal estudo, objetivou verificar se estes quatro metais pesados encontravam-se em concentrações capazes de comprometer a qualidade ambiental deste sistema aquático e em havendo comprometimento, qual dos compartimentos analisados estavam retendo os metais. Se comprovada a existência de contaminação, tentaria-se delimitar a fonte emissora da contaminação, considerando como hipótese principal, o lodo de esgoto depositado em parte do entorno deste lago.

Os sedimentos de fundo coletados, nas treze estações de amostragem, foram obtidos com coletor de gravidade modificado. Os testemunhos assim recuperados foram subamostrados em topo e base. Nestas subamostras determinou-se os valores de $\mathrm{pH}$ e Eh. Os materiais obtidos foram submetidos a análises químicas totais, análises granulométricas, análises macroscópicas, determinações das percentagens de matéria orgânica e umidade. A água da interface foi coletada juntamente com o sedimento de fundo por coletor de gravidade, e submetida a análise química total. Neste mesmo material também foram medidos os valores de $\mathrm{pH}$ e Eh. Os sedimentos particulados em suspensão foram coletados a partir da filtragem da água da interface e posteriormente analisados em MEVIEDS (análises químicas pontuais qualitativas).

Os resultados obtidos com estas análises, demonstraram a existência de três materiais distintos compondo o compartimento referente ao sedimento de fundo: Sedimento Argiloso, Aterro e Sedimento Aluvionar. Nestes três materiais, foram detectados $\mathrm{Cu}, \mathrm{Cr}, \mathrm{Zn}$ e $\mathrm{Ni}$, tendo sido as maiores concentrações obtidas nos Sedimentos Argilosos. Estes sedimentos são os únicos a apresentarem características favoráveis à retenção dos metais: fração granulométrica fina (silte-argilosa a silte), maior teor de matéria orgânica, pH neutro a alcalino e Eh redutor. Os teores obtidos para o $\mathrm{Cu}, \mathrm{Cr}, \mathrm{Ni}$ e $\mathrm{Zn}$ foram 
tratados no aplicativo "SURFER" resultando em mapas de isoconcentração química para estes metais nos Sedimentos Argilosos coletados nos períodos climáticos chuvoso e seco. As curvas de isoconcentração química de cada um destes metais, apontaram ligeira correlação entre a concentração destes metais com os parâmetros físico-químicos (principalmente Eh) obtidos nestes sedimentos. A comparação dos mapas de isoconcentração, entre as amostras dos períodos chuvoso e seco, demonstraram existir diferenças substanciais nas concentrações dos metais analisados de um para outro período.

Dos dados obtidos foram calculados o Fator de Contaminação ou Enriquecimento e o Índice de Geoacumulação (lgeo) para $\mathrm{Cu}, \mathrm{Cr}$, Ni e Zn nos Sedimentos Argilosos. O Fator de Contaminação do $\mathrm{Cu}, \mathrm{Ni}$ e $\mathrm{Zn}$, indicou que estes sedimentos em algumas das estações de amostragem são considerados contaminados. Por outro lado, o lgeo indicou a não contaminação dos Sedimentos Argilosos por estes metais. O $\mathrm{Cr}$ foi o único dos quatro metais que segundo os dois critérios aplicados, exibiu valores que não implicavam na contaminação do ambiente lacustre.

Os resultados das análises químicas totais da água da interface, demonstraram que esta não continha $\mathrm{Cu}, \mathrm{Cr}$ e $\mathrm{Ni}$ em solução, tendo sido apenas $\circ \mathrm{Zn}$, detectado nestas condições. Por outro lado, os resultados das análises químicas pontuais qualitativas em MEV/EDS sobre os sedimentos particulados em suspensão, demonstraram que estes continham $\mathrm{Cr}$, Ni e $\mathrm{Zn}$ e eventualmente $\mathrm{Cu}$ e que não se encontravam associados a matéria orgânica. $\mathrm{A}$ presença destes metais em tais sedimentos, pode estar indicando um aporte de metais pesados do resíduo localizado na borda oeste deste ambiente lacustre.

O lodo de esgoto depositado ao longo de toda a borda oeste deste ambiente lacustre analisado, contribui de forma efetiva na entrada de metais neste lago. Seja de modo dissolvido, seja como transporte de partículas por arrasto mecânico. Tal fato, encontra apoio nas análises das curvas de isoconcentração obtidas para os quatro metais pesados no Sedimento Argiloso, uma vez que estes metais exibiram concentrações elevadas nas amostras da estação de amostragem mais próxima da borda onde encontra-se depositado o lodo de esgoto em superfície. 


\section{ABSTRACT}

In this dissertation the existence of Copper (Cu), Chromium $(\mathrm{Cr})$, Zinc $(\mathrm{Zn})$ and Nickel (Ni) was investigated in bottom sediments, in water and in particle in suspension, sampled in the rainy and dry climatic periods. This materials were sampled in a lake located in the dependences of the Station of Treatment of Sewers of Barueri - SP. The objective of the study was to verify if these four heavy metals were in concentrations capable to compromise the environmental quality of this aquatic system. In having compromising, which would be keeping the metals of the analyzed compartments. If proven the existence of contamination, would try to delimit the issuing source of the contamination, considering as main hypothesis, the sewer deposited in the party to embroider west this lake.

The bottom sediments were collected in the thirteen sampling stations. The samples were obtained with gravity collector modified. The sediment cores were subsamples in top and base. In these $\mathrm{pH}$ and Eh were measured. The bulk sample was submitted to total chemical analyses, granulometrics analyses, macroscopic analyses, determinations of the percentages of organic matter and humidity. The water was collected together with the bottom sediment by gravity collector, and submitted the total chemical analysis. In this water $\mathrm{pH}$ and Eh were measured. The particle in suspension were collected starting from the filtering of the water and later analyzed in SEM/EDS (punctual chemical analyses).

The results obtained with these analyses demonstrated the existence of three different materials composing the bottom sediment: Clays Sediments, Antropic Material and River Sediment. In these three were materials $\mathrm{Cu}, \mathrm{Cr}, \mathrm{Zn}$ and $\mathrm{Ni}$ were detected. and the largest concentrations obtained in the Clays Sediments. The Clays Sediments presented as characteristics, the retention of the metals: silte-loamy to silte fraction, larger tenor of organic matter, neutral the alkaline $\mathrm{pH}$ and reducer $\mathrm{Eh}$. The tenors obtained for the $\mathrm{Cu}, \mathrm{Cr}, \mathrm{Ni}$ and $\mathrm{Zn}$ were treated in the application "SURFER" resulting in maps of chemical isoconcentrations for these metals in the Clays Sediments. The curves of 
chemical isoconcentration of each one of these metals, pointed quick correlation among the concentration of these metals with the physiochemical parameters (mainly Eh) obtained in these sediments. The comparison of the isoconcentration maps, among the samples of the rainy and dry periods demonstrated the existence of substantial differences in the concentrations of the analyzed metals of one for another period.

Factor of Contamination or Enrichment and the Index of Geoacumulation (Igeo) were calculated from the obtained data for $\mathrm{Cu}, \mathrm{Cr}, \mathrm{Ni}$ and $\mathrm{Zn}$, in the Clay Sediments. The Factor of Contamination for $\mathrm{Cu}, \mathrm{Ni}$ and $\mathrm{Zn}$, indicated that these sediments in some of the sampling stations are considered polluted. On the other hand, Igeo indicated the non-contamination of the Clay Sediments for these metals. $\mathrm{Cr}$ was the only of the four metals that according to the two applied criteria, it exhibited values that no implication in the contamination of the lake.

The results of the total chemical analyses of the water demonstrated that it didn't contain $\mathrm{Cu}, \mathrm{Cr}$ and $\mathrm{Ni}$ in solution; $\mathrm{Zn}$ has been, detected in these conditions. On the other hand, the results of the punctual qualitative (SEM/EDS) analyses of particle in suspension, showed the presence of $\mathrm{Cr}, \mathrm{Zn}$ and $\mathrm{Ni}$ and eventually $\mathrm{Cu}$ and they are not associates with the organic matter. The presence of these metals in such sediments, can indicate a contribution from a heavy metals of the located residue in the west border of lake. 


\section{1 - INTRODUÇÃO}

Uma das maiores preocupações atualmente, em âmbito mundial, têm sido a preservação e conservação do meio ambiente. Dentre os vários causadores da poluição ambiental destacam-se principalmente as indústrias e o crescimento populacional, gerando quantidades significativas de resíduos de diferentes naturezas.

Esses resíduos, muitas vezes nocivos ao meio, são depositados sobre o solo ou lançados nos cursos d'água superficiais sem qualquer tipo de tratamento, causando poluição e/ou contaminação dos mesmos.

Leis de proteção ambiental estão surgindo, visando solucionar ou ao menos minimizar tais problemas. Com isto está ocorrendo aumento na procura de técnicas e padronizações utilizadas, tanto na investigação quanto na recuperação destas áreas.

Neste cenário, a Região Metropolitana de São Paulo (RMSP) têm sido foco de inúmeros trabalhos de ordem ambiental, por concentrar o maior pólo industrial do país e por apresentar elevada densidade populacional (atualmente esta região abriga uma população de 17,2 milhões de habitantes, segundo EMPRESA METROPOLITANA DO PLANEJAMENTO DE SÃO PAULO EMPLASA, 2001). Essa região gera elevadas quantidades de esgoto de origem doméstica e lodos oriundos das Estações de Tratamento de Esgotos (ETE's), ambos com elevado potencial poluidor.

A ETE de Barueri localizada na RMSP gerou, de 1988 até 1996, grandes volumes de resíduos sólidos (lodos de esgoto) contendo quantidades significativas de $\mathrm{Ag}, \mathrm{Cd}, \mathrm{Cu}, \mathrm{Fe}, \mathrm{Hg}, \mathrm{Mn}, \mathrm{Ni}, \mathrm{Pb}$ e $\mathrm{Zn}$. Estes resíduos, desde o início das operações da ETE, foram depositados diretamente sobre o solo da própria estação sob a forma de pilhas, cobrindo uma área de $76.000 \mathrm{~m}^{2}$ (ASSUNÇÃO, 1996). Por este motivo, várias pesquisas científicas foram desenvolvidas nesta estação (ASSUNÇÃO, 1996; ASSUNÇÃO e SíGOLO, 1997; ASSUNÇÃO e SÍGOLO, 1998; SÍGOLO, 1998; ASSUNÇÃO e SÍGOLO, 2000; PENALOZA, 2001), objetivando verificar se a deposição de espessas camadas de resíduos dispostos ao ar livre (diretamente sobre o solo) estavam 
comprometendo a qualidade ambiental do solo e da água subterrânea nesta área.

Neste sentido esta dissertação é inédita, pois aborda a provável contaminação de um lago localizado nas dependências desta estação de tratamento, através da migração de metais pesados provenientes dos resíduos depositados em parte do entorno deste ambiente aquático. Para tanto, partiuse da premissa que os sistemas lagunares são considerados reservatórios potenciais de metais pesados por representarem bacia de sedimentação, exibindo características específicas de ambientes deposicionais.

\section{1 - OBJETIVOS}

Esta dissertação visa detectar a presença e estabelecer as concentrações químicas totais de metais pesados, especificamente $\mathrm{Cu}, \mathrm{Cr}, \mathrm{Zn}$ e $\mathrm{Ni}$, no topo e base dos "cores" de sedimentos de fundo coletados nos períodos climáticos chuvoso e seco no interior de um lago situado dentro da ETE de Barueri, além de detectar a presença destes metais na água da interface e no sedimento particulado em suspensão. No contexto desta proposta, pretende-se confeccionar mapas de isoconcentração química total para $\mathrm{Cu}, \mathrm{Cr}, \mathrm{Zn}$ e $\mathrm{Ni}$ detectados nas amostras do topo do "core" de sedimento de fundo (sedimento de origem lacustre) e determinar o grau de contaminação deste ambiente aquático.

Com estas técnicas, visa-se verificar:

1. Se os metais pesados migram do resíduo localizado em parte do entorno do lago para o interior deste;

2. Qual ou quais compartimentos estudados: sedimento de fundo, particulado em suspensão e água da interface; retém os metais pesados;

3. Se estes metais pesados atingiram concentrações suficientes para comprometer a qualidade ambiental deste meio aquático. 


\section{2 - METAIS PESADOS}

A expressão "metais pesados" corresponde a um grande grupo de elementos, presentes como traço no meio ambiente. Esse termo é aplicado aos elementos com densidade maior que $5 \mathrm{~g} / \mathrm{cm}^{3}$ ou com número atômico superior a 20. Essa expressão engloba os metais, semi-metais e não-metais, a partir das séries de transição e grupos IIA, IIIB, IVB, VB e VIB da tabela periódica.

Outras expressões são empregadas com freqüência para este grupo de elementos, tais como "elemento-traço" (ADRIANO, 1986; ESTEVES, 1988; ALLOWAY, 1995) e "metais tóxicos". O termo "elemento-traço" refere-se aos elementos químicos com baixas concentrações no meio ambiente (da ordem de partes por milhão a partes por bilhão). Esta expressão é a mais aceita atualmente em função da não distinção entre metal e não-metal e a sua ocorrência em baixa concentração.

Contudo, o termo "metais pesados" é freqüentemente aplicado onde há conotação de toxicidade, e deste modo, uma definição menos rigorosa de grupos, normalmente usada no contexto ambiental, é aquela que inclui metais leves tais como Arsênio, Selênio e Antimônio (RUDD, 1987), o que justifica o emprego desta expressão nesta dissertação.

\section{1 - METAIS PESADOS EM SISTEMAS NATURAIS}

Alguns metais pesados são componentes traços naturais de rochas ígneas, sedimentares, metamórficas e dos solos. Esses metais pesados também são encontrados em águas superficiais não impactadas, em decorrência da presença dos mesmos nos solos e/ou rochas presentes ao longo do canal do rio. A concentração natural de metais pesados, pode sofrer enriquecimento a partir de cinco fontes, segundo GOLDBERG (1954) apud FÖRSTNER (1983):

1) Formações Litogênicas: produtos de alteração a partir de áreas fontes ou escombros de rochas nos leitos dos rios. Esses materiais resistem apenas a pequenas mudanças, não importando o tempo de residência; 
2) Formações Hidrogênicas: partículas, produtos de precipitação, substâncias adsorvidas, formadas a partir de mudanças físico-química na água;

3) Formações Biogênicas: restos biológicos, produtos da decomposição de substâncias orgânicas;

4) Formações Atmogênicas: enriquecimento metálico resultante da deposição e precipitação de partículas existentes na atmosfera;

5) Formações Cosmogênicas: originadas a partir de partículas extraterrestres.

O enriquecimento de metais tóxicos nos diversos sistemas naturais a partir de fontes antropogênicas inserem-se nos quatro primeiros processos acima mencionados, interferindo diretamente nos seus mecanismos de distribuição através de atividades como a mineração e a industrialização. Nos últimos anos, nota-se que a principal fonte de enriquecimento de metais é de origem antrópica, em decorrência do desenvolvimento tecnológico e industrial.

\subsubsection{Toxicidade dos Metais Pesados em Ambientes Naturais}

Alguns metais pesados em pequenas concentrações são considerados essenciais para a sobrevivência dos organismos vivos. Esses metais quando sofrem enriquecimento pelos processos mencionados no subcapítulo 2.1, principalmente por fontes antropogênicas, podem tornar-se tóxicos.

Neste contexto, FÖRSTNER e WITTMANN (1981), classificaram os metais em três classes, levando-se em consideração o grau de toxicidade e a abundância do metal no meio ambiente:

1) Não críticos como $\mathrm{Na}, \mathrm{K}, \mathrm{Ca}, \mathrm{Mg}$, $\mathrm{Fe}$ e $\mathrm{Al}$;

2) Tóxicos, mas muito raros ou insolúveis como $\mathrm{W}, \mathrm{Zr}$, Ba e Ti;

3) Muito tóxicos e relativamente disponíveis como $\mathrm{Ni}, \mathrm{Cu}, \mathrm{Zn}, \mathrm{As}, \mathrm{Cd}, \mathrm{Hg}$ e Pb.

Baseando-se na classificação acima, os metais de interesse desta pesquisa $(\mathrm{Cu}, \mathrm{Cr}, \mathrm{Zn}$ e $\mathrm{Ni}$ ), exceto o $\mathrm{Cr}$, são considerados elementos muito tóxicos e relativamente disponiveis. Todavia, não se deve deixar de levar em consideração que o $\mathrm{Cu}$ e $\mathrm{Zn}$ são considerados essenciais, em pequenas concentrações, aos organismos vivos. 


\section{2 - METAIS PESADOS EM SISTEMAS LACUSTRES}

Dentre os sistemas aquáticos continentais, os lagos são considerados reservatórios potenciais de metais pesados por representarem bacia de sedimentação, exibindo características específicas de ambientes deposicionais, podendo em determinadas áreas, atingir níveis de contaminação bastante elevados (ESTEVES, 1988). As principais fontes de metais pesados nos sistemas lagunares são: intemperismo de rochas ou erosão de solos ricos nestes metais e a atividade antrópica.

Os metais pesados de origem natural ocorrem principalmente como componentes traços de minerais detríticos, originados a partir da erosão das planícies aluvionares e do solo contendo tais metais. Estes metais são transportados e depositam-se nos sedimentos de fundo de lagos, rios e oceanos (FÖRSTNER e WITTMANN, 1981; MOORE e RAMAMOORTY, 1984; STUMM E MORGAN, 1996).

Os metais de origem antrópica são provenientes de esgotos domésticos, efluentes industriais, resíduos sólidos acondicionados de maneira inadequada e emissões de poluentes atmosféricos que uma vez descarregados em águas superficiais são associados ao material particulado ou transportados nas formas dissolvidas e/ou eventualmente coloidal.

Dentro dos ecossistemas lacustres a distribuição dos metais pesados provenientes de um meio natural ou antrópico é muito diferenciada nos diversos compartimentos, refletindo assim a interação direta entre macrófitas, sedimentos e hidrodinâmica da coluna d'água (AMAZARRAY, 1992). Segundo HAKANSON e JANSSON (1983); BAUDO et al. (1990); SALOMONS e STIGLIANI (1995); SINGH et al. (1999), o sedimento é o compartimento mais importante na retenção destes metais nos sistemas aquáticos, refletindo a qualidade da água e registrando os efeitos das emissões antrópicas.

Conforme SALOMONS e STIGLIANI (1995), os sedimentos retém quantidades significativas de metais tóxicos, na forma precipitada ou complexada, a partir de condições físico-químicas apropriadas. Os metais retidos no sedimento de fundo geralmente estão associados a fração granulométrica fina (GIBBS, 1977), menor que 0,062 mesh, em decorrência da 
grande área superficial destas partículas (JURASIC, 1982 apud SINGH et al., 1999).

Os sedimentos acumulados no fundo dos lagos realizam constantes trocas de nutrientes e outras substâncias com a água acima dele (coluna d'água) (HAMILTON e DAVISON, 1993 apud LERMAN et al., 1995). A interface sedimento-água atua ao mesmo tempo como depósito e fonte para os metais pesados no sistema aquático. Deste modo, os sedimentos de fundo não são apenas depósitos de produtos gerados na coluna d'água ou trazidos por rios, ventos e chuvas, mas um compartimento que reprocessa os materiais e pode alterar a qualidade ambiental da coluna d'água em um sistema aquático (MOZETO, 1997).

Em lagos rasos, a erosão do sedimento pelo vento libera a água intersticial com o conseqüente fluxo de metais pesados retidos no sedimento para a coluna d'água (SALOMONS e BACCINI, 1986). A água intersticial (água retida nos poros do sedimento) atua como agente de comunicação entre o sedimento e a água superficial. Alterações mínimas na composição do sedimento geralmente provocam mudanças significativas na qualidade dessa água.

Devido a interação entre os vários compartimentos existentes no sistema lagunar, MOZETO (1997), propõem a amostragem e análise dos diferentes compartimentos (sedimento de fundo, sedimento particulado em suspensão e água) por pelo menos um periodo sazonal, visando assim o melhor entendimento da contaminação neste ambiente aquático. Assim, neste trabalho foram coletadas e analisadas amostras de sedimento de fundo, sedimento particulado em suspensão e água da interface, onde o sedimento de fundo recebeu maior atenção em decorrência deste ser considerado, segundo HAKANSON e JANSSON (1983), fácil de coletar, analisar e interpretar, se comparado com a água que apresenta concentrações baixas de metais tóxicos causadores de problemas analíticos.

\subsubsection{Geoquímica dos Metais Pesados em Sistemas Lacustres}

Nos sistemas aquáticos, segundo RAMAMOORTHY e RUST (1978), os metais pesados ocorrem sob três formas químicas: a) íons livres, b) 
complexados a microsolutos de origem orgânica e/ou inorgânica com tamanho menor que $2 \mathrm{~nm}$ e c) associados a macrosolutos (material coloidal e particulado), de modo que a concentração total é representada pela equação abaixo:

$$
[M]=[M n+]+[M I]+[M L]
$$

Onde: [ $\mathrm{Mn+}]$ é a concentração do íon metálico livre, [ $\mathrm{MI}$ ] concentração total de complexos inorgânicos e [ $\mathrm{ML}$ ] concentração total de ligantes orgânicos.

Os metais tóxicos adicionados aos sedimentos, a partir de fontes naturais e antropogênicas, geralmente encontram-se na forma complexada. Esses metais podem ligar-se a partículas inorgânicas e orgânicas formando compostos estáveis. Os principais ligantes inorgânicos e orgânicos são: íons bicarbonato, hidróxido, carbonato, sulfato, fosfato, compostos húmicos e fúlvicos.

Conforme BOURG (1995), a complexação e precipitação dos metais pesados no sedimento ocorrem a partir dos seguintes fatores:

1) oxidação de componentes reduzidos tais como Ferro, Manganês e Sulfetos;

2) redução de metais de alta valência pela interação com a matéria orgânica (Selênio, Prata);

3) redução de sulfato para sulfeto (Ferro, Cobre, Prata, Zinco, Mercúrio, Níquel, Arsênio e Selênio precipitam-se como Sulfetos);

4) reações tipo alcalina (Estrôncio, Manganês, Ferro, Zinco, Cádmio e outros elementos são precipitados pelo aumento de $\mathrm{pH}$ usualmente causado pela interação com rochas alcalinas e sedimentos ou pela mistura com águas alcalinas);

5) adsorção ou co-precipitação de íons metálicos com óxidos de Ferro e Manganês, argilas e particulados de matéria orgânica;

Segundo SALOMONS et al., (1995), a complexação e precipitação dos metais pesados nos sedimentos depende principalmente do:

1) $\mathrm{pH}$;

2) Conteúdo de hidróxidos e óxidos de Ferro e Manganês; 
3) Potencial de oxi-redução;

4) Propriedades superficiais;

5) Natureza e concentração de constituintes na fase aquosa;

6) Quantidade e razão de fluxo de solução com mudança direta do sistema aquático ou terrestre.

A forma de distribuição desses metais pesados no ambiente aquático é muito importante para efeito da toxicidade (HAKANSON e JANSSON, 1983). Esses metais podem ser mais ou menos móveis nestes sistemas, dependendo da razão entre a fração dissolvida e precipitada. Conforme BAUDO et al. (1990); SALOMONS e STIGLIANI (1995), o metal pesado na forma dissolvida é considerado mais móvel e mais biodisponivel para os organismos que a forma particulada.

O modo como o metal está presente na água é chamado de especiação química, sendo esta dependente de fatores físico-químicos da água como salinidade, $\mathrm{pH}$, Eh, concentrações e características dos ligantes (complexos aniônicos).

\subsubsection{Efeitos do pH e Eh no comportamento geoquímico dos metais}

Como abordado no subcapítulo 2.2, os sólidos presentes nos corpos d'água superficiais armazenam quantidades significativas de metais pesados tóxicos, a partir de fenômenos geoquímicos controladores da retenção destes metais, tais como adsorção e precipitação. Esses fenômenos, por sua vez, são controlados por parâmetros físico-químicos do meio: A) $\mathrm{pH}$ e B) Eh (este refere-se ao potencial redox do meio).

$\mathrm{O}$ pH e Eh são variáveis controladoras da dispersão e disponibilidade dos metais, onde qualquer mudança nas condições físico-químicas do sistema aquático induzem a mobilidade dos metais pesados no hidrociclo.

A) $\mathrm{pH}$

De um modo geral, a solubilidade de muitos metais aumenta com o decréscimo do $\mathrm{pH}$, havendo relação direta entre este e a solubilidade, ou seja, quanto mais ácido for o $\mathrm{pH}$ do meio, maior será a mobilidade destes elementos. Com isso, metais retidos nos sedimentos migram para a coluna d'água, em decorrência do abaixamento do $\mathrm{pH}$, expressando assim a toxicidade destes poluentes (SALOMONS e STIGLIANI, 1995). 
No sistema aquático, os metais pesados na forma catiônica tendem a desorção ou forma dissolvida com o decréscimo de $\mathrm{pH}$ e a adsorção ou precipitação com aumento do $\mathrm{pH}$. Por outro lado, os metais pesados na forma aniônica tendem a solubilização com aumento de $\mathrm{pH}$, ao contrário da forma catiônica, como exposto na figura abaixo.

Figura 1 - Típica adsorção e precipitação de metais pesados na forma aniônica e catiônica, em função do $\mathrm{pH}$.

Modificado de SALOMONS e STIGLIANI (1995).

B) Eh

As condições redox do meio influem diretamente e significantemente na solubilidade de alguns metais, como $\mathrm{Fe}, \mathrm{Mn}, \mathrm{Cr}$. Dependendo de sua valência, - metal ocorre em formas mais ou menos solúveis (ambientes redutores favorecem a solubilidade de Fe e $\mathrm{Mn}$, mas decresce a solubilidade de $\mathrm{Cr}$ ). A mobilidade de outros metais pesados, cujo estado redox não é afetado por limites de condições redox encontrados em águas naturais, é todavia afetada indiretamente por agentes de disponibilidade e complexação, tais como $\mathrm{Fe} e$ Mn (hidróxidos e óxidos) e ânions redox-sensível, induzindo a precipitação.

Em condições de baixa redução, os sulfetos removem os cátions metálicos e metalóides para a solução, elevando a toxicidade destes metais. Por outro lado, em condições de baixa oxidação a pequena redução, a solubilidade dos metais decrescem em virtude da precipitação de óxidos, hidróxidos e carbonatos.

c) $\mathrm{pH}$ e Eh

Geralmente, em avaliações ambientais utilizam-se diagramas de $\mathrm{pH}$ e Eh, visando verificar a possível mobilidade do metal tóxico analisado. Esses diagramas demonstram que em meio ácido e com Eh oxidante a redutor, prevalece a alta solubilidade dos metais. A Tabela 1 exibe a mobilidade relativa dos metais em função destas duas variáveis. 
TABELA 1 - MOBILIDADE RELATIVA dOS METAIS PESADOS EM FUNÇÃO DO PH E EH.

\begin{tabular}{|c|c|c|c|c|}
\hline $\begin{array}{l}\text { Mobidade } \\
\text { Relativa }\end{array}$ & $\begin{array}{c}\text { Atividade Eletrons } \\
\text { Reduçăo }\end{array}$ & Oxidaçăo & $\begin{array}{l}\text { Atividades Protons } \\
\text { Neutro-Aucalino }\end{array}$ & ÁCido \\
\hline Muito Baixo & $\begin{array}{l}A l, C r, M o, V, \\
U, S e, S, B . \\
H g, C u, C d, p b\end{array}$ & Al, $\mathrm{Cr}, \mathrm{Fe}, \mathrm{Mn}$ & $\mathrm{Al}, \mathrm{Cr}, \mathrm{Hg}, \mathrm{Cu}$ & Si \\
\hline Baixo & $\begin{array}{l}S i_{1}, K_{1} P, N i \\
Z n, C O, F e\end{array}$ & $S i, K, P, P b$ & $\begin{array}{l}S i, K, p, p D, p O \\
Z n, C O\end{array}$ & $K, F \theta(I H)$ \\
\hline Médio & $M n$ & $\mathrm{Co}, \mathrm{N}, \mathrm{Hg}, \mathrm{Cu}$ & $\mathrm{Mn}$ & $\begin{array}{l}\text { Al, } p b, C u, \\
C r, V\end{array}$ \\
\hline Aito & $\mathrm{Ca}, \mathrm{Na}, \mathrm{Mg}, \mathrm{Sr}$ & $\begin{array}{l}\mathrm{Ca}, \mathrm{Na}, \mathrm{Mg}, \mathrm{Sr}, \\
M O, V, U, S O\end{array}$ & $\begin{array}{l}\mathrm{Ou}, \mathrm{Na}, \mathrm{Mg}, \mathrm{Cr} \\
\mathrm{Zn}, \mathrm{Cd}, \mathrm{Hg}\end{array}$ & $\begin{array}{c}\mathrm{Ca}, \mathrm{Na}, \mathrm{Mg}, \\
\mathrm{Co},(\mathrm{Mn})\end{array}$ \\
\hline Muito Alto & $C, 1,8 r$ & $C, I, B r, B$ & $\begin{array}{l}C, L, B r, S, B \\
M O, V, U, S e\end{array}$ & $C l, I, B r, B$ \\
\hline
\end{tabular}

Fonte: SALOMONS e STIGLIANI (1995).

2.2.1.1. Comportamento geoquímico do Cobre, Cromo, Níquel e Zinco em função dos parâmetros físico-químicos

Os metais pesados analisados nesta dissertação foram: Cobre (Cu), Cromo $(\mathrm{Cr})$, Niquel (Ni) e Zinco $(\mathrm{Zn})$, visto que ocorrem em abundância no resíduo e solo da margem sudoeste do lago (ASSUNÇÃO, 1996).

$\checkmark$ Cobre

O Cu ocorre na natureza no estado de oxidação (l) e (II), sendo que no estado (II) ele é isomorfo dos íons $\mathrm{Zn}^{2+}, \mathrm{Mg}^{2+}$ e $\mathrm{Fe}^{2+}$ (ADRIANO, 1986). A estabilidade do $\mathrm{Cu}$ (I) e (II) em solução varia consideravelmente, dependendo dos ligantes presentes. Segundo MOORE (1991), no sedimento de fundo o $\mathrm{Cu}$ tem forte afinidade com hidróxidos e óxidos de $\mathrm{Fe}$ e $\mathrm{Mg}$, carbonatos, argilas e matéria orgânica. Devido às propriedades químicas do $\mathrm{Cu}$, ele associa-se fortemente a matéria orgânica. Condições ácidas e com baixo potencial de oxidação promovem a solubilização do Cu (Figura 2).

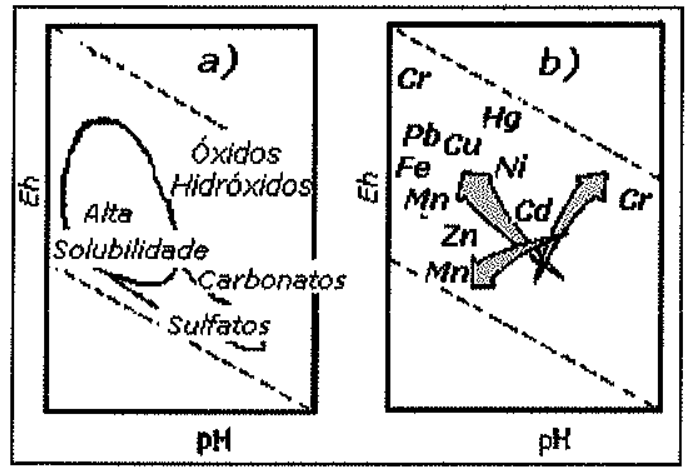

Figura 2 - Tendência de solubilização de metais pesados em relação ao pH e Eh. A) Minerais controladores da solubilidade de metais. B) Tendência de aumento da solubilidade.

Fonte: SALOMONS e STIGLIANI (1995). 


\section{$\checkmark$ Cromo}

O $\mathrm{Cr}$ ocorre na natureza no estado de oxidação (II) a (VI), sendo as formas trivalentes, hexavalentes e cromo metálico, as mais importantes. $\mathrm{O} \mathrm{Cr}$ trivalente é o estado de oxidação mais estável, sendo solúvel na água somente com $\mathrm{pH}$ ácido. A principal forma química do $\mathrm{Cr}$ na água de lagos, segundo MOORE (1991), inclui o $\mathrm{CrOH}_{2}, \mathrm{Cr}(\mathrm{OH})^{3+}$ e $\mathrm{Cr}(\mathrm{OH})^{4-} \cdot \mathrm{Cr}^{6+}$. A espécie aniônica varia com $\circ \mathrm{pH}$, podendo ser cromato $\left(\mathrm{CrO}_{4}{ }^{2-}\right)$, hidrocromato $\left(\mathrm{HCrO}^{4-}\right)$ ou dicromato $\left(\mathrm{Cr}_{2} \mathrm{O}_{7}{ }^{2-}\right)$. O $\mathrm{Cr}$ encontra-se móvel em sistemas aquáticos, quando $\mathrm{O}$ $\mathrm{pH}$ do meio é muito ácido e o Eh é oxidante ou quando o pH é muito básico e o Eh é redutor (Figura 2). A Figura 3 exibe, a insolubilidade do $\mathrm{Cr}$ em pH neutro a levemente alcalino e em condições redox inferiores e consequentemente a sua precipitação como hidróxido e/ou óxido insolúvel.

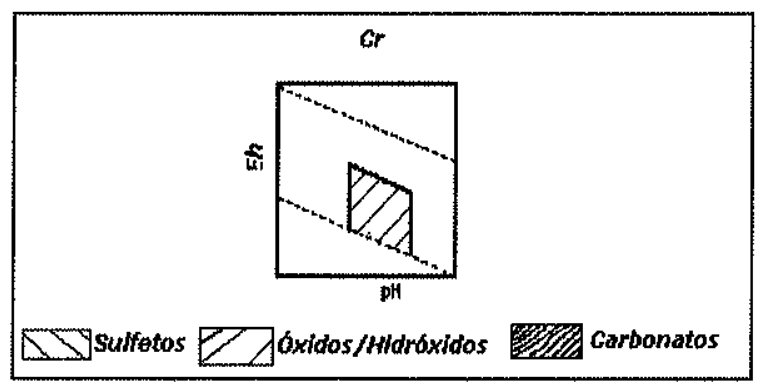

Figura 3 - Diagrama de Eh-pH da precipitação do $\mathrm{Cr}$ na forma de óxidos/hidróxidos. Modificado de SALOMONS e STIGLIANI (1995).

\section{$\checkmark$ Niquel}

O Ni ocorre na natureza no estado de oxidação (-I), (0), (I), (II), (III) e (IV), sendo que o estado de valência que prevalece é o (II). Em condições inferiores de oxidação, tendendo a pequena redução e com pH neutro a mediamente alcalino, o Ni precipita-se na forma de carbonato e/ou hidróxido e/ou óxidos (Figura 4). Em condições inferiores de redução, o Ni pode ser removido para a solução em decorrência da formação de sulfetos (Figura 4).

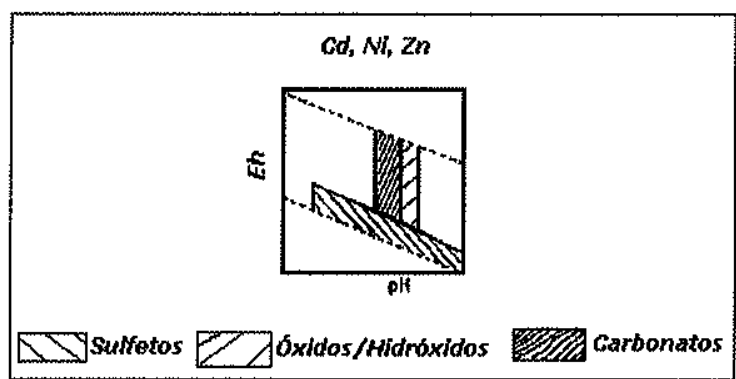

Figura 4 - Diagrama de $\mathrm{Eh}-\mathrm{pH}$ da precipitação de $\mathrm{Cd}, \mathrm{Ni}$ e $\mathrm{Zn}$ na forma de óxidos/hidróxidos e carbonatos.

Modificado de SALOMONS e STIGLIANI (1995). 


\section{$\checkmark \quad$ Zinco}

Conforme ADRIANO (1986), o estado de oxidação do $\mathrm{Zn}$ em ambientes naturais é exclusivamente (II). Esse metal tem uma forte tendência de reagir com compostos ácidos, alcalinos e compostos inorgânicos. O Zn (II) predomina em pH ácido e com condições aeróbicas inferiores. Já quando o pH varia de 8 a 11, o $\mathrm{Zn}$ ocorre na forma de $\mathrm{Zn}(\mathrm{OH})_{2}$ e $\mathrm{Zn}(\mathrm{OH})_{3}$. Os cloretos, sulfatos e nitratos de $\mathrm{Zn}$, são altamente solubilizados na água, enquanto que os óxidos, carbonatos, fosfatos, silicatos e complexos orgânicos são insolúveis em água (MERIAN, 1991). Quando o pH é ácido e as condições de redução são inferiores, o Zn torna-se móvel (Figura 4 e 2B). Conforme MERIAN (1991), os rios e lagos contaminados freqüentemente por água de esgoto e resíduos, contém altos níveis de $\mathrm{Zn}$. 


\section{3- CARACTERIZAÇÃO DA ÁREA DE ESTUDO}

\section{1 - LOCALIZAÇÃO}

O ambiente lacustre estudado está situado entre as coordenadas $46^{\circ} 51$ W e $23^{\circ} 30^{\prime}$ S, no limite ocidental da área da ETE de Barueri, no município de Barueri.

Localmente esta ETE encontra-se entre a margem esquerda do rio Tietê e o leito da estrada de ferro da FEPASA, nas proximidades do rio Cotia, ocupando uma área de aproximadamente $750.000 \mathrm{~m}^{2}$, inserindo-se no contexto da RMSP. O lago em questão encontra-se nas proximidades da portaria da ETE, que dá acesso ao Município de Barueri e ocupa uma área com cerca de $29.000 \mathrm{~m}^{2}$.

As Figuras 5 e 6 exibem respectivamente, a localização da ETE com as suas principais vias de acesso e a localização do lago nesta estação. 


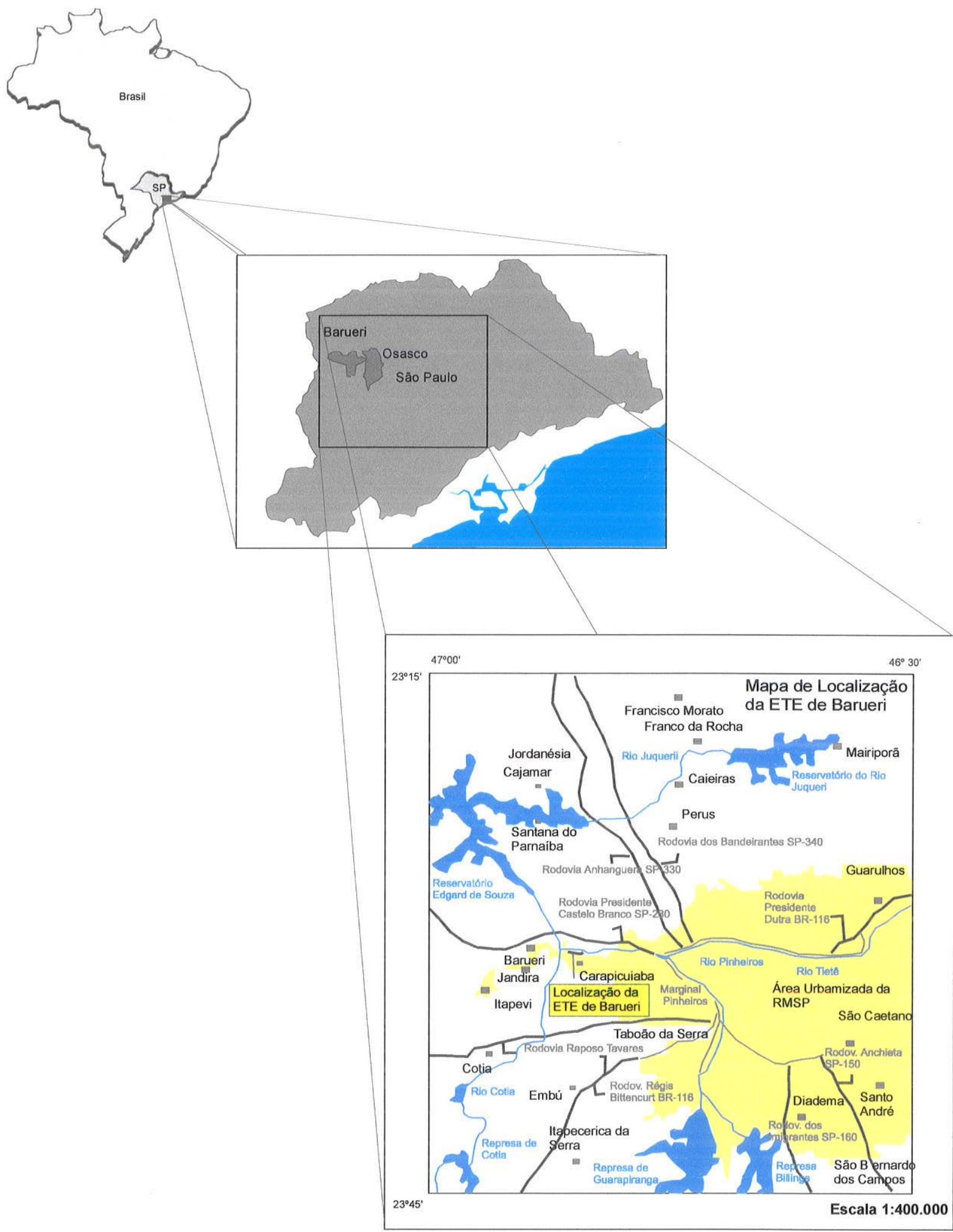

Figura 5 - Mapa de localização e principais vias de acesso da ETE de Barueri. Modificado de ASSUNÇÃO (1996) 


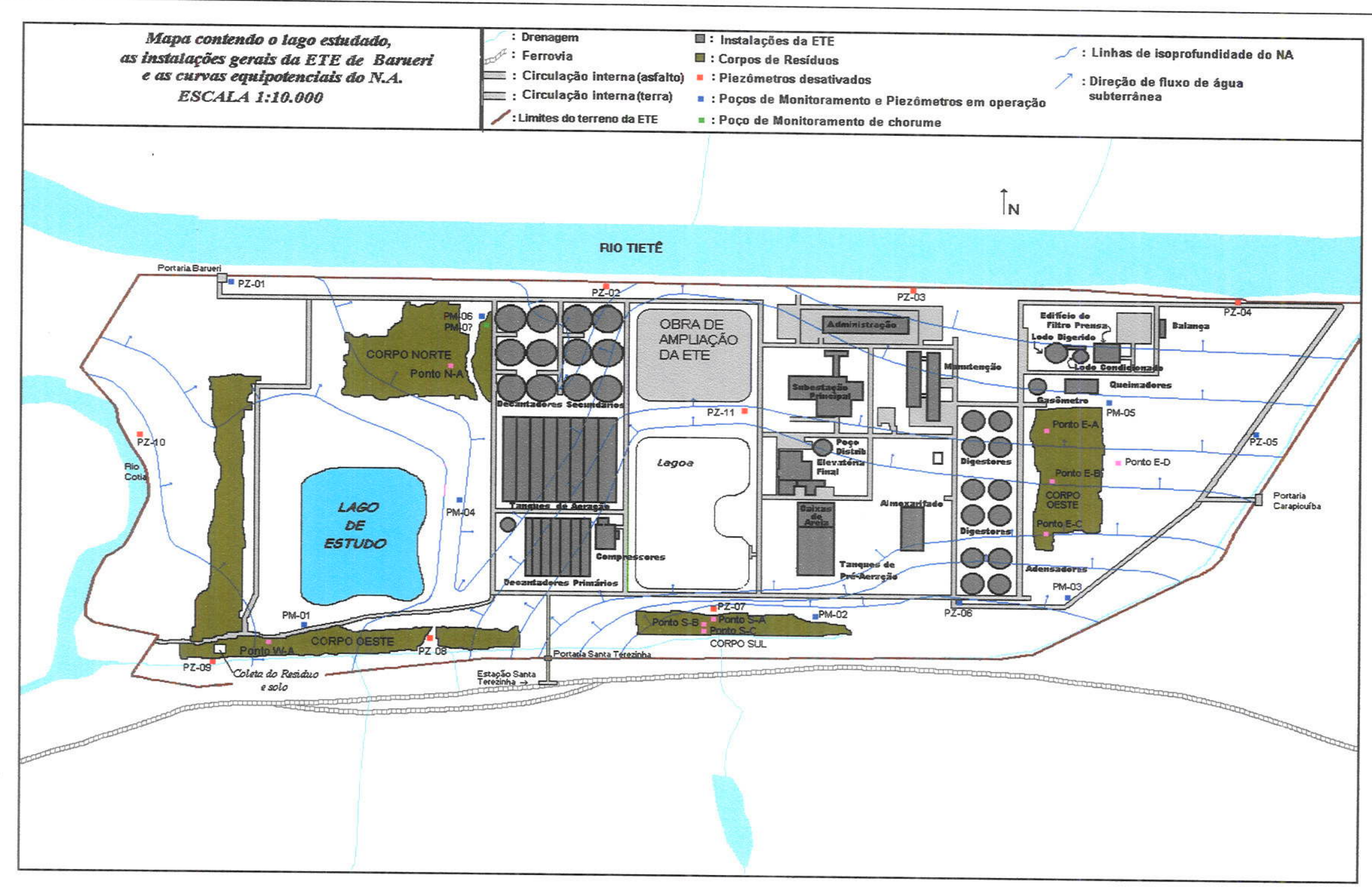

Figura 6 - Mapa de localização do lago de estudo. Modificado de ASSUNÇÃO (1996). 


\section{$3.2-C L I M A$}

O clima da área recebe influência direta da proximidade do Oceano Atlântico, causada pelo deslocamento das massas de ar marítimas para o interior e conseqüente aumento do índice pluviométrico. Segundo a classificação de Köeppen (NIMER, 1989), esta área pode ser enquadrada como clima situado entre os grupos $C_{\mathfrak{f b}}$ - Temperado sem Estação Seca e $C_{w}$ " Subtropical com Inverno Seco.

No período seco a precipitação média mensal mínima é da ordem de $30 \mathrm{~mm}$, e no período chuvoso superior a $100 \mathrm{~mm}$. As temperaturas médias são inferiores a $18^{\circ} \mathrm{C}$ nos meses mais frios e superiores a $22^{\circ} \mathrm{C}$ nos meses mais quentes (SÍGOLO, 1998). A umidade relativa do ar, nessa área, não é alta, e os ventos em geral não são fortes, exibindo taxa de evaporação entre $1000 \mathrm{~mm}$ e $1300 \mathrm{~mm}$ por ano (DEPARTAMENTO DE ÁGUAS E ENERGIA ELÉTRICA DAEE, 1975).

\subsubsection{Temperatura}

Segundo o DAEE (1975), as temperaturas médias da região que compreende o município de Barueri, encontram-se no Quadro 1, a seguir.

QUADRO 1 - COMPORTAMENTO DAS TEMPERATURAS NA REGIÃO DE BARUERI.

\begin{tabular}{|c|}
\hline Mês Mais Quente do Ano: Fevereiro $\left(22^{\circ} \mathrm{C}\right)$ \\
\hline Mês Mais Frio do Ano: Julho $\left(14^{\circ} \mathrm{C}\right)$ \\
\hline Temperatura Média Anual: $18^{\circ} \mathrm{C}$ \\
\hline Temperatura Média do Mếs Mais Quente do Ano: 21 a $22^{\circ} \mathrm{C}$ \\
\hline Temperatura Média do Mếs Mais Frio do Ano: 14 a $15^{\circ} \mathrm{C}$ \\
\hline Média das Temperaturas Máximas no Mês Mais Quente do Ano: 26 a $28^{\circ} \mathrm{C}$ \\
\hline
\end{tabular}

Fonte: DAEE (1975).

\subsubsection{Pluviosidade}

No mapa de isoetas do Estado de São Paulo (DAEE, 1975), a área estudada encontra-se entre as curvas de $1300 \mathrm{~mm}$ e $1400 \mathrm{~mm}$ de precipitação média anual. As chuvas não se distribuem uniformemente durante o ano, de tal forma que os meses de outubro a março são considerados mais chuvosos e os 
meses de abril a setembro são considerados mais secos, conforme pode ser observado no Quadro 2.

QUADRO 2 - PRECIPITAÇAO MÉDIA MENSAL ANUALIZADA, REFERENTES AO PERIODO DE 1916 A 1974. DADOS COLETADOS NO POÇO PLUVIOMÉTRICO LOCALIZADO NA BARRAGEM DE EDGAR DE SOUZA, MUNICIPIO VIZINHO A BARUERI.

\begin{tabular}{|c|c|c|c|}
\hline 1816 & $\begin{array}{c}\text { PRECIPIT } 1 \text { C } 10 \\
(\mathrm{~mm})\end{array}$ & MES & PRECHPU $1 \mathrm{CAO}$ \\
\hline Janeiro & 236 & Julho & 34 \\
\hline Fevereiro & 190 & Agosto & 40 \\
\hline Março & 144 & Setembro & 79 \\
\hline Abril & 65 & Outubro & 119 \\
\hline Maio & 53 & Novembro & 129 \\
\hline Junho & 49 & Dezembro & 201 \\
\hline \multicolumn{4}{|c|}{ 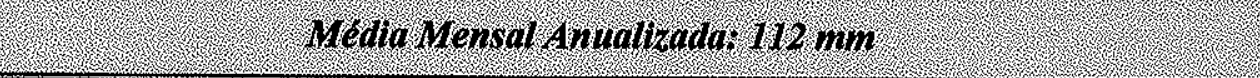 } \\
\hline
\end{tabular}

Fonte: DAEE (1975).

\section{3 - GEOMORFOLOGIA}

Com base na proposição de ALMEIDA (1964), a área de estudo pode ser enquadrada no compartimento geomorfológico denominado Planalto Paulistano, originado a partir da superfície erosiva Japi, a qual foi posteriormente modificada por efeitos superimpostos da superfície erosiva do Alto Tietê, que, por sua vez, está associada a eventos tectônicos de idade Terciária.

A área que compreende a ETE, localiza-se sobre estreita faixa de várzea do rio Tietê formada pelo retrabalhamento de seus próprios depósitos aluvionares. Essa faixa é bastante plana, apresentando coeficientes de declividade inferiores a $1 \%$. No local, ela é limitada ao norte pelo atual curso retificado do rio Tietê e ao sul pela área de relevo mais inclinado e acidentado, sustentado por Suítes Granitóides do Proterozóico Superior (ASSUNÇÃO, 1996).

\section{4 - SOLOS}

A partir do Mapa Pedológico do Estado de São Paulo, elaborado pelo INSTITUTO AGRONÔMICO DE CAMPINAS - IAC (1999), verifica-se que a região de Barueri insere-se em uma área urbanizada (mancha de urbanização), de tal forma que o solo desta região não está exposto neste mapa. Nos arredores do município de Barueri, a partir desta mesma fonte, identificou-se a 
presença de solos classificados como argissolos vermelho-amarelados, originados a partir da alteração intempérica de rochas cristalinas graníticas distribuídas em escala regional.

$\mathrm{Na}$ observação de campo realizada na ETE, verificou-se a presença de dois tipos de solos, classificados como Argissolos vermelho-amarelados e Neossolos, conforme EMPRESA BRASILEIRA DE PESQUISA AGROPECUÁRIA - EMBRAPA (1999):

1. Argissolos vermelho-amarelados: resultado da alteração de rochas granitóides milonitizadas. A alteração intempérica das rochas graníticas milonitizadas, proporcionou o desenvolvimento de solos bem estruturados. Esses obedecem à seguinte seqüência vertical, do topo para base: horizonte orgânico superficial, horizonte endurecido vermelho muito compacto, horizonte aloterítico vermelho amarelado muito friável, horizonte isalterítico amarelo esbranquiçado friável e rocha fresca. A seqüência completa deste perfil de solo pode chegar a $15 \mathrm{~m}$, sendo gradual a passagem de um horizonte para outro.

Os argissolos vermelho-amarelados foram utilizados como Aterro durante a construção da ETE. Deste modo, solos com essas características podem ocorrer sotopostos aos corpos de resíduos dispostos sob a forma de solos movimentados (Aterros) e no interior do lago estudado (compondo parte da porção basal do sedimento de fundo).

2. Neossolos: Compreendem sedimentos areno-argilosos que constituem a maior parte da superfície do terreno. Esses sedimentos foram depositados pelo rio Tietê e fazem parte de sua planície de inundação, além de compor parte do sedimento de fundo basal encontrado em algumas das estações amostradas no interior do lago pesquisado.

\section{5 - GEOLOGIA}

O contexto geológico dos arredores da área estudada é apresentado na Figura 7, em ampliação do Mapa Geológico do Estado de São Paulo, modificado por ASSUNÇÃO (1996). 


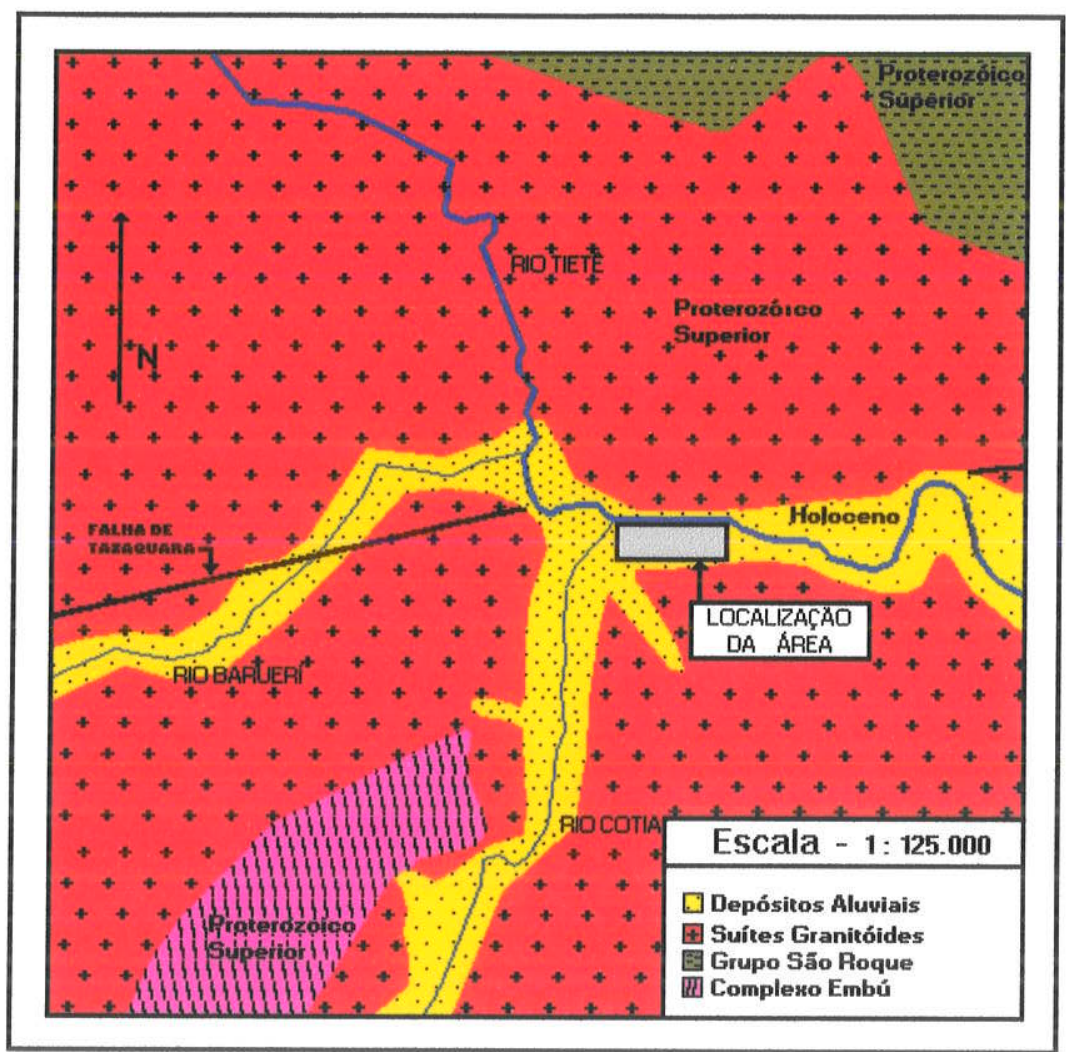

Figura 7 - Mapa geológico da ETE de Barueri e de seus arredores. Fonte: ASSUNÇÃO (1996).

Os arredores da ETE são delimitados por quatro unidades litoestratigráficas distintas:

1) Depósitos Holocênicos: TURCQ e MELO (1989), descrevem terem sido estes corpos depositados no final do Pleistoceno. São representados por depósitos aluviais recentes, com alternância de camadas de argilas, areias e conglomerados inconsolidados.

Essa unidade é de extrema importância para este trabalho em decorrência da mesma aflorar no terreno da ETE sob a forma de pacotes sedimentares. Esses pacotes sedimentares são constituídos por camadas argilosas ricas em matéria orgânica intercaladas com camadas detríticas mais grosseiras, podendo atingir até $20 \mathrm{~m}$ de espessura.

2) Suítes Granitóides: Corpos granitóides representados por granitos intrusivos de aspecto porfirítico, coloração cinza-claro, com fenocristais de feldspato distribuídos em matriz rica em horblenda verde e biotita, apresentando indícios de deformação dinâmica (milonitos e blastomilonitos). 
Segundo ALMEIDA e HASUI (1984) estas rochas são de origem sintectônicas a pós-tectônicas.

Essa unidade ocorre in situ nos arredores da ETE e dentro desta estação de tratamento, essas rochas aparecem como blocos rolados e compondo o Material de Aterro e solo.

3) Grupo São Roque: COUTINHO (1969), apud DAEE (1975), estabelece para este grupo uma seqüência meta-sedimentar bem definida, formada por metaconglomerados seguidos de metarenitos, filitos, quartzitos e calcáreos, entremeados por rochas metabásicas, com a base da seqüência representada por metaconglomerados. Os meta-sedimentos síltico-argilosos são os termos mais abundantes do Grupo São Roque.

Segundo INSTITUTO DE PESQUISAS TECNOLÓGICAS - IPT (1981a), a idade do Grupo São Roque seria Brasiliana (em torno de $640 \mathrm{Ma}$ ). O DEPARTAMENTO NACIONAL DE PESQUISA MINERAL - DNPM/CPRM (1991), admite idades mais antigas para esta unidade (cerca de $1800 \mathrm{Ma}$ ). Este Grupo ocorre a uma distância de aproximadamente $7 \mathrm{~km}$ ao norte da ETE (ASSUNÇÃO 1996).

4) Complexo Embú: Formado por xistos, filitos, migmatitos, gnaisses migmatizados e corpos lenticulares de quartzitos, anfibolitos e rochas calciossilicaticas. Esse complexo ocorre na porção sudoeste da área de estudo, a uma distância de aproximadamente $8 \mathrm{Km}$, sendo representado principalmente por migmatitos heterogêneos.

Segundo o DNPM/CPRM (1991), a idade desta unidade insere-se no Proterozóico Superior.

\section{6 - HIDROLOGIA}

\subsection{1 Águas Superficiais}

A área estudada situa-se a pequena distância dos rios Tietê e Cotia, e

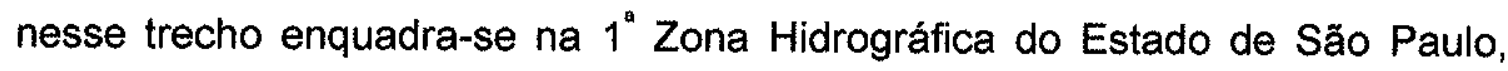
Bacia 2 - Alto Tietê (DAEE, 1975). Nessa região, ambas drenagens tiveram seus cursos originais retificados, tendo a estação de tratamento sido construída sobre parte dos seus antigos leitos e várzeas. 
Neste setor, a água, segundo Mapa de Níveis Atuais e Tendências da Qualidade das Águas do Estado de São Paulo - COMPANHIA DE TECNOLOGIA DE SANEAMENTO AMBIENTAL - CETESB (1994) é classificada como péssima, com Índice de Qualidade das Águas (IQA) entre 0 e 19. Os elementos e compostos encontrados nesta água: oxigênio dissolvido, demanda bioquímica de oxigênio, coliformes fecais, temperatura da água, $\mathrm{pH}$, nitrogênio total, fosfato total, resíduo total e turbidez, evidenciam um alto nível de degradação ambiental deste ambiente.

\subsection{2 Águas Subterrâneas}

Os aqüíferos subterrâneos existentes na área classificam-se regionalmente em três categorias distintas, conforme DAEE (1975):

1) Aqüíferos Associados a Rochas Cristalinas não Alteradas: Pequenos volumes, associados a sistemas de fraturas, localizados em maior profundidade e apresentando baixa vazão específica $\left(0,13\right.$ a $\left.0,22 \mathrm{~m}^{3} / \mathrm{h} / \mathrm{m}\right)$;

2) Aqüíferos Associados a Rochas Cristalinas Alteradas: Pequenos volumes, associados à porosidade das rochas alteradas e secundariamente a fraturas, localizados próximos a superfície, apresentam vazões superiores às dos Aqüíferos Associados a Rochas Cristalinas não Alteradas, sendo muito influenciáveis pela poluição das águas superficiais;

3) Aqüíferos Associados a Aluviões Recentes do Vale do Rio Tietê: Pequenos volumes, associados exclusivamente à porosidade dos sedimentos, localizados próximos a superfície, apresentando baixas vazões, sendo muito influenciáveis pela poluição das águas superficiais. 


\section{4 - MATERIAIS E MÉTODOS}

Os materiais e métodos empregados nesta pesquisa foram aplicados na confecção da malha de amostragem; na obtenção de coordenadas geográficas, dados batimétricos e parâmetros físico-químicos do lago; na amostragem do sedimento de fundo, água da interface e particulado em suspensão; nas análises granulométricas do sedimento de fundo; nas análises químicas totais do sedimento de fundo e água da interface; nas análises químicas pontuais qualitativas do sedimento particulado em suspensão; na determinação do teor de umidade e matéria orgânica presentes nas amostras de sedimento de fundo; na confecção de mapas de isoconcentração química para os metais investigados e dosados $(\mathrm{Cu}, \mathrm{Cr}, \mathrm{Zn}$ e $\mathrm{Ni}$ ) no sedimento lacustre, e na determinação do grau de contaminação deste ambiente aquático.

\section{1 - TRABALHO DE CAMPO}

Os trabalhos de campo iniciais tiveram como finalidade 0 reconhecimento batimétrico e geométrico do lago e de sua interação com os processos de tratamento gerais empregados na ETE de Barueri, bem como o planejamento e execução de amostragens preliminares. Após esta etapa, realizaram-se missões de campo nas estações climáticas chuvosa (março a abril) e seca (julho a agosto), durante o ano de 2000, a fim de coletar amostras de sedimento de fundo, água da interface e particulado em suspensão, e medidas de $\mathrm{pH}$ e Eh no sedimento de fundo e na água.

\subsubsection{Reconhecimento Inicial}

$\mathrm{Na}$ realização dos trabalhos iniciais de campo foram executadas as seguintes atividades:

1) Reconhecimento das instalações da ETE: Fez-se reconhecimento das instalações da ETE, bem como a verificação do seu funcionamento e suas interações com o ambiente lagunar. 
2) Coleta preliminar de amostras de sedimento de fundo: Coletou-se duas amostras de sedimento, em dois pontos distintos do lago, visando verificar o grau de heterogeneidade do sedimento de fundo.

\subsubsection{Mapeamento e Batimetria do Lago}

Com o emprego de topofil, trena, fio de náilon, pesos de localização das estações, barco inflável para quatro pessoas e remos, foram obtidos dados batimétricos. Dois perfis foram inicialmente realizados permitindo a obtenção de dados referentes a profundidade do lago. Posteriormente, cinco medidas do comprimento e oito da largura do lago foram executadas e, com o tratamento digital dessas medidas no aplicativo "AUTOCAD 14" e "COREL DRAW 9,0", obteve-se o mapa de contorno (Figura 8).
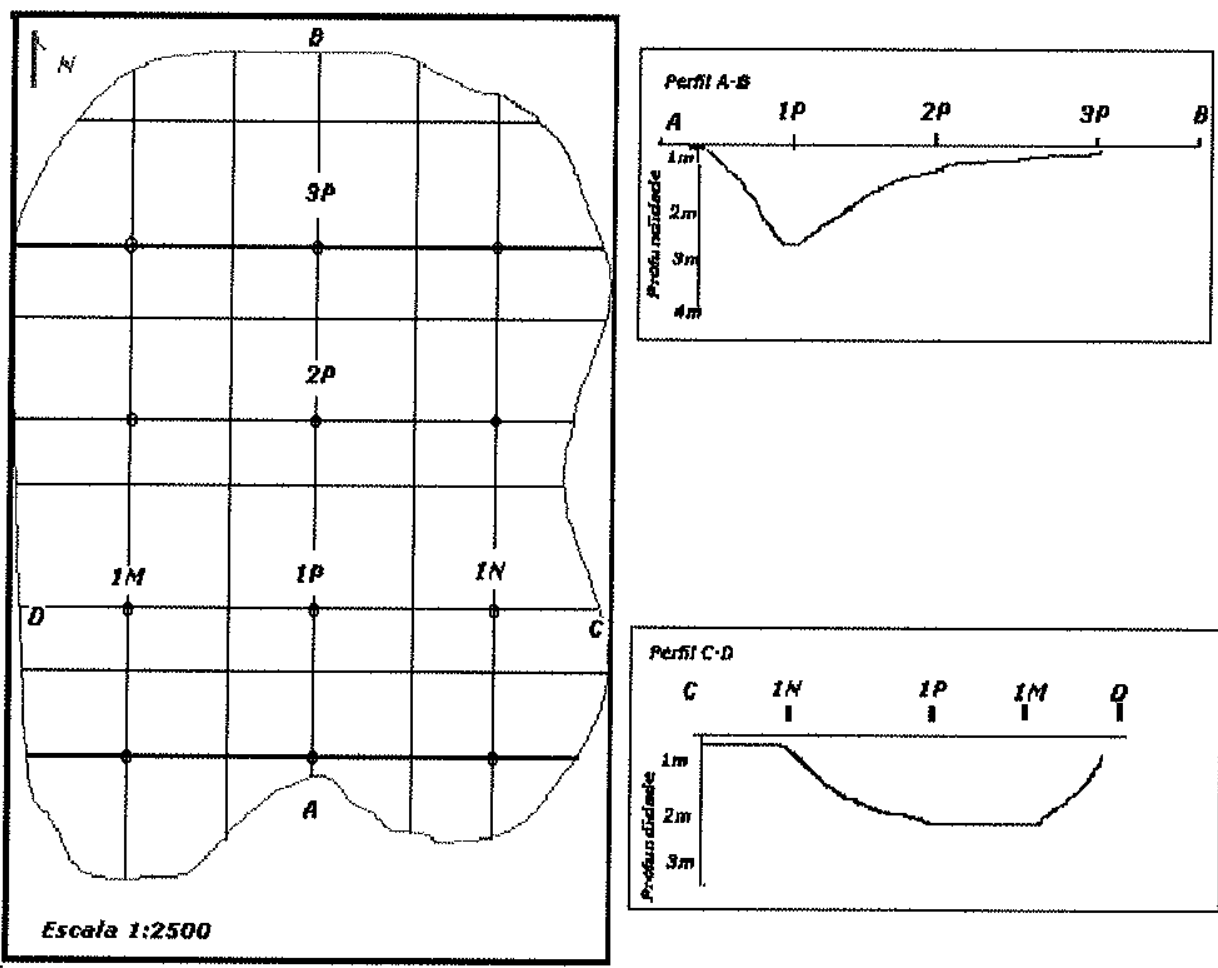

Figura 8 - Mapa de contorno do lago com a localização dos pontos batimétricos e perfis $A-B$ e C-D referentes a profundidade deste ambiente.

\subsubsection{Obtenção de Coordenadas Geográficas}

As coordenadas geográficas do lago foram obtidas a partir do caminhamento realizado em torno do mesmo com GPS portátil modelo GAMIN II. A leitura destas medidas, em UTM, foram obtidas de $50 \mathrm{em} 50 \mathrm{~m}$ tanto ao redor do lago, como no seu interior. $\mathrm{Na}$ confecção do mapa georreferenciado a 
partir do aplicativo "AUTOCAD 14", levou-se em consideração a precisão do aparelho que estava com erro de $10 \mathrm{~m}$.

O georreferenciamento do lago tornou-se necessário, pois o Software utilizado na construção de curvas de isoconcentração química "SURFER", processa mapas utilizando as coordenadas $X$ e $Y$, e a variável $Z$.

\subsubsection{Amostragem}

Conforme BAUDO et al. (1990); MUDROCH e MACKNIGHT (1994); MUDROCH e ACZUE (1995), a localização e o número de estações de amostragem podem afetar consideravelmente a qualidade e a viabilidade dos dados analisados, sendo necessária a realização de estudo preliminar da área para determinação da heterogeneidade ou não dos sedimentos. MUDROCH e ACZUE (1995) sugerem que o número de estações de amostragem, para determinação de metais pesados em ambientes lacustres, sejam suficientes para cobrir toda a área pesquisada.

Desta forma, construiu-se malha uma de amostragem regular, conforme MUDROCH e MACKNIGHT (1994), a partir dos dados da heterogeneidade dos sedimentos de fundo, profundidade e dimensões do lago. Essa malha é composta por treze estações de amostragem (denominadas pela sigla ETE) traçadas de $50 \mathrm{em} 50 \mathrm{~m}$, exceto para a ETE 05 cuja distância é de $30 \mathrm{~m}$ em relação ao ponto anterior, em decorrência deste estar localizado próximo a borda do lago (Figura 9). 


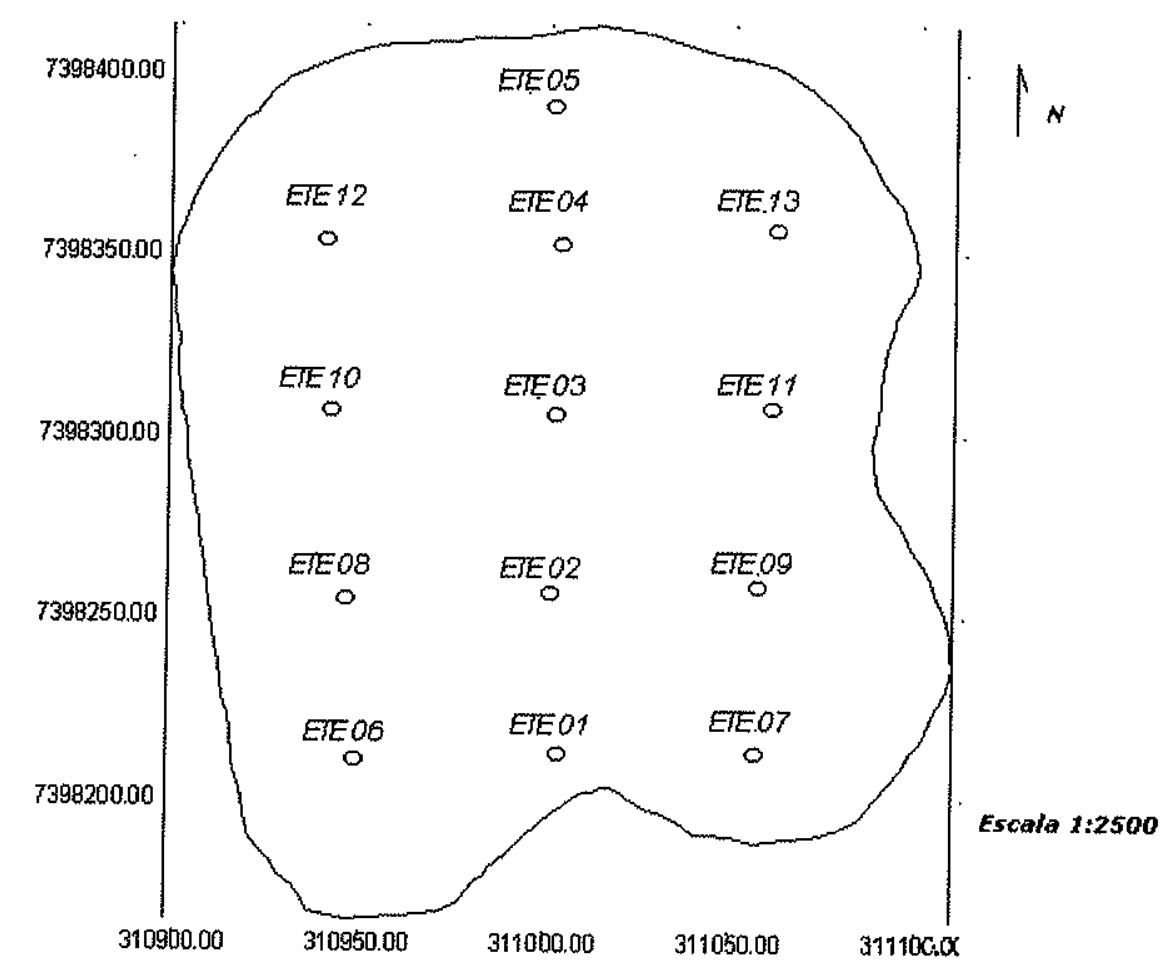

Figura 9 - Em destaque, malha de amostragem regular com as respectivas estações de coleta.

\subsubsection{Amostragem do sedimento de fundo}

Em sistemas lagunares, segundo FÖRSTNER e WITTMANN (1981), o sedimento de fundo representa o principal reservatório para os metais pesados.

A amostragem e determinação da composição química do sedimento fornece informações sobre a atuação desse material como retentor de metais pesados. $O$ tipo de coletor empregado nas amostragens voltadas para estes fins, é de extrema importância, pois devem ser isentos de qualquer possibilidade de contaminação da amostra.

Neste caso, optou-se pelo uso de amostrador de gravidade "core" modelo Kajak-Brinkhurst (MUDROCH e MACKNIGHT, 1994; BAUDO et al., 1990; MUDROCH e ACZUE, 1995), modificado. Esta modificação constou da adaptação de hastes de trado, visando facilitar o seu manuseio e a coleta do sedimento em ambiente lagunar raso (Figura 10AB). Esse equipamento mostrou-se adequado para o uso em pequenas embarcações, além de fornecer baixo grau de contaminação ao sedimento por ser composto principalmente por polietileno. 

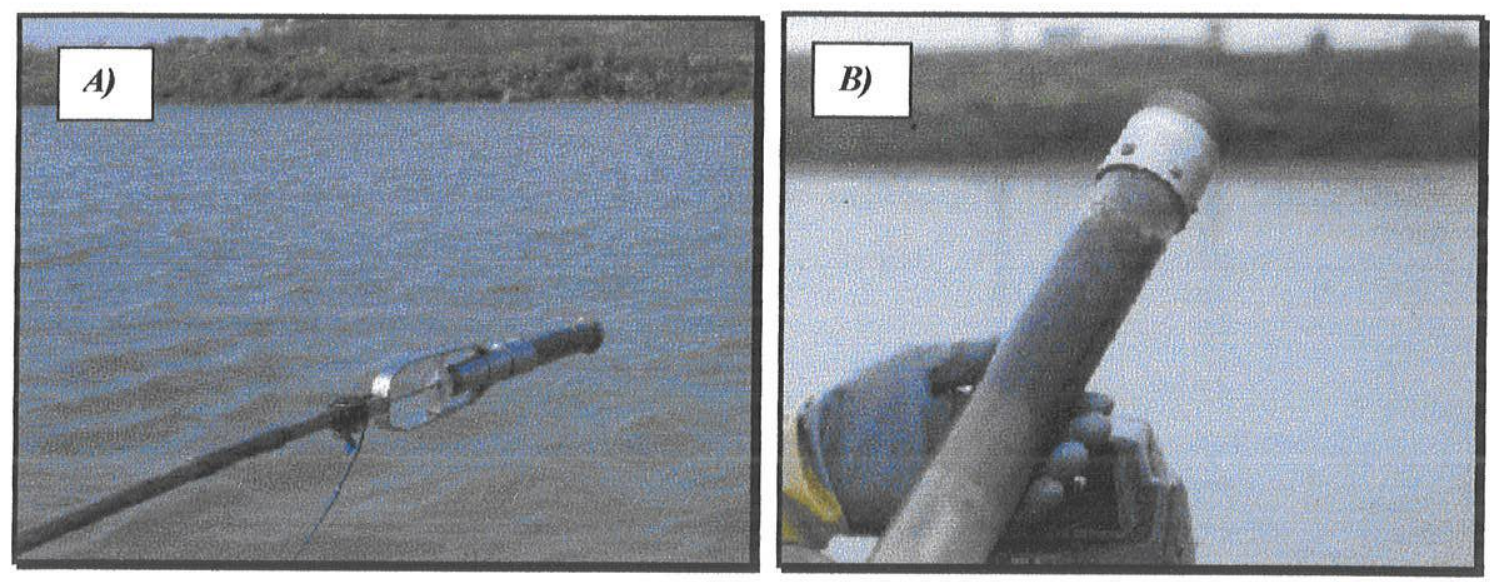

Figura $10 \mathrm{AB}$ - Coleta do sedimento com amostrador de gravidade modelo KajakBrinkhust Modificado. A) Inserção do coletor na água, visando a coleta do sedimento. B) Recuperação do sedimento amostrado.

Em algumas estações de amostragem não foi possível coletar o sedimento de fundo com esse equipamento, em decorrência destes sedimentos serem compactos e de difícil coleta, empregando-se neste caso tubos de PVC. Foram utilizados nesta operação de coleta tubos PVC com aproximadamente $2 \mathrm{~m}$ de comprimento, tampas de PVC (usada para promover vácuo), marreta de borracha e serra metálica (Figura 11ABC). Os primeiros $2 \mathrm{~cm}$ das amostras de topo coletadas por tubo PVC, foram descartadas devido ao contato com a serra, evitando-se assim a contaminação deste sedimento. 

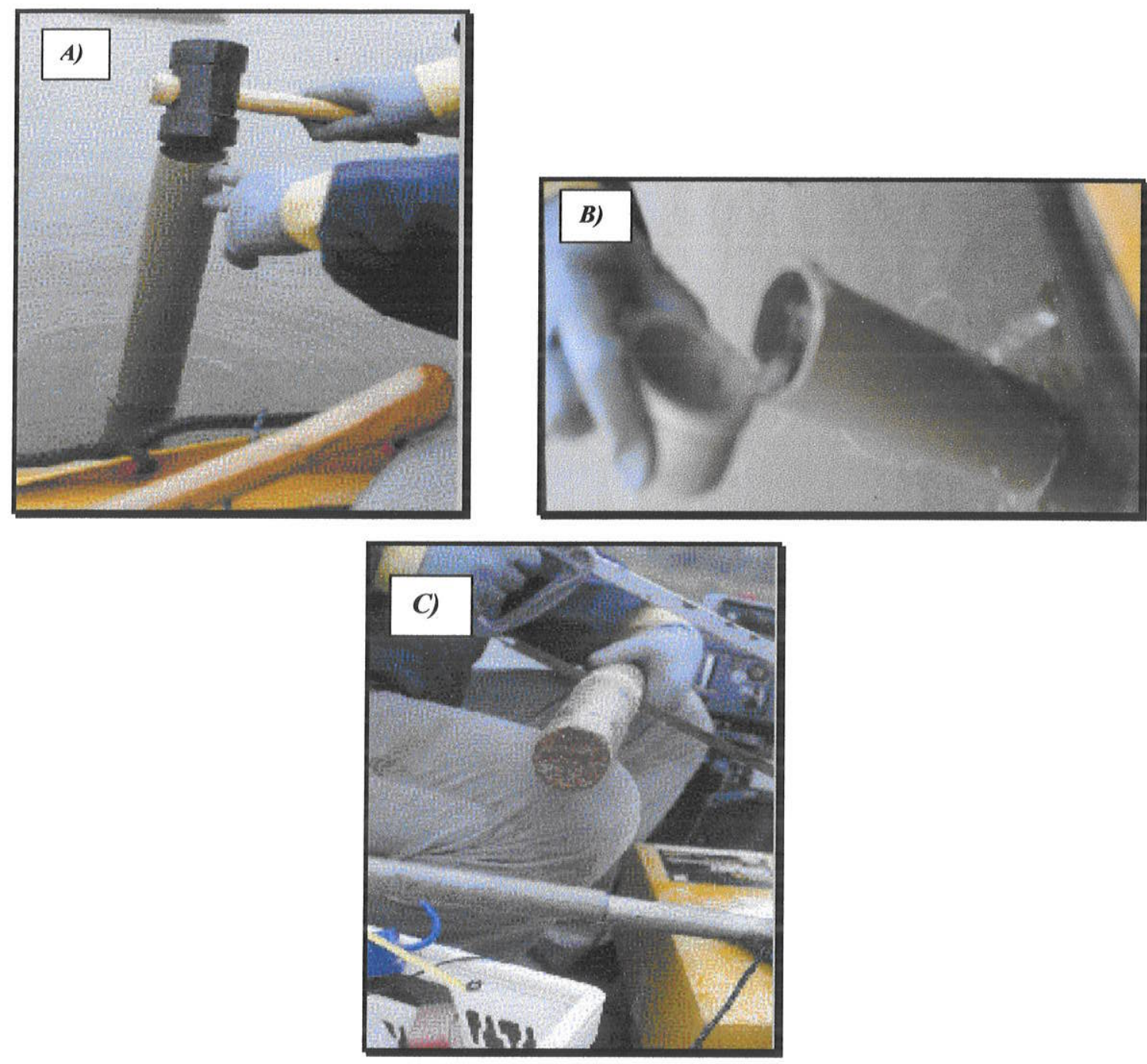

Figura 11 ABC - Procedimento de coleta do sedimento de fundo, a partir do emprego de tubo PVC. A) Colocação do tubo PVC na água. B) Retirada da água, recuperada juntamente com o sedimento. C) Tubo PVC sendo serrado para retirada do sedimento.

Os sedimentos de fundo coletados, tanto por amostrador de gravidade como por tubo PVC, foram subamostrados em topo e base, de tal modo que estes intervalos de subamostragem variaram em função da profundidade do "core" recuperado.

Para a subamostragem e armazenamento das subamostras, empregouse espátula e sacos de polietileno fechados a vácuo. Os equipamentos de polietileno e teflon são os mais utilizados na coleta e armazenamento de amostras para a detecção de metais pesados, pois esses não as contaminam (MUDROCH e MACKNIGHT, 1994; MUDROCH e AZCUE, 1995). 
As subamostras de sedimento foram armazenadas em caixa de isopor com temperatura de aproximadamente $4^{\circ} \mathrm{C}$, visando evitar alterações físicoquímicas muito acentuadas (MUDROCH e AZCUE, 1995).

Os sedimentos de fundo foram coletados e subamostrados em dois períodos climáticos distintos, de alta e baixa pluviosidade, com intuito de verificar alterações na distribuição e concentração dos metais pesados nas duas estações mais contrastadas do ano.

\section{A) Amostragem do Sedimento no Período Chuvoso}

No período climático em questão, coletou-se amostras de sedimento nas treze estações (definidas como ETE 01 até 13), a partir do uso de coletor de gravidade e tubo de PVC. Nas estações ETE 01, 02, 05, 06, 07, 08, 09, 11, 12 e 13 empregou-se coletor de gravidade, enquanto que nas estações 03,04 e 10 utilizou-se tubos de PVC de aproximadamente 1,50m, 1,00m e 2,00m de altura, respectivamente.

Após a coleta, subamostrou-se os sedimentos de topo em intervalos de 0 a $3 \mathrm{~cm}$ ou de 0 a $5 \mathrm{~cm}$. O intervalo de subamostragem do material basal variou devido a profundidade do "core" recuperado, no geral não ultrapassando $20 \mathrm{~cm}$.

\section{B) Amostragem do Sedimento no Período Seco}

Durante esta coleta não foi possivel amostrar o sedimento nas estações ETE 11 e 13 (Figura 9). Nesta amostragem, constatou-se que o volume d'água do lago diminuiu cerca de $1 \mathrm{~m}$, em relação ao volume d'água verificado na coleta anterior (período chuvoso).

Nesta amostragem empregou-se tubo PVC apenas na estação 04 , os outros pontos foram coletados a partir de amostrador de gravidade. Os intervalos de subamostragem para o topo coincidiram com os aplicados no período chuvoso $(0$ a $3 \mathrm{~cm}$ ou 0 a $5 \mathrm{~cm}$ ). Em decorrência da variação da profundidade do "core" recuperado, não foi possível subamostrar a base usando os mesmos intervalos aplicados no período chuvoso, estes em alguns pontos chegaram a $40 \mathrm{~cm}$ (ETE 07 e 10). 


\subsubsection{Amostragem da água da interface e do sedimento particulado em suspensão}

Os sedimentos acumulados no fundo dos ambientes aquáticos realizam constantes trocas de nutrientes e outras substâncias com a água acima dele (coluna d'água). A interface sedimento-água atua ao mesmo tempo como depósito e fonte para os metais pesados no sistema aquático, justificando a importância do estudo conjunto desta água (água da interface) e do sedimento de fundo.

A água da interface foi amostrada durante a coleta do sedimento de fundo, por amostrador de gravidade. Nos pontos onde utilizou-se tubo PVC para coletar o sedimento de fundo não foi possível amostrar a água.

Essa água foi filtrada a partir de seringas de polietileno esterilizadas e filtros de éster de celulose de 0,8, 0,4 e 0,22 $\mu \mathrm{m}$ da MILLIPORE (Figura 12AB). Após a filtragem, essa água foi armazenada em dois frascos de polietileno de $50 \mathrm{ml}$ cada; um para análise de ânions e outro para a de cátions. Ambos os fracos foram pré-lavados com água tridestilada e ácido clorídrico para limpeza, no dia anterior ao trabalho de campo, conforme proposto em MUDROCH e ACZUE (1995). No frasco separado para armazenar a água para determinação de Fe total, $\mathrm{Mn}, \mathrm{Ni}, \mathrm{Cu}, \mathrm{Pb}, \mathrm{Zn}, \mathrm{Ag}, \mathrm{Cd}$ e $\mathrm{Cr}$, adicionou-se $10 \mathrm{ml}$ de $\mathrm{HNO}_{3}$ a $1 \%$.
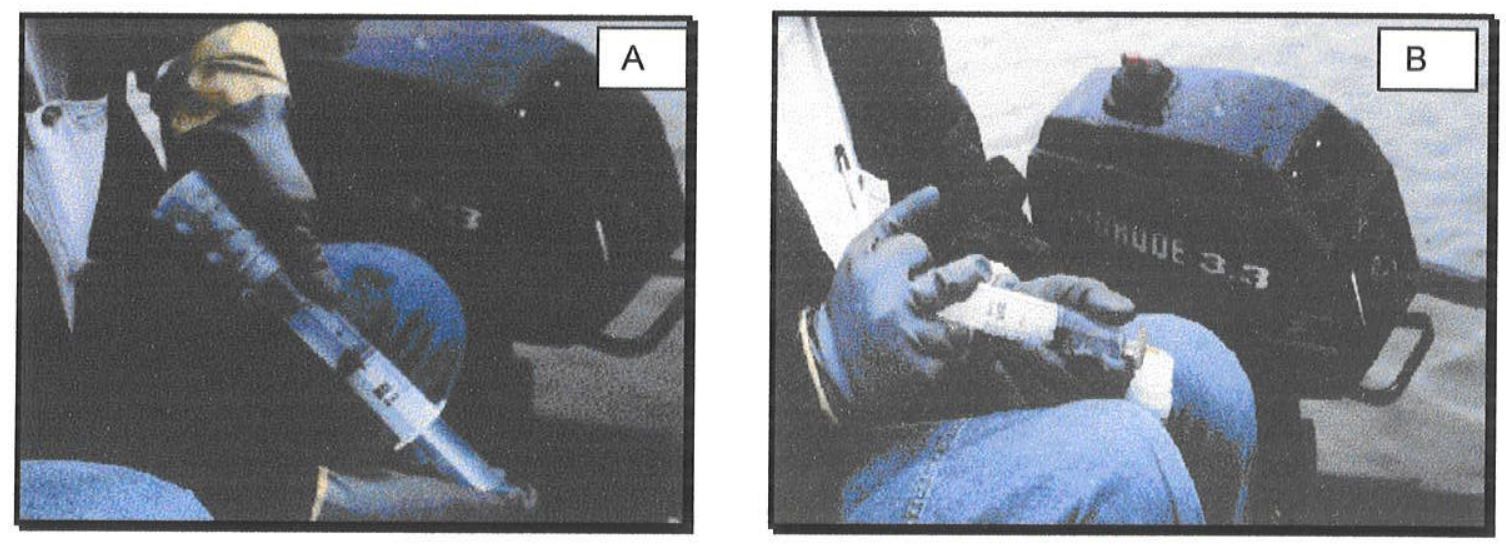

Figura $12 \mathrm{AB}$ - Filtragem da água da interface e coleta do sedimento particulado em suspensão. A) Passagem da água já filtrada no filtro $0,8 \mu \mathrm{m}$ para a seringa, visando a filtragem em filtro 0,22 $\mu \mathrm{m}$. B) Filtragem da água em filtro 0,22 $\mu \mathrm{m}$.

Juntamente com a coleta da água de interface, amostrou-se o sedimento particulado em suspensão, a partir do emprego dos mesmos equipamentos usados para filtrar a água. Os filtros contendo o sedimento particulado em 
usados para filtrar a água. Os filtros contendo o sedimento particulado em suspensão, foram estocados em sacos de polietileno e foram armazenados (no campo) em caixa de isopor com temperatura de aproximadamente $4^{\circ} \mathrm{C}$, juntamente com os frascos contendo a água da interface e com as amostras de sedimento de fundo (Figura 13). Imediatamente após a chegada do campo, essas amostras foram mantidas sob refrigeração no Laboratório de Geoquímica do Departamento de Geologia Sedimentar e Ambiental (DGSA) do Instituto de Geociências (IGc) da Universidade de São Paulo (USP), aguardando a realização das análises sedimentares, químicas e microscópicas.

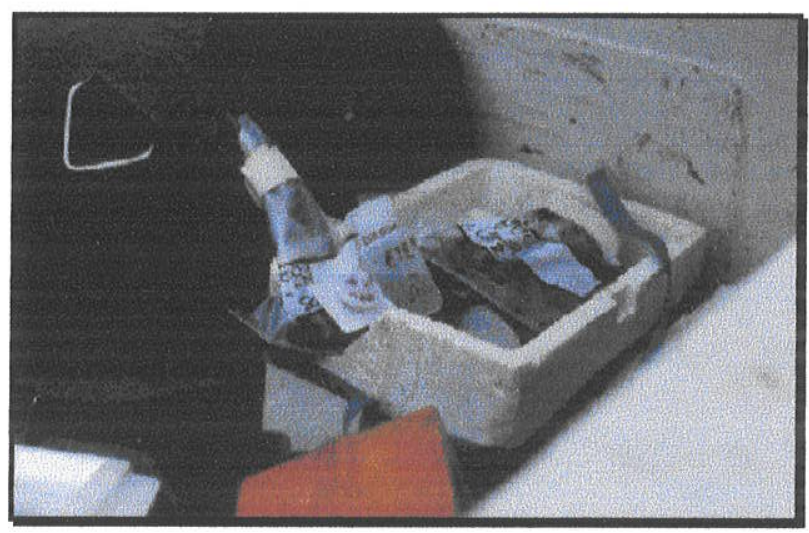

Figura 13 - Estocagem das amostras de sedimento de fundo, água da interface e sedimento particulado em suspensão em caixa de isopor com temperatura de $4^{\circ} \mathrm{C}$.

A água de interface bem como o sedimento particulado em suspensão, foram coletados no período chuvoso e seco, conforme ocorrido com as amostras de sedimento de fundo:

A) Amostragem da Água da Interface e do Sedimento Particulado em Suspensão no Período Chuvoso

A água da interface, no período de alta pluviosidade, foi coletada nas estações ETE 02, 05, 06, 07, 08, 09, 10, 11, 12 e 13 por coletor de gravidade, visando a determinação de metais e ânions (Figura 09). Os sedimentos particulado em suspensão foram coletados nas mesmas estações de amostragem, a partir da filtragem da água por filtros de 0,8, 0,4 e 0,22 $\mu \mathrm{m}$, conforme mencionado no subcapítulo acima. Nas estações ETE 01, 03 e 04 não foi possível coletar água e o sedimento particulado em suspensão, em função do amostrador utilizado nesses pontos (tubo PVC) não ser apropriado para esta amostragem. 
B) Amostragem da Água da Interface e do Sedimento Particulado em Suspensão no Período Seco

A água e o sedimento particulado em suspensão foram amostrados nas estações ETE $01,02,03,05,06,07,08,09,10,12$, a partir de amostrador de gravidade. Conforme informado anteriormente, nas estações ETE 11 e 13 não foi possível coletar amostras por motivos de acesso a esses.

\subsubsection{Obtenção de Parâmetros Físico-Químicos no Sedimento de Fundo e na Água da Interface}

As medidas de potenciais de oxi-redução em amostras de sedimento e água são muito utilizadas na avaliação da qualidade ambiental, pois indicam de forma satisfatória, a condição redox do meio, principalmente em termos de estagnação. No entanto, a literatura recomenda uma certa cautela na interpretação dos valores de Eh.

Segundo MUDROCH e MACKNIGHT (1994), medidas de potenciais redox em ambientes de águas naturais envolvem uma complexa teoria e problemas práticos, em oposição à aparente simplicidade da medida eletroquímica. Embora os sistemas aquosos contenham oxigênio ou agentes oxidantes que apresentem valores positivos de Eh e agentes redutores que apresentem valores negativos de Eh uma interpretação quantitativa detalhada destes potenciais é, segundo estes autores, injustificada na maioria dos casos. Isto se deve ao fato de que a maioria dos potenciais medidos em águas naturais representam uma somatória de potenciais, e não o valor de uma única espécie química.

Assim, como os valores redox (Eh), o pH é um bom parâmetro para indicar as condições do meio em que reside a amostra e os eventuais processos químicos e/ou biológicos que estejam ocorrendo no sistema natural. Estritamente, o pH é um parâmetro complementar ao Eh e, sua medida, assim como a medida de $\mathrm{Eh}$, requer cuidado especial.

Neste estudo, O Eh e o pH foram obtidos a partir do emprego de pHmêtro portátil DIGIMED modelo DM-2 e pHmêtro portátil GEOLAB, sendo o primeiro utilizado na determinação dos parâmetros físico-químicos do 
sedimento de fundo e o segundo usado na obtenção de dados referentes a água da interface.

Para a determinação do valor de Eh no sedimento de fundo e na água da interface, usou-se eletrodo com anel de platina DMR-MP1 da marca DIGICRON. Na obtenção do pH utilizou-se eletrodo de vidro DME-CVR 13 da marca DIGICRON. A medida de Eh consistiu na leitura do potencial acusado pelo eletrodo de platina versus o valor obtido no eletrodo de referência interno (calomelanos ou $\mathrm{Ag} / \mathrm{AgCl}$ ), enquanto que a de $\mathrm{pH}$ consistiu na leitura acusada pelo eletrodo de vidro versus eletrodo de referência interno.

Os eletrodos usados na obtenção de valores de $\mathrm{pH}$ e Eh, foram lavados com água destilada e secos com lenço de papel durante o seu uso no campo. No laboratório, antes e depois do trabalho de campo, os eletrodos foram lavados com sabão neutro e água destilada e calibrados a partir de soluções padrões.

\subsubsection{Medidas de pH e Eh no sedimento de fundo}

O Eh e o $\mathrm{pH}$ foram medidos nas subamostras de topo e base do "core" de sedimentos, a partir da inserção dos eletrodos de platina e de vidro no sedimento, a uma profundidade de $5 \mathrm{~cm}$ (Figura 14).

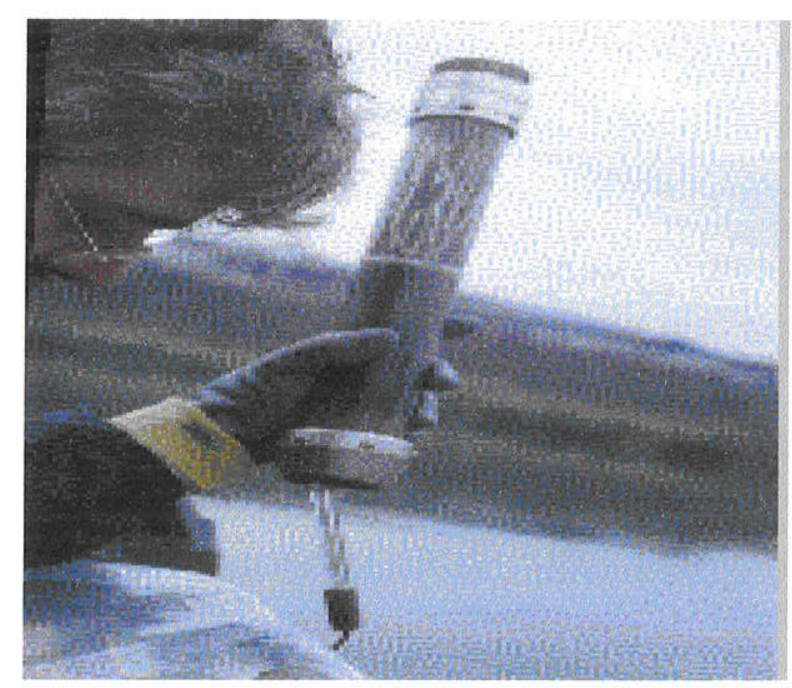

Figura 14 - Medidas de Eh e Ph no sedimento de fundo.

\subsubsection{Medidas de pH e Eh na água da interface}

As medidas de $\mathrm{pH}$ e Eh da água da interface, foram obtidas a partir da inserção dos eletrodos na água coletada junto com o sedimento de fundo. 


\section{2 - TRABALHO DE LABORATÓRIO}

As amostras de sedimento de fundo, água da interface e sedimento particulado em suspensão, seguiram os seguintes procedimentos de análise:

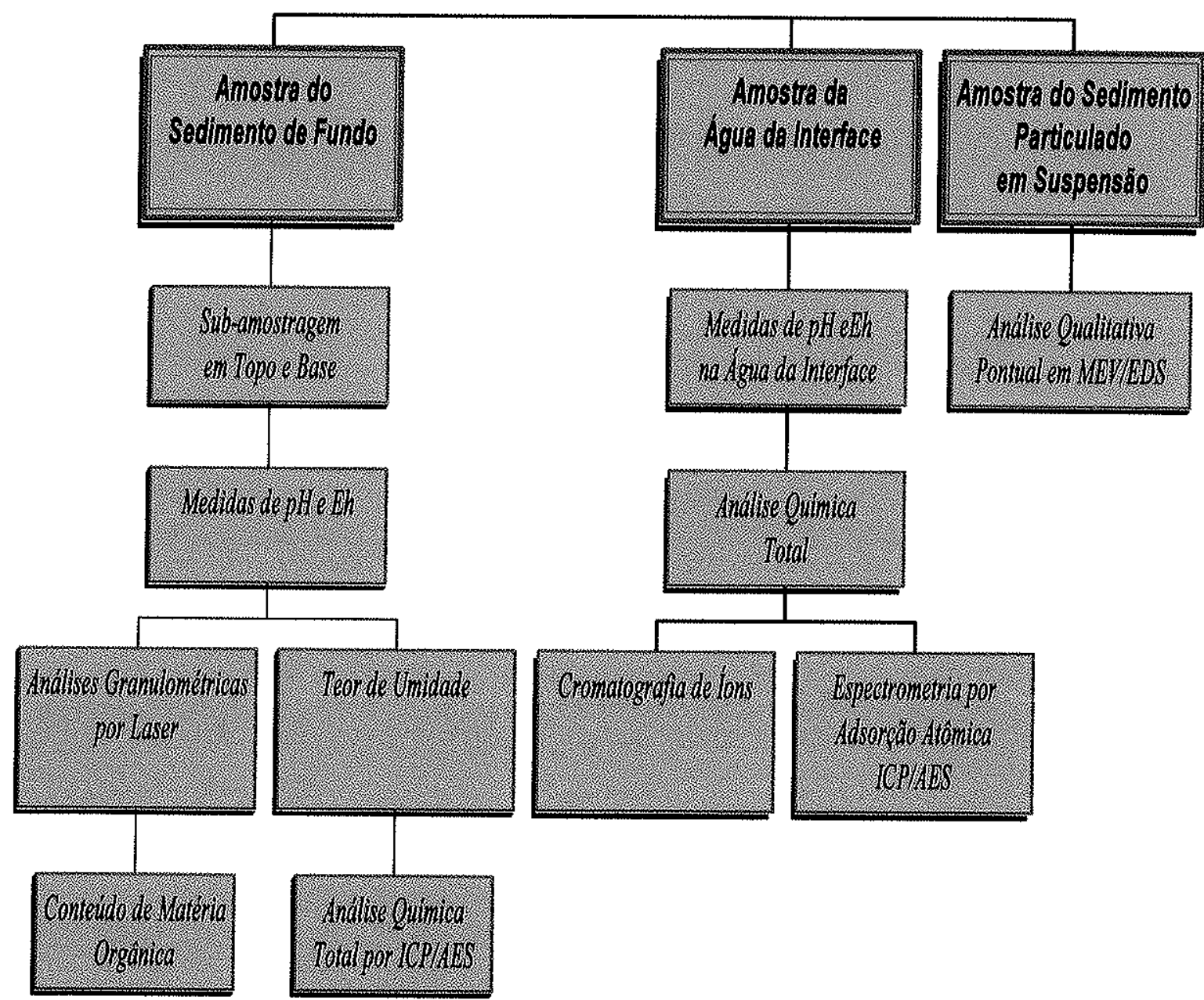

Figura 15 - Organograma geral de tratamento analítico das amostras de sedimento de fundo, água da interface e sedimento particulado em suspensão.

Nas amostras de sedimento de fundo, água da interface e sedimento particulado em suspensão, coletadas nos períodos chuvoso e seco, foram realizadas as seguintes análises: determinação do teor de umidade e matéria orgânica, análise granulométrica a laser, análise química total, cromatrografia de íons e análise química pontual qualitativa (Figura 15). 


\subsubsection{Análises Realizadas nas Amostras de Sedimento de Fundo}

\subsubsection{Análises sedimentares}

Nos sedimentos de fundo, foram realizadas análises macroscópicas, determinação do teor de umidade, obtenção do conteúdo de matéria orgânica, análises granulométricas por Laser e análises químicas totais por ICP-AES.

\subsubsection{Análise macroscópica}

No campo, as amostras de topo e base do "core" foram caracterizadas macroscopicamente. Para a realização desta caracterização, levou-se em conta a cor, textura, plasticidade e compactação do sedimento analisado.

\subsection{Dosagem do teor de umidade}

A determinação do teor de umidade das subamostras implicou na pesagem antes e após serem colocadas em estufa com temperatura de aproximadamente $40^{\circ} \mathrm{C}$. $O$ tempo de permanência na estufa compreendeu duas semanas, até a secagem completa.

\subsection{Dosagem do conteúdo de matéria orgânica}

Para a determinação do conteúdo de matéria orgânica presentes nas amostras de topo e base do "core" de sedimento de fundo, empregou-se a metodologia adotada por NAVARRA et al. (1980), que utiliza água oxigenada para ataque da matéria orgânica. A dosagem do conteúdo de matéria orgânica foi realizada a partir do ataque do sedimento seco, aproximadamente $5 \mathrm{~g}$ de amostra, por água oxigenada "Peróxido de Hidrogênio" (a 100 volumes e 30\%) a quente (chapa com temperatura de 40 a $50^{\circ} \mathrm{C}$ ) por período de tempo de duas a três semanas ou até estes sedimentos não reagirem mais ao ataque.

\subsection{Análises granulométricas}

Neste caso as subamostras de topo e base do "core", foram peneiradas a úmido em peneira de 16 mesh com abertura de $1,00 \mathrm{~mm}$. Apenas a fração menor que $1,00 \mathrm{~mm}$ foi encaminhada ao Laboratório de Caracterização Tecnológica (LCT) da Faculdade de Engenharia de Minas da USP, na forma de 
polpa. Esta análise foi realizada a partir do analisador MALVERN modelo MASTERSIZER S.

O princípio de operação deste analisador consiste na interação de feixe de luz com as partículas, estando estas em meio fluido. Neste método, quando parte do feixe de luz sofre espalhamento, parte é absorvida e parte é transmitida, esse espalhamento inclui luz refratada e refletida, sendo o diâmetro médio das partículas medido pela intensidade de energia de luz em determinados ângulos de espalhamento. Um conjunto de lentes, detectores elétricos e microprocessador, captam a intensidade de energia espalhada e transformam-na em distribuição granulométrica das partículas. As partículas pequenas geram um ângulo de espalhamento maior do que o ângulo gerado pelas partículas maiores.

\subsubsection{Análises químicas totais}

Várias técnicas analíticas são utilizadas para a determinação de metais pesados em sedimentos. Nesse estudo, optou-se pela utilização do método de Espectrometria de Emissão Atômica (ICP-AES).

\subsection{Espectrometria de emissão atómica (ICP-AES)}

As amostras de topo e base do "core" de sedimento, separadas para análise química total foram secas em estufa com temperatura de $40^{\circ} \mathrm{C}$ e foram moídas em moinho de bolas de ágata no Laboratório de Tratamento de Amostras do Departamento de Geologia Mineralogia e Geotectônica (DGMG) do IGc da USP. Durante esta moagem, limpou-se a panela de ágata com areia, água bidestilada, álcool e ar comprimido.

As amostras moídas (fração menor que 200 mesh) foram encaminhadas ao Laboratório de Química/Plasma do DGMG do IGc da USP. O aparelho utilizado nesse laboratório é um espectrômetro modelo ARL-3410 seqüencial com nebulizador convencional (tipo MEINHARD).

As análises químicas realizadas pelo ICPIAES foram obtidas a partir da fusão alcalina do pó de sedimento com mistura de meta e tetraborato de sódio em mufla. Nesse caso a mufla não estava pré-aquecida, em decorrência da presença de matéria orgânica que pode inflamar devido a alta temperatura. Assim, colocaram-se os cadinhos com a mufla desligada e estes foram 
mantidos até que a temperatura da mufla atingisse $1000^{\circ} \mathrm{C}$. Segundo JARVIS e JARVIS (1992) apud JANASI et al. (1995), a fusão alcalina garante a dissolução de minerais refratários como Zircão, Cromita, Berilo, Monazita e outros, permitindo a quantificação de elementos traços como $\mathrm{Zr}, \mathrm{Cr}$ e Be, desde que presentes em teores passíveis de detecção pelo método utilizado .

A massa fundida (pérola) foi dissolvida, avolumada, filtrada e colocada em dois frascos. Cerca de $250 \mathrm{ml}$ da solução foi separada para a análise de elementos maiores, enquanto que $50 \mathrm{ml}$ foram separados para a análise de elementos traços e tratados com 2 gotas de HF 48\%. Neste último caso impedindo-se a possivel precipitação de alguns elementos traços tais como $\mathrm{Zr}$, que são mantidos em solução pela formação de complexos com o $\mathrm{F}$.

Essas análises foram realizadas em duas corridas separadas, de tal modo, que na primeira foram analisados os elementos maiores $(\mathrm{Si}, \mathrm{Al}, \mathrm{Fe}, \mathrm{Mg}$, $\mathrm{Ca}, \mathrm{Na}$ e $\mathrm{K}$ ) e na segunda os elementos menores e traços (Ti, $\mathrm{P}, \mathrm{Mn}, \mathrm{Ba}, \mathrm{Be}$, $\mathrm{Co}, \mathrm{Cr}, \mathrm{Cu}, \mathrm{La}, \mathrm{Ni}, \mathrm{Sr}, \mathrm{Zr}$ e V). As curvas de calibração deste aparelho foram obtidas a partir de materiais de referência certificados e do branco.

\subsubsection{Análises Realizadas nas Amostras de Ảgua da Interface}

\subsubsection{Análises químicas}

A análise da água da interface teve a finalidade de verificar a existência ou não de contaminação por metais pesados encontrados no sedimento de fundo. Para esta determinação, utilizou-se Espectrômetro de Absorção Atômica (AAS) e Cromatógrafo de ĺons, ambas análises realizadas no Centro de Pesquisas de Águas Subterrâneas (CEPAS) do DGSA do IGc da USP.

\subsection{Espectrometria de absorçăo atómica (AAS)}

Essa técnica foi utilizada sobre as amostras de água da interface, visando detectar os cátions $\left(\mathrm{Cu}^{2+}, \mathrm{Pb}^{2+}, \mathrm{Zn}^{2+}, \mathrm{Al}^{3+}, \mathrm{Sr}^{2+}, \mathrm{Ba}^{2+}, \mathrm{Ca}^{2+}, \mathrm{Mg}^{2+}, \mathrm{Fe}^{\text {total }}\right.$, $\mathrm{Cr}^{\text {total }}, \mathrm{Mn}^{2+}, \mathrm{Cd}^{2+}$ e $\mathrm{Ag}^{+}$) e metais pesados. $\mathrm{O}$ aparelho utilizado nessa pesquisa foi Espectrofotômetro marca CG-AA7000BC. 


\subsection{Cromatografia de ions}

Aplicada sobre as amostras de água da interface, esta técnica objetivou detectar os ânions $\left(\mathrm{Cl}^{-}, \mathrm{NO}_{2}{ }^{-}, \mathrm{Br}^{-}, \mathrm{NO}_{3}{ }^{-}, \mathrm{PO}_{4}{ }^{2-} \mathrm{e} \mathrm{SO}_{4}{ }^{2-}\right)$. O aparelho utilizado foi Cromatógrafo de ĺons marca DIONEX modelo 2010i.

\subsubsection{Análises Realizadas nas Amostras de Sedimento Particulado em} Suspensão

\subsubsection{Microscopia eletrônica de varredura com energy dispersive spectrum (MEV/EDS)}

A microscopia eletrônica de varredura é uma técnica de alta resolução, permitindo a visualização de partículas e o estabelecimento das relações texturais existentes entre estas.

O Microscópio Eletrônico de Varredura acoplado ao Energy Dispersive Spectrum (MEV/EDS), permite diferentes análises morfológicas e minerais, concomitantemente com a obtenção de análises químicas pontuais qualitativas e semi-quantitativas.

Essa técnica foi aplicada em algumas amostras (ETE 02, 06, 07, 08, 10 e 12) de sedimento particulado em suspensão coletadas nos períodos chuvoso e seco. As amostras a serem analisadas no MEVIEDS foram coladas com fita de carbono em Stubs e foram recobertas com cinco ou mais camadas de carbono, visando principalmente a qualidade dos dados qualitativos. Nesse estudo, para cada ponto analisado, obteve-se espectros correspondentes às análises químicas qualitativas e imagens Split (de um lado a imagem com elétrons retrodifusos e do outro imagem de elétrons secundários) e em alguns casos imagens com elétrons retroespalhados.

O equipamento utilizado foi Microscópio Eletrônico de Varredura modelo LEO 440I com EDS da marca OXFORD (Laboratório de Microscopia Eletrônica do - DGSA do IGC da USP). 


\section{3 - TRATAMENTO DOS DADOS}

\subsubsection{Tratamento dos Dados Obtidos nas Análises Granulométricas}

Os resultados obtidos nas análises granulométricas, sobre os sedimentos de fundo coletados nas estações climáticas chuvosa e seca, foram tratados no aplicativo "EXCEL 97" e no aplicativo "TRIDAW 2.9c", resultando em planilhas eletrônicas e diagramas triangulares de distribuição granulométrica. Para a determinação da fração granulométrica, utilizou-se a tabela Alemã, exposta abaixo.

TABELA 2 - ESCALA GRANULOMÉTRICA ALEMÃ (ATTERBERG MODERNIZADA).

\begin{tabular}{|c|c|c|}
\hline Ditametro (m) & \multicolumn{2}{|c|}{ Atterberg (modemizada) } \\
\hline 60 & \multicolumn{2}{|c|}{$B L O C O$} \\
\hline \multirow{3}{*}{$\begin{array}{l}20 \\
6\end{array}$} & Grande & \multirow{3}{*}{8} \\
\hline & Médio & \\
\hline & Fino & \\
\hline 2 & & \multirow{4}{*}{ 武 } \\
\hline 0.6 & Grossia & \\
\hline $\begin{array}{c}0.2 \\
0.06\end{array}$ & Modia & \\
\hline 0.06 & Fina & \\
\hline 0.02 & Grasso & \multirow{3}{*}{ 标 } \\
\hline \multirow{2}{*}{0.06} & Médio & \\
\hline & Fino & \\
\hline
\end{tabular}

ARGILA

Modificado de SUGUIO (1973).

\subsubsection{Tratamento dos Dados Obtidos nas Análises Químicas}

Os dados referentes às análises químicas, realizadas sobre os sedimentos de fundo, foram tratados no aplicativo "EXCEL 97", resultando em planilhas eletrônicas e gráficos binários. 
As concentrações químicas do $\mathrm{Cu}, \mathrm{Cr}, \mathrm{Zn}$ e $\mathrm{Ni}$, obtidas nas análises químicas totais sobre os Sedimentos Argilosos, coletados tanto no período chuvoso como no seco, foram tratadas no aplicativo "SURFER 6.0", visando a construção de mapas de isoconcentração química para estes metais nestas duas estações climáticas. Neste caso, utilizou-se mapa georreferenciado do lago e tabelas contendo as coordenadas $X, Y$ e a variável $Z$.

Para a confecção destes mapas, foi necessário interpolar alguns pontos, em decorrência da não existência destes dados, ou devido aos valores obtidos nas análises não corresponderem ao Sedimento Argiloso (tal fato ocorre na estação ETE01, cujos dados foram obtidos nos Sedimentos Aluvionares). Essa interpolação foi realizada a partir da média dos dados mais próximos à estação de amostragem em questão. Estes mapas, foram construídos a partir do método estatístico correspondente ao Inverso do Quadrado da Distância (IQD)

Os dados obtidos no "SURFER", foram utilizados apenas na verificação da provável tendência das concentrações dos metais nas estações de amostragem, a partir de uma escala de cores. Estes mapas não são integralmente precisos, neste estudo, devido ao pequeno número de estações de amostragem, servindo principalmente como representação gráfica e de indicativo de distribuição dos elementos analisados considerando esta ressalva.

\subsubsection{Verificação do Grau de Contaminação dos Metais Pesados}

Em decorrência do aumento da concentração química de metais poluentes nos sistemas aquáticos por atividades antrópicas, algumas técnicas estão surgindo visando quantificar o grau de contaminação do meio. As dificuldades para estabelecer critérios de qualidade para os sedimentos são muitas e diversas formas de avaliação vêm sendo utilizadas com o intuito de estabelecer procedimentos-padrão e critérios para a determinação do impacto ambiental de poluentes associados aos sedimentos.

Conforme FÖRSTNER et al. (1990), existem razões importantes para que se estabeleçam tais critérios de qualidade para os sedimentos:

1. Diferentemente da água, os sedimentos integram concentrações de contaminantes que aí permanecem por um período de tempo, podendo, 
portanto, reduzir o número de amostras de monitoramento, observação e reconhecimento;

2. As perspectivas a longo prazo, na administração de recursos hídricos, envolvem estratégias integradas nas quais poluentes associados aos sedimentos devem ser considerados;

3. Planos para os destinos de esgotos serão baseados, cada vez mais, na capacidade que um sistema de recebimento tem de assimilação de poluentes, o que requer o conhecimento das propriedades de componentes sedimentares, como maior sumidouro.

Uma vez que os metais podem ser encontrados na natureza e são parte da crosta terrestre, deve-se fazer a distinção entre os metais de origem natural e antropogênica. Ambas fontes contribuem para a qualidade das águas nos ambientes superficiais e têm duas importantes conseqüências, segundo NOVOTNY (1995):

1. Se o conteúdo de metais de um corpo d'água, sedimento ou água é devido a causas naturais, então ele é considerado como um background (natural);

2. Somente a contaminação do sistema água-sedimento a partir de fontes de cultura que impedem a reutilização da água sem prévio tratamento é considerado poluição.

Uma avaliação objetiva do teor de contaminação por metais pesados depende da escolha de um índice base apropriado com nível de referência. Segundo COVELLI e FONTOLAN (1997), vários autores têm utilizado os teores do folhelho "shales" médio de TUREKIAN e WEDEPOHL (1961) como índice de referência, em estudos de contaminação de sedimento. Outra alternativa é a obtenção do conteúdo pré-industrial dos testemunhos mais profundos, assumindo-se não estarem contaminados e assegurando-se ainda que não tenham ocorrido bioturbações. Neste estudo, optou-se pela utilização dos teores obtidos nos folhelhos médio de TUREKIAN e WEDEPOHL (1961), para os metais de estudo ( $\mathrm{Cu}, \mathrm{Cr}, \mathrm{Zn}$ e $\mathrm{Ni})$, conforme exibe a tabela abaixo, pois o lago é composto por diferentes materiais de origem natural e antrópica, não sendo possível obter o conteúdo pré-industrial. 
TABELA 3 - CONCENTRAÇÓES NATURAIS DE $\mathrm{Cu}, \mathrm{Cr}, \mathrm{Zn}$ e Ni EM FOLHELLOS.

Metais

\begin{tabular}{cc} 
& (ppm) \\
\hline$C u$ & 45 \\
$C r$ & 90 \\
$N i$ & 68 \\
$Z n$ & 95 \\
\hline
\end{tabular}

Fonte: TUREKIAN e WEDEPOHL (1961).

No presente trabalho, adotou-se como critério de avaliação da qualidade dos sedimentos o Indíce de Geoacumulação (lgeo) e Fator de Contaminação ou Fator de Enriquecimento (F.E.), em decorrência destes trabalharem com concentrações dos metais naturais (background) e com as concentrações atuais (encontradas na área de estudo). Nesse caso, foram utilizados estes dois métodos, visando verificar se o fator de correção aplicado no Igeo realmente induz a erros interpretativos, já que este minimiza o grau de contaminação, conforme descrevem CALMANO e FÖRSTNER (1996). Existem divergências quanto aos valores geoquímicos de fundo ou background, bem como no que diz respeito a quantificação da contribuição antropogênica.

Outros métodos também são utilizados nas avaliações das contaminações dos sedimentos, tais como: determinação da concentração de sulfetos ácidos voláteis (AVS) ou sulfetos solúveis a frio (ANKLEY, 1996); extração seqüencial de elementos traços (TESSIER et al., 1979; TESSIER et al., 1985; CALMANO e FÖRSTNER, 1996); análise traíde (ANDERSON et al. 2001). A Universidade Federal de São Carlos (UFSCar), a Universidade de Campinas (UNICAMP) e a CETESB estão desenvolvendo projeto temático de pesquisa, junto à FAPESP, para o desenvolvimento de critérios de qualidade de sedimentos, denominado QUALISED (MOZETO et al., 1998).

\subsubsection{Fator de Contaminação}

O Fator de Contaminação ou Fator de Enriquecimento é expresso pelo parentesco entre a concentração de um poluente na camada superficial recente do sedimento e o seu background natural de concentração. 


$$
C_{f}^{i}=\frac{C^{i}{ }_{o-x}}{K^{i}{ }_{n}}
$$

onde:

$C_{f}^{i}$ : é o fator de contaminação para um determinado elemento (i);

$C^{i}{ }_{0-x}$ : é a determinação empírica da concentração da substância em questão (i) para sedimento superficial $(0-x \mathrm{~cm})$. Neste caso, utilizou-se as concentrações químicas dos metais pesados obtidas nos Sedimentos Argilosos;

$K_{n}^{i}$ (ou $B n$ ): é a determinação empírica (ou padrão natural do nível de background para um dado elemento). Usou-se a concentração de metais pesados em "shales", proposta por TUREKIAN e WEDEPOHL (1961);

O fator de contaminação avalia a contaminação de elementos individuais:

Se $C^{i}{ }_{0-x}>K_{n}^{i}$ as substâncias são consideradas contaminantes ou enriquecidas;

$\mathrm{Se}^{i}{ }_{0-x}<K_{n}^{i}$ o elemento não mostra ser contaminado.

Segundo HAKANSON e JANSSON (1983), o Fator de Contaminação pode ser classificado como:

$$
\begin{aligned}
& C_{f}^{i}<1 \Rightarrow \text { fator de contaminação baixo; } \\
& 1 \leq C_{f}^{i}<3 \Rightarrow \text { fator de contaminação moderado; } \\
& 3 \leq C^{i}{ }_{f}<6 \Rightarrow \text { fator de contaminação considerável; } \\
& C_{f}^{i} \geq 6 \Rightarrow \text { fator de contaminação muito alto. }
\end{aligned}
$$

\subsubsection{2 Índice de Geoacumulação}

O Índice de Geoacumulação (lgeo) compara dados atuais com o conteúdo natural ou insignificante da concentração de poluentes. Particularmente são usadas amostras coletadas em diferentes profundidades em um mesmo ponto de amostragem, sendo fundamental a padronização com o tamanho dos grãos. O Igeo compara a concentração medida do elemento na 
fração fina do sedimento $\left(C_{n}\right)$ com o valor de background geoquímico dos sedimentos fósseis argilosos e silticos.

$$
\operatorname{Igeo}=\left(\log _{2} C_{n}\right) /\left(1,5 * B_{n}\right)
$$

Onde,

Igeo: $O$ índice de geoacumulação proposto, varia de 0 (nesse caso incluí-se valores menores que zero) a 6 (inclui-se valores maiores que 6), sendo 0 praticamente despoluído e 6 altamente poluido;

$C_{n}$ : Concentração do elemento " $n$ " na fração fina do sedimento. Nesse caso utilizou-se as concentrações detectadas nos Sedimentos Argilosos;

$B_{n}$ : Valor base em Sedimento Argilosos. Utilizou-se a concentração de metais em sedimentos finos extraídos de TUREKIAN e WEDEPOHL (1961);

1,5: fator de correção.

O Igeo divide-se em 7 graus, sendo que o 6 reflete $100 \%$ do enriquecimento sobre o valor de background. O lgeo tem sido utilizado e discutido em vários trabalhos (FÖRSTNER, 1990; FÖRSTNER et. al., 1990; CALMANO e FORSTNER, 1996; COVELLI et al., 1997; SUTHERLAND, 2000). A maior deficiência deste método consiste na não contagem do efeito biológico nos vários poluentes. 


\section{5 - RESULTADOS}

Os resultados expostos a seguir foram obtidos no decorrer das análises realizadas no campo e no laboratório, sobre as amostras de sedimento de fundo, água da interface e sedimento particulado em suspensão.

\section{1 - SEDIMENTO DE FUNDO}

\subsubsection{Caracterização Macroscópica}

Durante as missões de campo, fez-se a caracterização macroscópica das subamostras do topo e base do "core" de sedimento de fundo, para cada estação de amostragem, distinguindo-se três grupos de materiais: Sedimento Argiloso, Material de Aterro e Sedimento Aluvionar (Tabela 4).

TABELA 4 - GRUPOS DE SEDIMENTOS SUBAMOSTRADOS NO TOPO E BASE DO "CORE" NAS DIFERENTES ESTACCOES DE AMOSTRAGEM.

\begin{tabular}{|c|c|c|}
\hline $\begin{array}{l}\text { Sedinento } \\
\text { Argiloso }\end{array}$ & $\begin{array}{l}\text { Material de } \\
\text { Aterro }\end{array}$ & $\begin{array}{l}\text { Sedimento } \\
\text { Aluvionar }\end{array}$ \\
\hline & & $\begin{array}{l}\text { ETE01 Topo } \\
\text { ETE01 Base }\end{array}$ \\
\hline ETE02 Topo & & ETE02 Base \\
\hline ETE03 Topo & ETE03 Base & \\
\hline ETE04Topo & & ETE04 Base \\
\hline ETE05 Topo* & ETE05 Base & \\
\hline ETE06 Topo* & ETE06 Base & \\
\hline ETE07 Topo* & ETE07 Base & \\
\hline ETE08 Topo** & ETE08 Base & \\
\hline ETE09 Topo* & ETE09 Base & \\
\hline ETE10 Topo** & ETE10 Base & \\
\hline ETE11 Topo & ETE11 Base & \\
\hline ETE12 Topo** & ETE12 Base & \\
\hline ETE13 Topo & ETE13 Base & \\
\hline
\end{tabular}


Na maioria das estações de coleta, as subamostras do topo do "core" foram classificadas como Sedimentos Argilosos (Tabela 4), exceto na estação ETE 01 (possível Sedimento Aluvionar, uma vez que este exibiu as características macroscópicas deste material). Macroscopicamente estas foram caracterizadas pelo elevado grau de plasticidade, textura fina e coloração acinzentada (Figura 16A). Localmente, estes sedimentos exalaram forte odor de $\mathrm{H}_{2} \mathrm{~S}$ e apresentaram coloração cinza esverdeada (subamostras do topo do "core" das ETE 08, 10 e 12), e em algumas estações, no período chuvoso de coleta, estes estavam mais oxidados com coloração levemente avermelhada (ETE 05, 06, 07 e 09). Este material, face a estas características, foi considerado o único sedimento genuinamente lacustre detectado neste lago.

O Aterro foi coletado em algumas estações na porção basal do "core" de sedimento (ETE03, 05, 06, 07, 08, 09, 10, 11, 12 e 13), apresentando-se com elevado grau de compactação, textura areno-siltosa, coloração avermelhada e incluindo fragmentos de rochas (Figura 16B). Esse material originou-se a partir do aterramento da área que compreende a ETE de Barueri, ocorrido durante sua implantação.

Os Sedimentos Aluvionares foram coletados na porção basal do "core" de sedimento nas estações ETE 02 e 04, enquanto que na ETE 01 esse foi amostrado no topo e na base do testemunho (Tabela 4). Esse sedimento caracterizou-se pela presença de seixos, coloração amarelada, textura arenosa e grau médio de compactação. Esse sedimento foi originado a partir da antiga sedimentação do Rio Tietê.
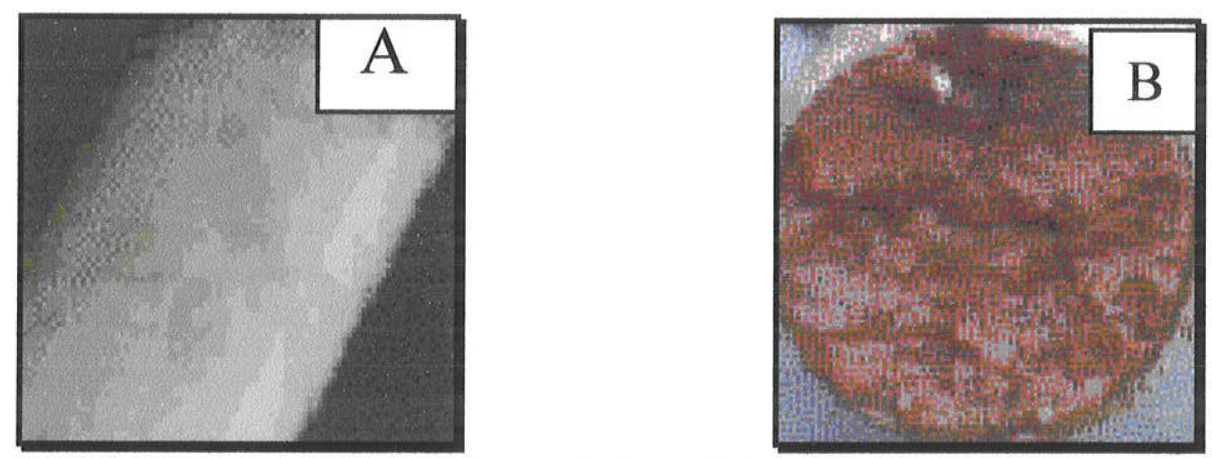

Figura 16 AB - A) Subamostra do topo do "core" de sedimento de fundo, Sedimento Argiloso. B) Subamostra coletada em algumas estações de amostragem na porção basal do "core", Aterro. 


\subsubsection{Teor de Umidade}

O teor de umidade foi obtido nas amostras de Sedimento Argiloso, Aterro e Sedimento Aluvionar, coletadas nos períodos de alta e baixa pluviosidade. A Tabela 5, exibe a porcentagem do teor de umidade, nas amostras de Sedimento Argiloso.

TABELA 5 - PORCENTAGEM DOS TEORES DE UMIDADE DOS SEDIMENTOS ARGILOSOS (SUBAMOSTRAS DE TOPO - T) COLETADOS NOS PERIODOS CHUVOSO E SECO.

\begin{tabular}{ccc}
\hline & & \\
Amostras de & Teor de Umidade & Teor de Umidade \\
Pedinento Argiloso & Periodo Chuvoso & Peco \\
\hline \hline ETE02T & $69 \%$ & $75 \%$ \\
ETE03T & $58 \%$ & $74 \%$ \\
ETE04T & $62 \%$ & $65 \%$ \\
ETE05T & $46 \%$ & $69 \%$ \\
ETE06T & $62 \%$ & $71 \%$ \\
ETE07T & $52 \%$ & $65 \%$ \\
ETE08T & $23 \%$ & $75 \%$ \\
ETE09T & $39 \%$ & $65 \%$ \\
$E T E 10 T$ & $58 \%$ & $44 \%$ \\
$E T E 11 T$ & $49 \%$ & $n . d$ \\
$E T E 12 T$ & $61 \%$ & $60 \%$ \\
$E T E 13 T$ & $59 \%$ & $n . d$ \\
\hline
\end{tabular}

n.d: Teor de Umidade nâo detectado na amostra de sedimento em questão.

De maneira geral, os Sedimentos Argilosos coletados no período climático seco exibiram teores de umidade mais elevados que os do chuvoso, exceto para as amostras das estações de coleta ETE10 e 12 (Tabela 5). As amostras de Sedimento Argiloso referentes ao período de coleta chuvoso, apresentaram teores de umidade entre $23 \%$ a $69 \%$, sendo o teor máximo observado na ETE02T (69\%) e o mínimo na ETE08T (23\%). No período climático seco, os Sedimentos Argilosos exibiram teores de umidade entre $44 \%$ a $75 \%$, de tal forma que o maior teor foi detectado nas amostras ETE02T (75\%) e $08 \mathrm{~T}(75 \%)$ e o menor na ETE10T (44\%).

A Tabela 6 abaixo, exibe a porcentagem de teor de umidade obtida para o Aterro, nos dois períodos climáticos de estudo. 
TABELA 6 - PORCENTAGEM DOS TEORES DE UMIDADE DO ATERRO (SUBAMOSTRAS DE BASE B) COLETADOS NOS PERIODOS CHUVOSO E SECO.

\begin{tabular}{|c|c|c|}
\hline 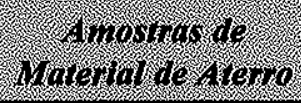 & $\begin{array}{l}\text { Teor de Vhidade } \\
\text { Peribdo Chrioso }\end{array}$ & $\begin{array}{l}\text { Teot de timidade } \\
\text { hertodo Sheo }\end{array}$ \\
\hline ETE03B & $25 \%$ & $44 \%$ \\
\hline ETE05B & $48 \%$ & $31 \%$ \\
\hline ETE06B & $22 \%$ & $48 \%$ \\
\hline ETE07B & $41 \%$ & $31 \%$ \\
\hline ETEOSB & $n . d$ & $50 \%$ \\
\hline ETE09B & $29 \%$ & $44 \%$ \\
\hline ETEIOB & $26 \%$ & $22 \%$ \\
\hline$E T E 11 B$ & $32 \%$ & n.d \\
\hline ETE $12 B$ & $24 \%$ & $24 \%$ \\
\hline ETE $13 B$ & $24 \%$ & n.d \\
\hline
\end{tabular}

A variação do teor de umidade não foi uniforme para as amostras de Aterro coletadas nos dois períodos climáticos de estudo. Para este material foram observados maiores teores de umidade, ora nas amostras do período chuvoso (ETE03B, 06B e 09B) ora nas do seco (ETE05B, 07B e 10B), conforme exposto na tabela acima. O teor de umidade detectado no Aterro do período chuvoso variou de $22 \%$ a $48 \%$, sendo o valor máximo determinado na ETEO5B (48\%) e o mínimo na ETE06B (22\%). No período seco, os teores de umidade para o Aterro variaram de $22 \%$ a $50 \%$, de tal forma que o maior valor foi detectado na amostra ETE08B (50\%) e o menor na ETE10B (22\%).

A porcentagem do teor de umidade, determinada para o Sedimento Aluvionar, encontra-se na Tabela 7.

TABela 7- PORCENTAgem dos teores DE UMIDADE do SEDIMENTO AluVIONAR (SUBAMOSTRAS DE TOPO - TE BASE - B) COLETADOS NOS PERIODOS CHUVOSO E SECO.

\begin{tabular}{|c|c|c|}
\hline 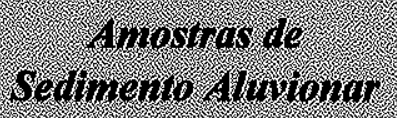 & Peor de limilowe & Peor de univolde \\
\hline ETE01T & $25 \%$ & $33 \%$ \\
\hline ETE01B & $18 \%$ & $24 \%$ \\
\hline ETE02B & $29 \%$ & $38 \%$ \\
\hline ETE04B & $23 \%$ & $24 \%$ \\
\hline
\end{tabular}


As amostras de Sedimento Aluvionar, coletadas no período seco, exibiram teores de umidade mais elevados que as do chuvoso (Tabela 7). 0 teor de umidade do Sedimento Aluvionar, correspondente ao período de alta pluviosidade, variou de $18 \%$ a $29 \%$, o primeiro detectado na amostra ETE01B e o segundo na amostra ETE02B. No período seco, o teor de umidade para os Sedimentos Aluvionares oscilaram entre $24 \%$ a $38 \%$, estando o maior valor observado na amostra ETE02B (38\%) e o menor nas ETE01B (24\%) e 04B $(24 \%)$.

\subsubsection{Matéria Orgânica}

O teor de matéria orgânica obtido nos Sedimentos Argilosos, Aterros e Sedimentos Aluvionares, correspondem apenas às amostras coletadas no período seco. Não foi possivel determinar esses teores nas amostras do período chuvoso e na amostra ETE12 Seco, em decorrência destas terem sido usadas, em sua totalidade, nas análises granulométricas (pipetagem) e nas análises químicas totais. A Tabela 8 , exibe a porcentagem de matéria orgânica determinada nos Sedimentos Argilosos.

TABELA 8 - PORCENTAGEM DE MATÉRIA ORGÂNICA OBTIDA NO SEDIMENTO ARGILOSO (SUBAMOSTRA DO TOPO - T) DO PERIODO CLIMATICO SECO.

\begin{tabular}{|c|c|}
\hline 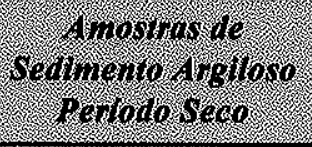 & 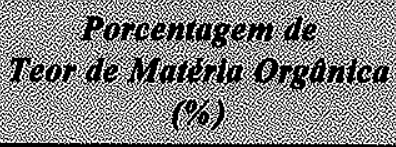 \\
\hline ETE02T & 12 \\
\hline ETE03T & 4 \\
\hline ETE04T & 7 \\
\hline ETE05T & 8 \\
\hline ETE06T & 8 \\
\hline ETE07T & 4 \\
\hline ETE08T & 18 \\
\hline ETE09T & 5 \\
\hline ETE 10T & 11 \\
\hline ETE11T & $n . d$ \\
\hline ETE $12 T$ & $n . d$ \\
\hline ETE $13 T$ & n.d \\
\hline
\end{tabular}

n.d: Teor de Matéria Orgânica nåo detectado na amostra de sedimento em queståo.

Os Sedimentos Argilosos exibiram teores de matéria orgânica entre 4\% a $18 \%$ neste período climático, residindo o maior valor na ETE08T (18\%) e o menor nas ETE03T (4\%) e 07T (4\%). 
A porcentagem de matéria orgânica detectada no Aterro, coletado no período seco, encontra-se na Tabela 9.

TABELA 9 - PORCENTAGEM DE MATÉRIA ORGÂNICA OBTIDA NO ATERRO (SUBAMOSTRA DA BASE - B) DO PERIODO CLIMATICO SECO.

\begin{tabular}{|c|c|}
\hline 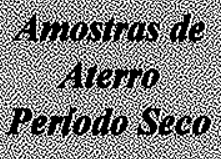 & 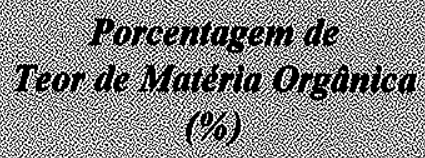 \\
\hline ETEO3B & 4 \\
\hline ETE05B & 2 \\
\hline ETE06B & 2 \\
\hline ETE07B & 2 \\
\hline ETEO $08 B$ & 6 \\
\hline ETEO9B & 0 \\
\hline ETE $10 B$ & 3 \\
\hline ETE11B & $n . d$ \\
\hline ETE $12 B$ & $n . d$ \\
\hline ETE $13 B$ & n.d \\
\hline
\end{tabular}

n. $\overline{d: T e o r ~ d e ~ M a t e ́ r i a ~ O r g a ̂ n i c a ~ n a ̃ o ~ d e t e c t a d o ~ n a ~ a m o s t r a ~ e m ~ q u e s t a ̃ o . ~}$

Observa-se a partir da tabela acima que os teores de matéria orgânica, detectados no Aterro, variaram entre 0 a $6 \%$, sendo o maior valor observado na amostra ETE08B (6\%) e o menor na ETE 09B (0\%).

A Tabela 10, exibe a porcentagem de matéria orgânica determinada no Sedimento Aluvionar, coletado na estação climática de baixa pluviosidade.

TABela 10 - PoRCentagem de MATÉRIA ORgÁNICA ObTIDA NO SEDIMENTO ALUVIONAR (SUBAMOSTRAS DO TOPO - T E BASE - B) DO PERIODO CLIMATICO SECO.

\begin{tabular}{|c|c|}
\hline 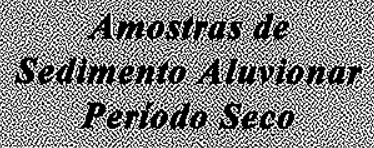 & 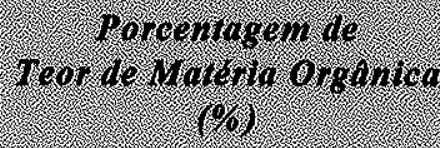 \\
\hline ETE01T & 3 \\
\hline ETEOIB & 8 \\
\hline ETEO2B & 3 \\
\hline ETEO4B & 3 \\
\hline
\end{tabular}

n.d: Teor de Matéria Orgánica nåo detectado na amostra em questão.

Apesar do número reduzido de amostras, verificou-se que a porcentagem de matéria orgânica não variou muito nos Sedimentos Aluvionares analisados, exceto para a amostra coletada na estação ETE01B, 
cuja porcentagem de matéria orgânica apresentou-se mais elevada que nas restantes.

\subsubsection{Granulometria}

Os Sedimentos Argilosos, Aterros e Sedimentos Aluvionares, coletados no período seco, foram analisados granulometricamente via laser. As amostras do período chuvoso foram analisadas pelo método da pipetagem, cujos resultados não foram satisfatórios, pois estavam acima do intervalo de confiabilidade da análise, de 0,95 a 1,05. Como não haviam mais amostras (para a maioria das estações) não foi possível refazer tal determinação. A Tabela 11, apresenta os valores das análises granulométricas determinadas para os Sedimentos Argilosos amostrados no período de baixa pluviosidade.

TABELA 11 - DISTRIBUIÇÃO DAS FRAÇŐES GRANULOMÉTRICAS OBTIDAS NOS SEDIMENTOS ARGILOSOS (SUBAMOSTRAS DO TOPO - T) DO PERIODO SECO.

\begin{tabular}{|c|c|c|c|c|}
\hline $\begin{array}{l}\text { Amostan le } \\
\text { Scathento ligioso }\end{array}$ & 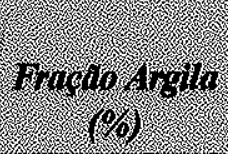 & Fingto silte & 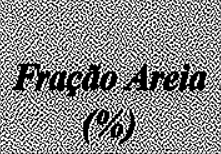 & 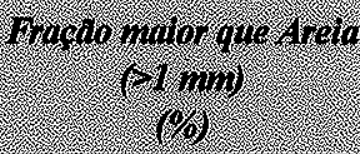 \\
\hline ETE02T & $n . d$ & n.d & $n . d$ & $n . d$ \\
\hline ETE03T & 22 & 67 & 11 & 0 \\
\hline ETE04T & 19 & 68 & 11 & 2 \\
\hline ETE05T & 13 & 73 & 13 & 1 \\
\hline ETE06T & 16 & 77 & 5 & 2 \\
\hline ETE07T & 13 & 75 & 12 & 0 \\
\hline ETE08T & $n . d$ & n.d & n.d & n.d \\
\hline ETE09T & 16 & 75 & 8 & 1 \\
\hline ETE1OT & 22 & 72 & 6 & 0 \\
\hline ETE11T & 11 & 62 & 21 & 6 \\
\hline ETE12T & 18 & 76 & 3 & 3 \\
\hline ETE13T & $n \cdot d$ & n.d & n.d & n.d \\
\hline
\end{tabular}

n.d: Fração Granulométrica não detectada na amostra de sedimento em questão.

Quanto a fração granulométrica, os Sedimentos Argilosos, foram classificados como silto-argilosos, exceto a amostra ETE11T que foi considerada silto-arenosa (Tabela 11).

A Tabela 12, apresenta a distribuição granulométrica para ○ Aterro coletado no período seco. 
TABELA 12 - DISTRIBUIÇÃo DAS FRAÇÖES GRANULOMÉTRICAS OBTIDAS NO ATERRo (SUBAMOSTRA DA BASE - B) DO PERIODO SECO.

\begin{tabular}{|c|c|c|c|c|}
\hline 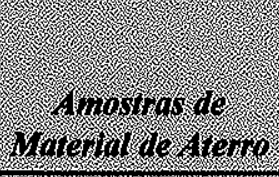 & Froolo trgila & Hrogosirg & Froto dria & 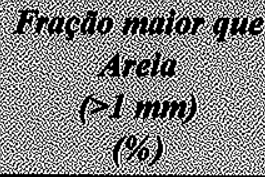 \\
\hline ETEO3B & 14 & 55 & 21 & 9 \\
\hline ETE05B & n.d & $n . d$ & $n . d$ & $n . d$ \\
\hline ETE06B & 14 & 45 & 39 & 2 \\
\hline ETE07B & 1 & 56 & 32 & 2 \\
\hline ETE $08 B$ & $n . d$ & n.d & $n . d$ & $n . d$ \\
\hline ETEO9B & 19 & 66 & 14 & $I$ \\
\hline ETE1OB & 22 & 71 & 6 & 1 \\
\hline ETEIIB & 12 & 57 & 29 & 2 \\
\hline$E T E 12 B$ & $n . d$ & $n . d$ & n.d & $n . d$ \\
\hline ETE $13 B$ & 17 & 48 & 32 & 3 \\
\hline
\end{tabular}

n.d: Fração Granulométrica não detectada na amostra em questăo.

O Aterro exibiu fração granulométrica silto-arenosa, com exceção das amostras ETE09B e 10B que exibiram frações silto-argilosas (Tabela 12).

A granulometria do Sedimento Aluvionar, coletado no período seco, encontra-se na Tabela 13.

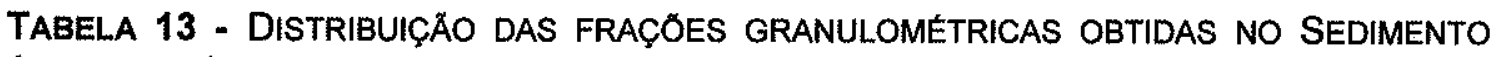
ALUVIONAR (SUBAMOSTRAS DO TOPO - TE BASE - B) DO PERIODO SECO.

\begin{tabular}{|c|c|c|c|c|}
\hline 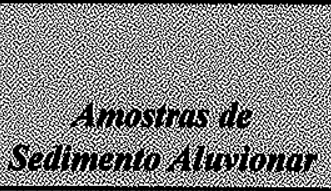 & maghto 4 rgilo & Firato sile & $\begin{array}{l}\text { Mrocto inera } \\
\text { (o) }\end{array}$ & 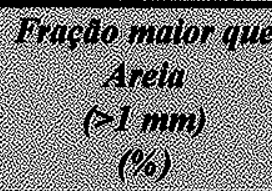 \\
\hline ETE01T & 15 & 45 & 22 & 18 \\
\hline ETEOIB & 16 & 38 & 41 & 5 \\
\hline ETEO2B & 12 & 33 & 47 & 8 \\
\hline ETE04B & 12 & 42 & 39 & 7 \\
\hline
\end{tabular}

As amostras ETE01T e 04B correspondentes aos Sedimentos Aluvionares, apresentaram frações granulométricas silto-arenosas, enquanto que as ETE01B e 02B apresentaram frações areno-siltosas. $A$ diferença principal entre os Sedimentos Aluvionares (correspondentes as ETE01T e 04B) e o Aterro, ambos classificados como silto-arenosos, está na porcentagem de grãos maiores que a fração areia (maiores que $1 \mathrm{~mm}$ ), com os Sedimentos 
Aluvionares apresentando maiores quantidades destes grãos se comparado com o Aterro, com exceção da amostra ETE03B (Tabelas 12 e 13).

Estes valores foram tratados no aplicativo "TRIDAW", resultando no diagrama triangular, exposto a seguir.

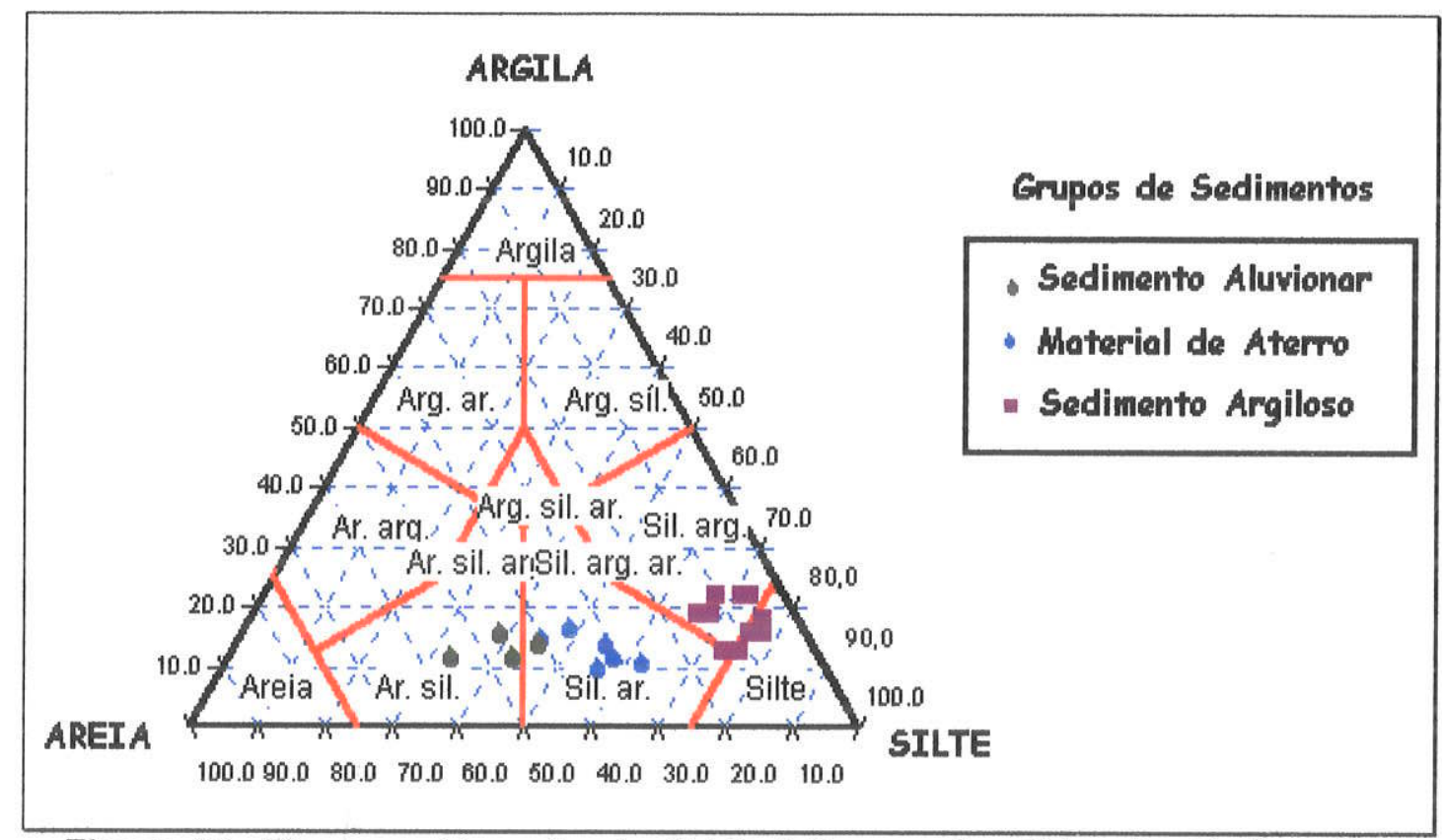

Figura 17- Diagrama triangular da distribuição granulométrica dos Sedimentos Argilosos, Aterros e Sedimentos Aluvionares.

Neste diagrama verifica-se claramente a separação das três classes de materiais (Sedimentos Argilosos, Aterros e Sedimentos Aluvionares), obtidas no lago estudado, com base na distribuição granulométrica. Os Sedimentos Argilosos, ocuparam a área correspondente a fração silto-argilosa a silte. As amostras de Aterro ocuparam o campo correspondente a fração silto-arenosa e os Sedimentos Aluvionares ocuparam o campo correspondente a fração arenosiltosa a silto-arenosa.

\subsection{5 pH e Eh}

Os valores de $\mathrm{pH}$ e Eh foram obtidos nos Sedimentos Argilosos, Aterros e Sedimentos Aluvionares, concomitantemente com a amostragem destes materiais, nos períodos climáticos chuvoso e seco.

Para os Sedimentos Argilosos, verificou-se que os valores de $\mathrm{pH}$ foram mais elevados durante as medições realizadas no período climático de alta pluviosidade, exceto para as amostras ETE08T e 12T, conforme exposto na Tabela 14. 
TABELA 14 - VALORES DE PH OBTIDOS NOS SEDIMENTOS ARgILOSOS (SUBAMOSTRA DO TOPO - T), NOS PERIODOS CHUVOSO E SECO.

\begin{tabular}{|c|c|c|}
\hline 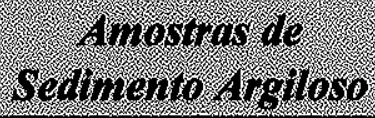 & $(6,10000$ & Pero \\
\hline ETE02T & 7,42 & 7,21 \\
\hline ETE03T & 7,72 & 7,29 \\
\hline ETE04T & 7,74 & 6,97 \\
\hline ETE05T & 8,06 & 7,44 \\
\hline ETE06T & 7,86 & 7,36 \\
\hline ETE07T & 8,12 & 7,68 \\
\hline ETE08T & 5,08 & 6,18 \\
\hline ETE09T & 7,98 & 7,64 \\
\hline ETE10T & 7,43 & 7,03 \\
\hline ETE11T & 7,80 & n.d \\
\hline ETE12T & 7,42 & 7,53 \\
\hline ETE $13 T$ & 7,47 & $n . d$ \\
\hline
\end{tabular}

Nas amostras de Sedimento Argiloso do período chuvoso, os maiores valores de $\mathrm{pH}$ foram determinados nas ETE05T $(8,06)$ e $07 T(8,12)$ e o menor na ETE08T $(5,08)$. Por outro lado, no período seco os maiores valores de $\mathrm{pH}$ foram detectados nas ETE07T $(7,68)$ e 09T $(7,64)$ e o menor na ETE08T $(6,18)$, conforme exposto na tabela acima.

Os Sedimentos Argilosos amostrados no período de alta pluviosidade, foram classificados como neutros a ligeiramente alcalinos, em decorrência dos valores de $\mathrm{pH}$ variarem entre 7,42 a 8,12, excetuando-se a amostra da estação ETE08 que exibiu valor ácido (Tabela 14). As amostras deste mesmo sedimento, coletadas no período seco, apresentaram pH quase neutro com tendência ínfima a alcalinidade, em virtude deste parâmetro variar de 6,97 a 7,68 , com exceção da amostra ETE08 que apresentou valor um pouco mais ácido que as restantes (Tabela 14).

A partir destes dados, construíram-se curvas de isovalores de $\mathrm{pH}$ nas estações de coleta, para os Sedimentos Argilosos amostrados tanto no período de alta pluviosidade como no de baixa (Figura 18AB), no intuito de verificar a distribuição especial deste parâmetro nas amostras de sedimento lacustres. Para construção destas curvas de isovalores, foram utilizados valores resultantes da interpolação dos pontos vizinhos para as estações de 
amostragem ETE01, 11 e 13. As curvas de isovalores determinadas nas ETE01, 11 e 13 para os Sedimentos Argilosos, não foram consideradas, pois não corresponderam a uma medida confiável, e sim a um produto da interpolação de dados. Na ETE01, não foi possivel utilizar os valores de $\mathrm{pH}$ obtidos no campo, em decorrência do material coletado no topo do "core" desta estação não ser considerado Sedimento Argiloso, e sim Sedimento Aluvionar.
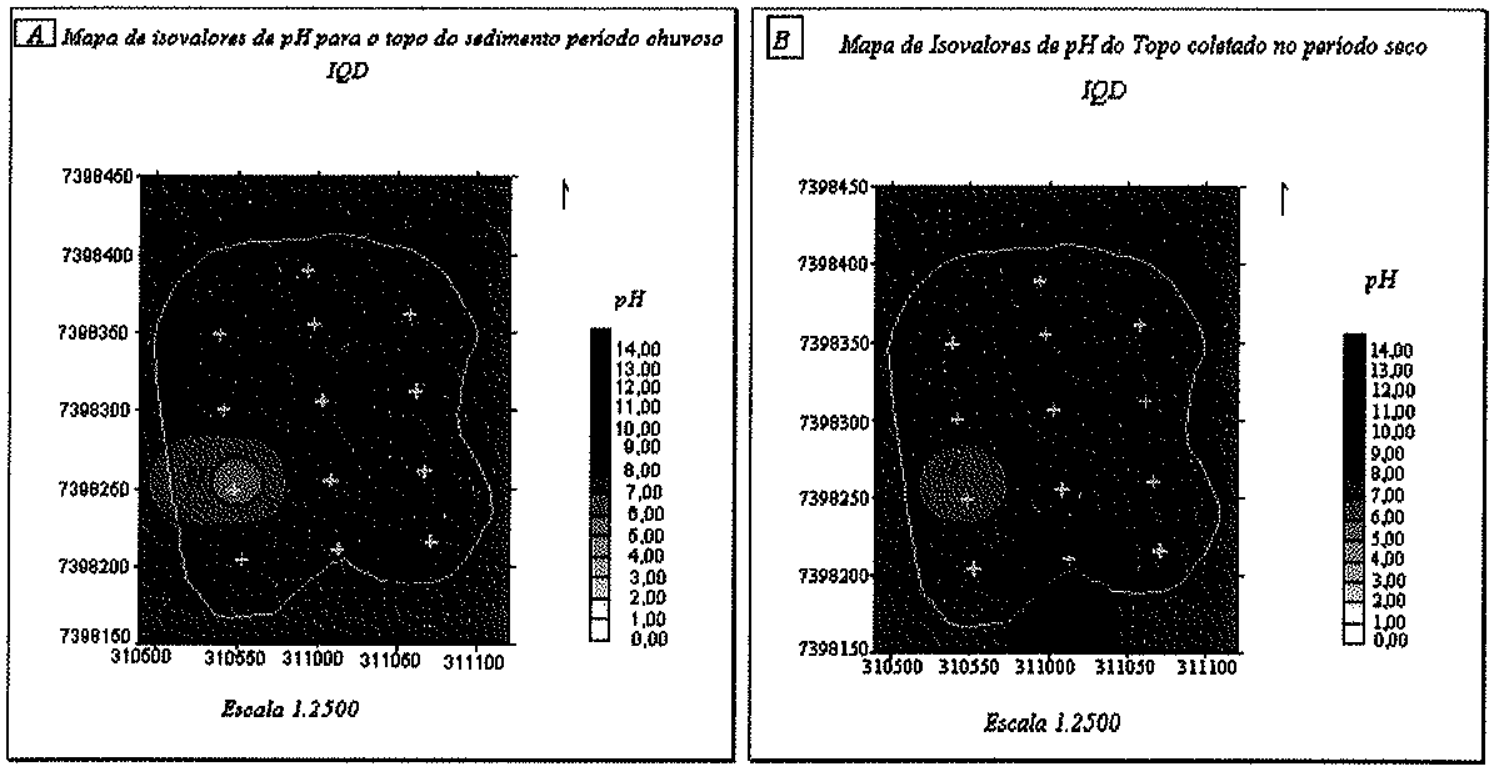

Figura 18 AB - A) Mapa de isovalores de pH dos Sedimentos Argilosos coletados no período chuvoso. B) Mapa de isovalores de $\mathrm{pH}$ dos Sedimentos Argilosos coletados no periodo seco.

Os Sedimentos Argilosos, coletados nos dois períodos de estudo em questão, exibiram curvas de isovalores de $\mathrm{pH}$ semelhantes, para as diferentes estaçס̃es de amostragem (Figuras 18AB). A amostra de Sedimento Argiloso coletada na estação ETE08, apresentou comportamento inferior para suas curvas de isovalores de $\mathrm{pH}$, nos dois períodos analisados quando comparadas com as demais.

O outro material coletado (Aterro), também exibiu valores de $\mathrm{pH}$ ligeiramente superiores para as medições realizadas no periodo de alta pluviosidade, com exceção da amostra ETE09B, conforme exposto na Tabela 15. 
TABELA 15 - VALORES DE PH OBTIDOS NOS ATERROS (SUBAMOSTRAS DA BASE - B), NOS PERIODOS CHUVOSO E SECO.

\begin{tabular}{|c|c|c|}
\hline $\begin{array}{l}\text { Ampostrat de } \\
\text { Alerto }\end{array}$ & chinoso & $\begin{array}{l}\text { pht } \\
\text { Sero }\end{array}$ \\
\hline ETE03B & 7,11 & 5,81 \\
\hline ETE05B & 7,48 & 7,07 \\
\hline ETE06B & 7,12 & 6,77 \\
\hline ETEOTB & 7,48 & 7,07 \\
\hline ETEO8B & 5,41 & 4,52 \\
\hline ETEO9B & 7,10 & 7,12 \\
\hline ETEIOB & 6,87 & 6,81 \\
\hline$E T E 11 B$ & 7,11 & n.d \\
\hline ETE12B & 7,28 & 5,63 \\
\hline ETE $13 B$ & 7,04 & n.d \\
\hline
\end{tabular}

No Aterro, os maiores valores de $\mathrm{pH}$ obtidos no período de alta pluviosidade foram detectados nas amostras ETE05B $(7,48)$ e $07 \mathrm{~B}(7,48)$ e o menor na ETEO8B $(5,41)$. No período de baixa pluviosidade, o valor mais elevado de $\mathrm{pH}$ foi observado na amostra $\operatorname{ETEO9B}(7,12)$ e os menores nas $08 \mathrm{~B}$ $(4,52)$ e $12 \mathrm{~B}(5,63)$. De um modo geral, verificou-se que as medições de $\mathrm{pH}$ realizadas no período seco, apresentaram ligeira tendência de aumento da acidez, se comparado com os do chuvoso.

Os resultados obtidos para as amostras do Aterro permitiram classificálas como quase neutras, em decorrência deste parâmetro físico-químico variar entre 6,87 a 7,48, excetuando-se a amostra ETE08T cujo valor obtido foi de 5,41 , indicando que esta é ácida. Os Aterros coletados no período seco foram classificados como ácidos a neutros, em virtude do $\mathrm{pH}$ variar de 5,63 a 7,07, com exceção da amostra da estação ETE08 que exibiu pH ácido (pH 4,52).

A Tabela 16, exibe os valores de $\mathrm{pH}$ obtidos nas amostras de Sedimento Aluvionar coletadas nos períodos chuvoso e seco.

TABELA 16 - VALORES DE PH OBTIDOS NOS SEDIMENTOS ALUVIONARES (SUBAMOSTRAS DE TOPO - TE BASE - B), NOS PERIODOS CHUVOSO E SECO.

\begin{tabular}{|c|c|c|}
\hline 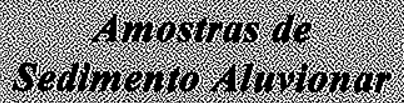 & $\begin{array}{l}\text { phl } \\
\text { churoso }\end{array}$ & Seco \\
\hline ETE01T & 7,55 & 10,05 \\
\hline ETEOIB & 6,18 & 8,90 \\
\hline ETEO2B & 7,13 & 7,01 \\
\hline ETE04B & 6,66 & 6,57 \\
\hline
\end{tabular}

n.d: medidas de $\mathrm{pH}$ não detectadas nas amostras em questăo. 
No periodo chuvoso, o valor mais elevado de $\mathrm{pH}$ obtido para o Sedimento Aluvionar foi observado na ETE01T $(7,55)$ e o menor na ETE01B $(6,18)$. Por outro lado, no periodo climático seco, o valor mais elevado de $\mathrm{pH}$ foi detectado na amostra ETE01T $(10,05)$ e o menor na ETEO4B $(6,57)$.

Os Sedimentos Aluvionares coletados no período de alta pluviosidade foram classificados como ácidos a neutros, em decorrência do $\mathrm{pH}$ variar entre 6,18 a 7,55. As amostras de Sedimento Aluvionar coletadas no período seco foram classificadas como neutras a básicas, em virtude deste parâmetro fisícoquímico variar entre 7,01 e 10,05, excetuando-se a amostra da ETE04B cujo valor de $\mathrm{pH}$ obtido foi de 6,57, indicando que esta é um pouco mais ácida.

Os resultados de $\mathrm{pH}$ obtidos para as amostras de Aterro e Sedimento Aluvionar não foram tratados no aplicativo "SURFER", pois a quantidade de dados para cada um destes materiais, não foram suficientes para confeccionar mapas de isovalores em tal aplicativo.

No campo, além dos valores de $\mathrm{pH}$, foram obtidas medidas de Eh para as amostras de Sedimento Argiloso, Aterro e Sedimento Aluvionar, nos dois períodos climáticos de estudo.

As amostras de Sedimento Argiloso, nos dois períodos de coleta, apresentaram Eh redutor, conforme exibe a Tabela 17.

TABELA 17 - VALORES DE EH OBTIDOS NOS SEDIMENTOS ARGILOSOS (SUBAMOSTRAS DE TOPO - T) COLETADOS NOS PERIODOS CHUVOSO E SECO.

\begin{tabular}{|c|c|c|}
\hline $\begin{array}{l}\text { Ampostros de } \\
\text { Sedingerto orgiloso }\end{array}$ & $(4)$ & 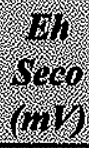 \\
\hline ETE02T & -298 & -307 \\
\hline ETE03T & -310 & -291 \\
\hline ETE04T & -244 & -239 \\
\hline ETE05T & -233 & -273 \\
\hline ETE06T & -299 & -275 \\
\hline ETE07T & -336 & -297 \\
\hline ETE08T & -201 & -302 \\
\hline ETEO9T & -347 & -306 \\
\hline ETE10T & -344 & -228 \\
\hline ETE11T & -305 & $n . d$ \\
\hline ETE12T & -312 & -262 \\
\hline ETE $13 T$ & -261 & $n . d$ \\
\hline
\end{tabular}

Os Sedimentos Argilosos coletados no período chuvoso foram classificados como redutores visto ter o Eh variado de $-201 \mathrm{mV}$ a $-347 \mathrm{mV}$, 
sendo que as amostras ETE09T $(-347 \mathrm{mV})$ e 10T $(-344 \mathrm{mV})$ foram consideradas as mais redutoras para este período de medição (Tabela 17). No período seco, as amostras de Sedimento Argiloso foram classificadas como redutoras em decorrência do Eh variar entre $-228 \mathrm{mV}$ a $-307 \mathrm{mV}$, de tal forma que os valores mais redutores foram observados nas estações ETE02T (-307mV) e 09T (-306mV).

A partir destes dados, foram construídos mapas de isovalores de Eh nas estações de coleta, para os Sedimentos Argilosos coletados tanto no período de alta pluviosidade como no de baixa (Figura 19AB). Tal procedimento visava verificar a distribuição especial deste parâmetro nas amostras deste sedimento. Para construção dos mapas de isovalores, foi necessária a utilização de valores resultantes da interpolação dos pontos vizinhos nas estações de amostragem ETE01, 11 e 13, conforme verificado pelas curvas de isovalores de $\mathrm{pH}$. Como explicado anteriormente, o valor de Eh obtido no campo para a ETE01, não foi utilizado para a construção destas curvas, em decorrência deste material não estar inserido no grupo dos Sedimentos Argilosos.
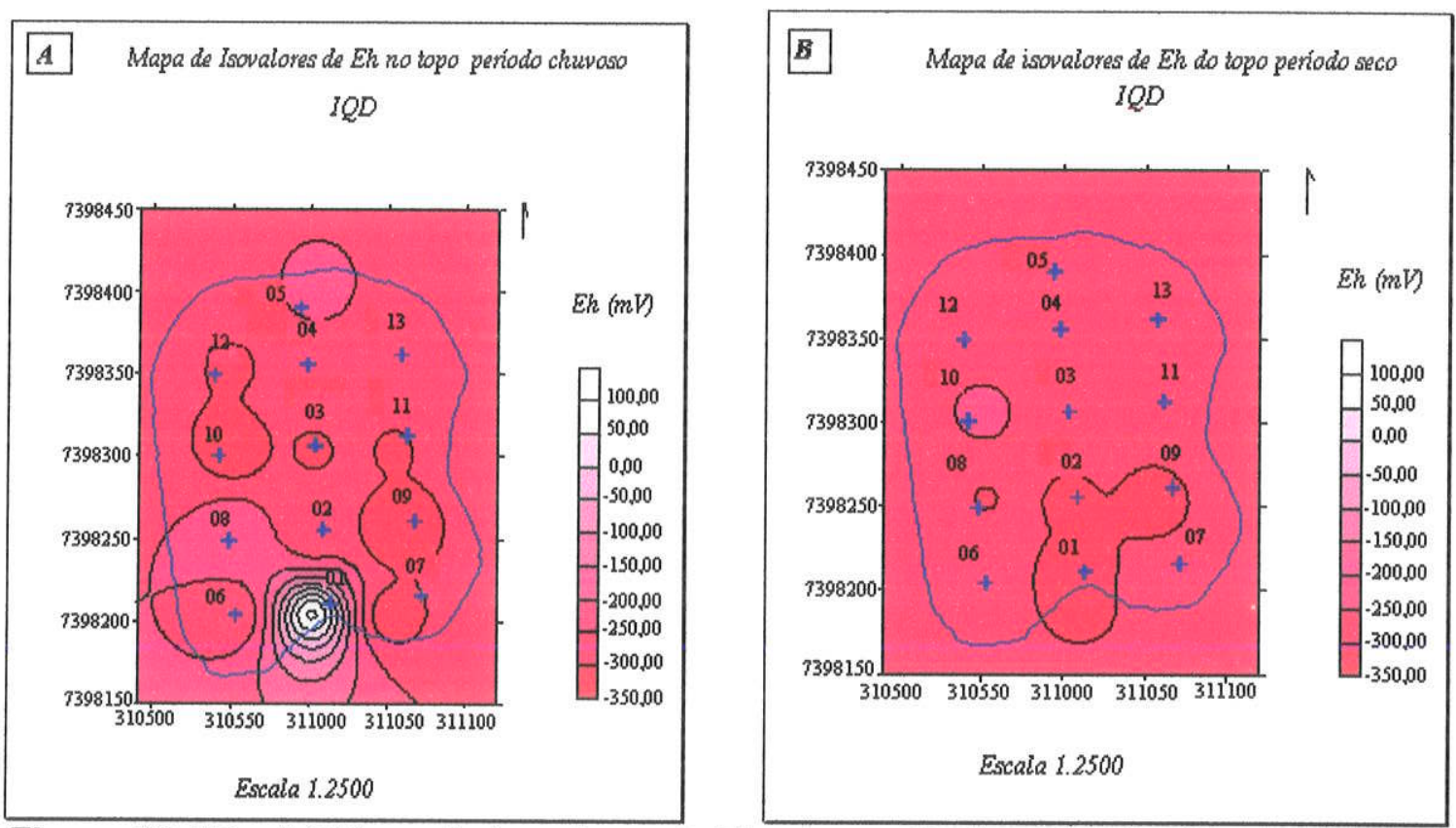

Figura 19 AB - A ) Mapa de isovalores de Eh para os Sedimentos Argilosos coletados no período chuvoso. B) Mapa de isovalores de Eh para os Sedimentos Argilosos coletados no período seco.

As curvas de isovalores de Eh, obtidas para os Sedimentos Argilosos nos períodos climáticos chuvoso e seco, apresentaram-se com elevada distinção, exceto para as estações de amostragem ETE04 e ETE09 (Figuras 
$19 \mathrm{AB}$ ). No período chuvoso, as amostras coletadas nas ETE03, 06, $07,09,10$, 11 e 12 apresentaram-se mais redutoras que as restantes, enquanto que as das estações ETE05 e 08 estavam um pouco menos redutoras (Figura 19A). No período seco, as amostras mais redutoras foram detectadas nas ETE02 e 09 e a menos redutora na ETE10 (Figura 19B).

Os Aterros amostrados tanto no período chuvoso como no seco, foram classificados como redutores, segundo os valores de Eh obtidos no campo (Tabela 18). As amostras de Aterro coletadas no período chuvoso, exibiram valores mais redutores de Eh que as do seco, excetuando-se as ETEO7B e 08B, conforme verificado na tabela abaixo.

\begin{tabular}{|c|c|c|}
\hline $\begin{array}{c}\text { Amostras de } \\
\text { Aterro. }\end{array}$ & 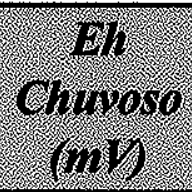 & $\begin{array}{l}\text { Shl } \\
\text { Seco } \\
(m i)\end{array}$ \\
\hline ETEO3B & $\overline{-271}$ & -94 \\
\hline ETE05B & -243 & -166 \\
\hline ETE06B & -160 & -152 \\
\hline ETE07B & -207 & -227 \\
\hline ETE08B & -205 & -240 \\
\hline ETE09B & -208 & -186 \\
\hline ETE10B & -208 & -63 \\
\hline ETE $11 B$ & -330 & $n . d$ \\
\hline ETE $12 B$ & -162 & -146 \\
\hline ETE $13 B$ & -139 & $n . d$ \\
\hline
\end{tabular}

Dos dados obtidos verifica-se ser a máxima observada sediada na amostra ETE11B ( $-330 \mathrm{mV}$ no período chuvoso). No período seco, a máxima obtida foi observada na amostra ETE08B (-240mV).

Quanto aos Sedimentos Aluvionares, observou-se que os coletados no período de baixa pluviosidade eram mais redutores que os de alta pluviosidade, excetuando-se a amostra da ETE02B (Tabela 19). 
TABELA 19 - VALORES DE EH OBTIDOS NOS SEDIMENTOS ALUVIONARES (SUBAMOSTRAS DE TOPO - T E BASE - B) COLETADOS NOS PERIODOS CHUVOSO E SECO.

\begin{tabular}{|c|c|c|}
\hline 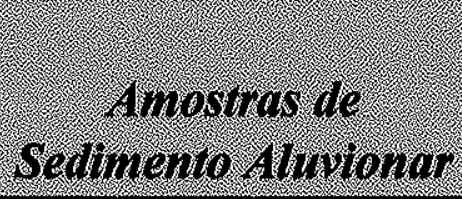 & 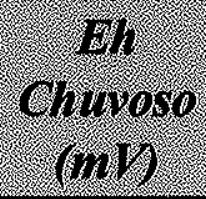 & $(\sec 2$ \\
\hline ETE01T & 107 & -316 \\
\hline ETE01B & -162 & -293 \\
\hline$E T E 02 B$ & -211 & -148 \\
\hline$E T E 04 B$ & 31 & -75 \\
\hline
\end{tabular}

n.d: Valores de Eh não detectados nas amostras em questão.

De acordo com a tabela exposta acima, pode-se classificar as amostras do período chuvoso como oxidantes (ETE01T e 04B) e como redutoras (ETE01B e 02B). No período seco, estas mesmas amostras foram classificadas como redutoras (valores de Eh entre $-75 \mathrm{mV} \mathrm{a}-316 \mathrm{mV}$ ).

Os resultados de Eh obtidos para as amostras de Aterro e Sedimento Aluvionar, não foram tratados no aplicativo SURFER, pois a quantidade de dados para cada um destes materiais, não foram suficientes para confeccionar mapas de isovalores.

\subsubsection{Análises Químicas Totais}

Nas amostras de Sedimento Argiloso, Aterro e Sedimento Aluvionar, foram realizadas análises químicas totais dos elementos maiores e traços.

\subsubsection{Elementos Maiores}

Nas Tabelas 20 e 21, estão expostos os resultados das análises químicas totais dos elementos maiores para as amostras de Sedimento Argiloso coletadas nos períodos chuvoso e seco, respectivamente. 
Tabela 20 - Elementos maiores detectados nas amostras de Sedimento ARGILOSO (SUBAMOSTRA DO TOPO - T) DO PERIODO CHUVOSO.

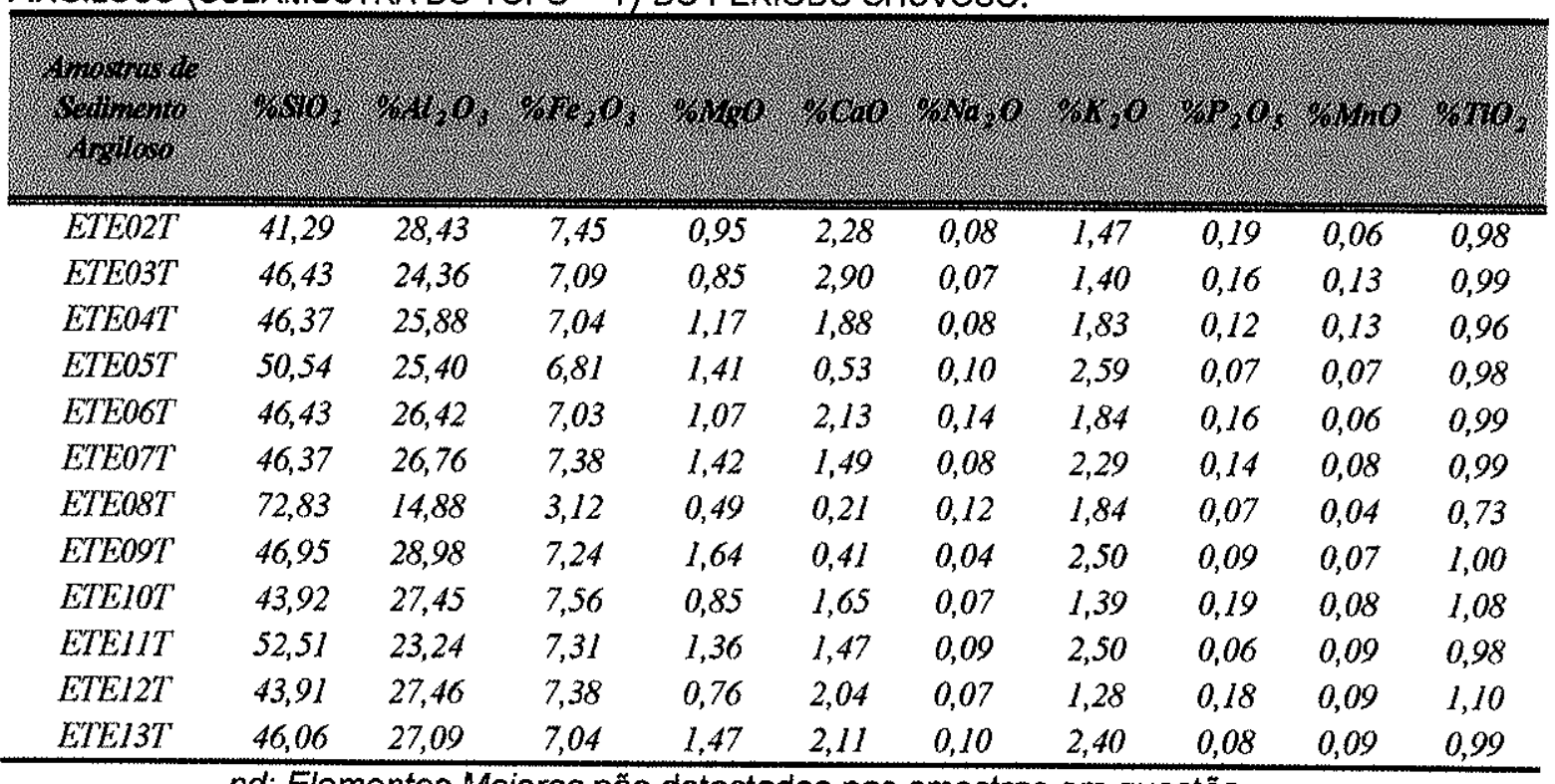

nd: Elementos Maiores nấo detectados nas amostras em questão.

TABELA 21 - ElEMENTOS MAIORES DETECTADOS NAS AMOSTRAS DE SEDIMENTO ARGILOSO (SUBAMOSTRA DO TOPO - T) DO PERIODO SECO.

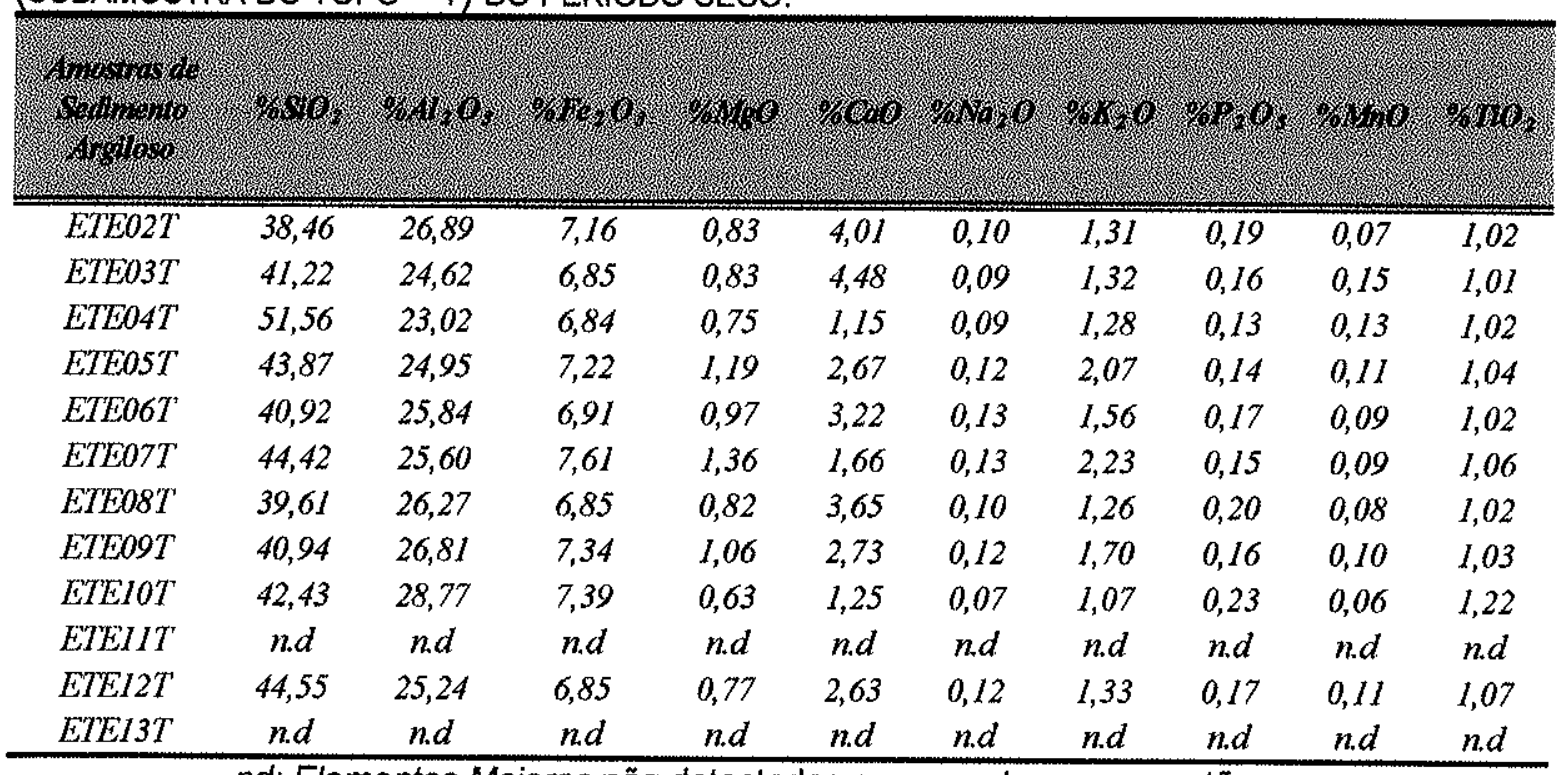

nd: Elementos Maiores não detectados nas amostras em questão.

O Sedimento Argiloso, amostrado tanto no período chuvoso como no seco, exibiu principalmente $\mathrm{Si}, \mathrm{Al}$ e $\mathrm{Fe}$ em sua composição (Tabelas 20 e 21). Estes três elementos representaram na maioria das amostras mais de $70 \%$ da composição das mesmas. A Figura 20 exibe a variação de $\mathrm{SiO}_{2}, \mathrm{Al}_{2} \mathrm{O}_{3}$ e $\mathrm{Fe}_{2} \mathrm{O}_{3}$, para o Sedimento Argiloso nos dois períodos climáticos de estudo. 


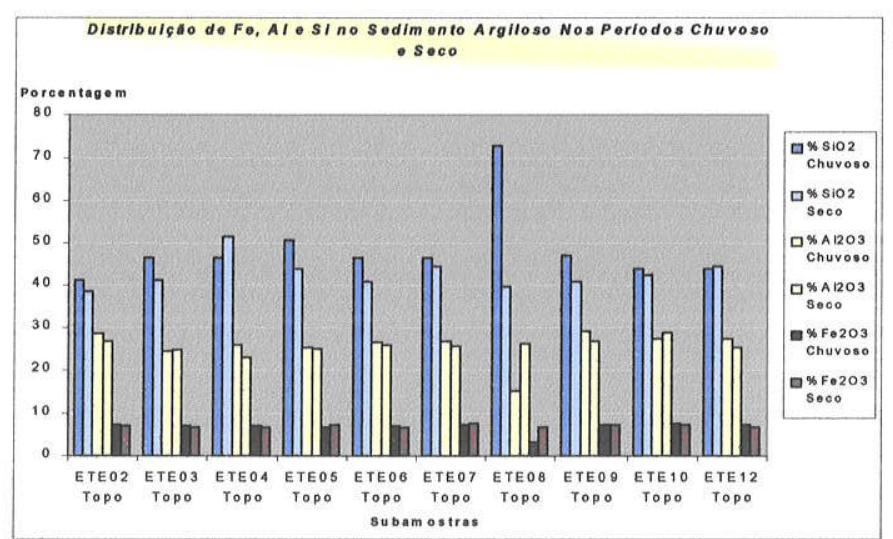

Figura 20 - Comparação entre as concentrações de $\mathrm{SiO}_{2}, \mathrm{Al}_{2} \mathrm{O}_{3}$ e $\mathrm{Fe}_{2} \mathrm{O}_{3}$, obtidas no Sedimento Argiloso em dois períodos climáticos distintos.

Com base nas Tabelas 20 e 21 e na Figura 20, notou-se que os Sedimentos Argilosos apresentaram porcentagens ligeiramente mais elevadas de $\mathrm{SiO}_{2}$ para as amostras coletadas no período climático de alta pluviosidade, com exceção das amostras ETE04T e 12T, quando comparadas com as mesmas amostras do período de baixa pluviosidade. Este mesmo comportamento de valores percentuais ligeiramente mais elevados para as amostras do período chuvoso também foi observado para os teores de $\mathrm{Al}_{2} \mathrm{O}_{3}$, com exceção das amostras ETE03T, 08T e 10T (Figura 20). Embora em valores numéricos menos significativos, os teores de $\mathrm{Fe}_{2} \mathrm{O}_{3}$, comparados entre um período e outro indicaram este mesmo comportamento observado para sílica e alumínio, respeitando uma ou outra exceção (ETE05, 07, 08, 09 e 12). Este maior conteúdo de $\mathrm{Al}$, Fe e Si nas amostras da estação chuvosa, provavelmente está relacionado ao aporte de sedimentos clásticos em direção a sedimentação do ambiente lacustre, neste período.

A leitura das Tabelas 20 e 21 para os alcalinos e alcalinos terrosos ( $M g$, $\mathrm{Ca}, \mathrm{Na}$ e K), exibiram os seguintes resultados. O Cálcio (Ca) e o Sódio ( $\mathrm{Na})$ denotaram menores concentrações, de modo geral, nas amostras coletadas no período chuvoso comparativamente com as do período seco, embora estes resultados sejam relativamente próximos. $\mathrm{O} \mathrm{Ca}$ detectado nas amostras ETE04T e 10T e o Na determinado nas ETE06T e 08T, apresentaram maiores concentrações nos materiais referentes ao período de alta pluviosidade, diferindo das outras amostras. Estes dois elementos comportaram-se entre um período e outro, de modo contrário ao observado com os elementos $\mathrm{Si}, \mathrm{Al}$ e Fe. 
A comparação das concentrações químicas do Potássio $(K)$ e do Magnésio $(\mathrm{Mg})$, em dois períodos climáticos distintos, demonstraram que estes elementos comportam-se similarmente ao $\mathrm{Si}, \mathrm{Al}$ e $\mathrm{Fe}$, ou seja, exibindo maiores concentrações no período chuvoso se comparados com o seco. No caso do K, apenas um ponto pode ser considerado exceção (ETE12) e no caso do Mg, dois pontos de amostragem divergem deste comportamento (ETE08 e 12).

As análises comparativas dos valores de Fósforo $(P)$ nos dois períodos de coleta, demonstraram elevadas semelhanças entre as concentrações deste elemento nestes dois períodos de estudo, em decorrência destes valores variarem aproximadamente $0,01 \%$ de uma estação climática para outra. Apenas as amostras obtidas e analisadas nas estações ETE05, 08, 09 e 10 não condizem com esta observação.

A mesma leitura efetuada para o Manganês $(\mathrm{Mn})$ exibiu este mesmo comportamento de um período para outro. Ou seja, os valores obtidos exibiram elevadas semelhanças entre uma coleta e outra, excetuando-se neste caso apenas as amostras ETE05T e 08T.

Quanto ao Titânio (Ti) analisado, pode-se também considerar que os resultados assemelharam-se de uma coleta para a outra, excetuando-se as amostras ETE05T, 07T, 08T e 10T. As restantes, se não são exatamente iguais, são semelhantes, com valores para mais ou para menos na casa dos $0,03 \%$.

Pode-se considerar, no contexto geral, que as distinções observadas para os diferentes elementos analisados nas estações de coleta nos períodos de maior e menor pluviosidade foram:

1. Os valores observados para $\mathrm{Si}, \mathrm{Al}, \mathrm{Fe}, \mathrm{Mg}$ e $\mathrm{K}$ apresentaram-se constantemente maiores quando a leitura e análise foi realizada sobre às amostras coletadas no período de maior pluviosidade;

2. Os teores de $\mathrm{Ca}$ e $\mathrm{Na}$ mostraram-se, freqüentemente menores no período de maior pluviosidade,

3. Para os elementos $P, M n$ e $T i$, a despeito das suas diferenças geoquímicas quanto a potenciais de oxidação e equilíbrio em meio aquoso, mostraram-se sempre semelhantes tanto em um período de coleta como no outro. 
As amostras de Aterro, embora já definidas como não sendo de origem lacustre, foram também analisadas e nas Tabelas 22 e 23, estão expostos os resultados das análises químicas totais dos elementos maiores para estas amostras coletadas nos períodos chuvoso e seco.

TABELA 22 - ELEMENTOS MAIORES DETECTADOS NAS AMOSTRAS DE ATERRO (SUBAMOSTRA DA BASE - B) DO PERIODO CHUVOSO.

\begin{tabular}{|c|c|c|c|c|c|c|c|c|c|c|}
\hline (4) & (6) & orluglo & $28 \%$ \% & 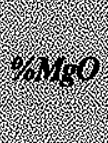 & 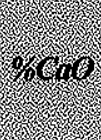 & (2) & 20.60 & 2010.0 & 28,140 & 0610 \\
\hline ETE03B & 63,37 & 19,38 & 6,98 & 0,35 & 0,09 & 0,01 & 0,82 & 0,08 & 0,03 & 0,95 \\
\hline ETEOSB & 48,75 & 26,97 & 7,05 & 1,49 & 0,44 & 0,12 & 2,64 & 0,09 & 0,14 & 0,94 \\
\hline ETEO6B & $n . d$ & $n . d$ & $n . d$ & $n . d$ & $n . d$ & $n . d$ & $n . d$ & n.d & $n . d$ & $n d$ \\
\hline ETEO7B & 50,09 & 27,69 & 6,76 & 1,27 & 0,23 & 0,15 & 2,34 & 0,07 & 0,09 & 0,96 \\
\hline ETE08B & $n . d$ & n.d & $n d d$ & n.d & n.d & $n . d$ & n.d & n.d & $n d$ & $n . d$ \\
\hline ETEOSB & 56,90 & 21,49 & 7,88 & 0,86 & 0,08 & 0,01 & 1,11 & 0,15 & 0,06 & 1,14 \\
\hline ETE $10 B$ & 58,39 & 20,36 & 9,48 & 0,76 & 0,09 & 0,01 & 0,89 & 0,12 & 0,32 & 1,34 \\
\hline$E T E I I B$ & 58,72 & 21,93 & 7,28 & 0,45 & 0,14 & 0,03 & 0,88 & 0,13 & 0,08 & 1,27 \\
\hline$E T E 12 B$ & 60,53 & 20,86 & 7,50 & 0,30 & 0,11 & 0,03 & 0,55 & 0,13 & 0,05 & 1,13 \\
\hline ETE $13 B$ & 55,91 & 22,03 & 9,56 & 0,46 & 0,1 & 0,03 & 0,57 & 0,216 & 0,083 & 1,47 \\
\hline
\end{tabular}

nd: Elementos Maiores năo detectados nas amostras em questão.

TABELA 23 - ELEMENTOS MAIORES DETECTADOS NAS AMOSTRAS DE ATERRO (SUBAMOSTRA DA BASE - B) DO PERIODO SECO.

\begin{tabular}{|c|c|c|c|c|c|c|c|c|c|c|}
\hline 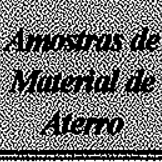 & 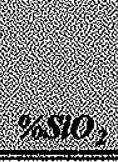 & 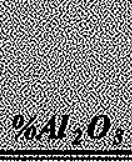 & 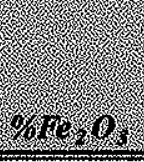 & 28.60 & 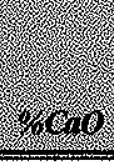 & 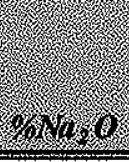 & 86,0 & 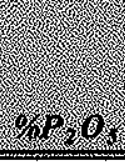 & 60 & 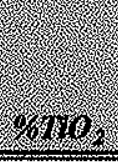 \\
\hline ETEO3B & 51,23 & $22,4 l$ & 7,16 & 0,73 & 1,26 & 0,08 & 1,21 & 0,13 & 0,09 & 1,06 \\
\hline ETEOSB & 59,18 & 20,76 & 6,42 & 1,66 & 0,26 & 0,12 & 3,58 & 0,04 & 0,07 & 0,93 \\
\hline$E T E 06 B$ & 64,07 & 18,29 & 5,05 & 0,88 & 0,34 & 0,16 & 2,07 & 0,04 & 0,07 & 0,85 \\
\hline ETE07B & 55,84 & 21,37 & 7,77 & 1,09 & 0,12 & 0,05 & 1,72 & 0,19 & 0,07 & 1,47 \\
\hline ETEOSB & 48,62 & 26,97 & 6,57 & 1,06 & 0,32 & 0,15 & 2,02 & 0,14 & 0,05 & 0,96 \\
\hline ETEO9B & 51,67 & 24,26 & 7,55 & 1,02 & 0,22 & 0,06 & 1,64 & 0,12 & 0,11 & 1,20 \\
\hline ETE1OB & 61,42 & 18,13 & 5,71 & 1,84 & 0,11 & 0,12 & 3,31 & 0,10 & 0,08 & 1,04 \\
\hline$E T E I I B$ & $n d$ & $n d$ & nd & nd & nd & nd & nd & nd & nd & nd \\
\hline$E T E 12 B$ & 61,90 & 19,15 & 6,63 & 0,24 & 0,13 & 0,04 & 0,51 & 0,06 & 0,05 & 1,05 \\
\hline ETE $13 B$ & nd & nd & $n d$ & nd & nd & nd & $n d$ & nd & nd & nd \\
\hline
\end{tabular}

nd: Elementos Maiores não detectados nas amostras em questão.

Mesmo não representando dados de maior importância nesta dissertação, as amostras de Aterro coletadas tanto no período chuvoso como no seco, apresentaram $\mathrm{Si}, \mathrm{Al}$ e $\mathrm{Fe}$ como componentes principais deste material. Observou-se que as amostras de Aterro coletadas na estação 
climática seca, apresentaram porcentagens mais elevadas de $\mathrm{SiO}_{2}$ que as do chuvoso, com exceção das amostras ETE03B e 09B. As porcentagens de $\mathrm{Al}_{2} \mathrm{O}_{3}$ foram mais elevadas nas amostras coletadas no período chuvoso, exceto para as ETE03B e 09B. A porcentagem de $\mathrm{Fe}_{2} \mathrm{O}_{3}$, foi praticamente a mesma, para estas amostras nos dois períodos de coleta.

As Tabelas 24 e 25, exibem os resultados das análises químicas totais dos elementos maiores para as amostras de Sedimento Aluvionar coletadas nos períodos chuvoso e seco, respectivamente.

TABela 24 - Elementos maiores detectados nas amostras de Sedimento ALUVIONAR (SUBAMOSTRA DO TOPO - T E BASE - B) DO PERIODO CHUVOSO.

\begin{tabular}{|c|c|c|c|c|c|c|c|c|c|c|}
\hline 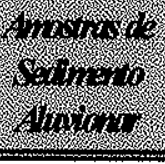 & $\% 810_{2}$ & 20120.0 & $\mathrm{Ank}_{2} \mathrm{O}_{3}$ & $\% 48$ & 2.060 & $2 \mathrm{Na}_{2} \mathrm{O}$ & $8 \pi R_{2} \theta$ & $\rho_{P_{2} O_{3}}$ & 20120 & $9810_{2}$ \\
\hline ETE0IT & 77,55 & 11,36 & 3,4 & 0,53 & 0,37 & 0,34 & 2,11 & 0,057 & 0,034 & 0,64 \\
\hline ETEOIB & 67,53 & 18,37 & 3,19 & 0,47 & 0,21 & 0,24 & 1,99 & 0,054 & 0,031 & 1,02 \\
\hline$E T E 02 B$ & 65,63 & 17,13 & 5,94 & 0,72 & 0,11 & 0,06 & 1,78 & 0,081 & 0,061 & 1,02 \\
\hline ETEO4B & 58,15 & 20,46 & 7,57 & 1,14 & 0,08 & 0,02 & 1,41 & 0,141 & 0,071 & 1,18 \\
\hline
\end{tabular}

TABela 25 - Elementos maiores detectados nas amostras de Sedimento ALUVIONAR (SUBAMOSTRA DO TOPO - TEDA BASE - B) DO PERIODO SECO.

\begin{tabular}{|c|c|c|c|c|c|c|c|c|c|c|}
\hline 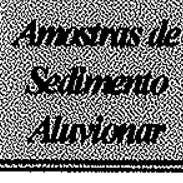 & $0,050_{2}$ & 8.11 .0 & $8 \mathrm{Fe}_{2} \mathrm{O}_{8}$ & $8 x 40$ & $26 \mathrm{GO}$ & $20 N_{2} 0$ & $2, \pi, 0$ & $0 \rho_{2}, O_{5}$ & $80 \mathrm{nin}$ & $8 \pi 0_{2}$ \\
\hline ETEOIT & 71,4 & 14,52 & 4,18 & 0,53 & 0,21 & 0,14 & 1,88 & 0,051 & 0,037 & 0,6 \\
\hline ETEOIB & 71,52 & 14,68 & 3,04 & 0,27 & 0,13 & 0,08 & 1,01 & 0,031 & 0,028 & 0,95 \\
\hline ETE02B & 61,5 & 19,32 & 5,88 & 0,87 & 0,16 & 0,11 & 2,41 & 0,089 & 0,054 & 0,94 \\
\hline ETE04B & 61,84 & 19,5 & 7,09 & 0,38 & 0,14 & 0,02 & 0,64 & 0,124 & 0,057 & 1,18 \\
\hline
\end{tabular}

Com base nas Tabelas 24 e 25, pode-se considerar que os Sedimentos Aluvionares, amostrados em dois períodos climáticos distintos, apresentaram em sua composição principalmente $\mathrm{Si}, \mathrm{Al}$ e $\mathrm{Fe}$. Os Sedimentos Aluvionares coletados no período climático chuvoso, exibiram porcentagens mais elevadas de $\mathrm{SiO}_{2}$ para as amostras ETE01T e ETE02B. As porcentagens de $\mathrm{Al}_{2} \mathrm{O}_{3}$, foram maiores para as amostras de Sedimento Aluvionar do período chuvoso, 
coletadas nas ETE02B e ETE04B. A porcentagem de $\mathrm{Fe}_{2} \mathrm{O}_{3}$ foi praticamente a mesma, para os Sedimentos Aluvionares correspondentes ao dois períodos analisados.

A partir destes resultados, verificou-se que os Sedimentos Argilosos, Aterros e Sedimentos Aluvionares, são compostos principalmente por $\mathrm{Si}, \mathrm{Al}$ e $\mathrm{Fe}$. A diferença composicional entre estes materiais residiu na quantidade de $\mathrm{Si}$ e Al. O primeiro foi encontrado em maior quantidade no Aterro e no Sedimento Aluvionar, ambas subamostradas na base dos "cores", e o segundo nos Sedimentos Argilosos, topo do "core".

\subsubsection{Elementos Menores}

\section{A. Sedimentos Argilosos}

Os elementos menores detectados neste sedimento nos períodos chuvoso e seco foram: $\mathrm{Ba}, \mathrm{Co}, \mathrm{Cr}, \mathrm{Cu}, \mathrm{Ni}, \mathrm{Sr}, \mathrm{Zn}$ e $\mathrm{Zr}$, e encontram-se expostos nas Tabelas 26 e 27.

TABELA 26 - ElemENTOS MENORES DETECTAdOS NAS AMOSTRAS DE SEDIMENTO ARgILOSO (SUBAMOSTRA DO TOPO - T) DO PERIODO CHUVOSO.

\begin{tabular}{|c|c|c|c|c|c|c|c|c|}
\hline 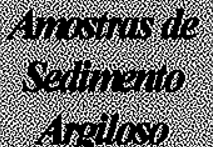 & $\frac{6}{6}$ & rep & or & $\frac{6 \pi}{6 \pi n}$ & rit & ris & $\frac{2 \pi}{20}$ & $\frac{\gamma}{\rho j}$ \\
\hline$E T E 02 T$ & 674 & 19 & 69 & 77 & 103 & 122 & 169 & 60 \\
\hline ETE03T & 626 & 20 & 69 & 43 & 89 & 122 & 148 & 228 \\
\hline ETE04T & 701 & 17 & 73 & 33 & 63 & 104 & 137 & 190 \\
\hline ETE05T & 828 & $<15$ & 58 & 98 & 28 & 74 & 134 & 392 \\
\hline ETE06T & 695 & 16 & 65 & 103 & 71 & 120 & 167 & 196 \\
\hline ETE07T & 813 & 17 & 71 & 128 & 79 & 103 & 192 & 213 \\
\hline ETE08T & 624 & $<15$ & $<15$ & $<15$ & $<15$ & 75 & 70 & 600 \\
\hline ETE09T & 915 & 18 & 69 & 89 & 61 & 89 & 163 & 143 \\
\hline ETEIOT & 686 & 19 & 69 & 32 & 81 & 133 & 154 & 165 \\
\hline ETE IIT & 735 & 21 & 68 & 23 & 15 & 88 & 138 & 269 \\
\hline ETE12T & 648 & 15 & 65 & 25 & 81 & 135 & 141 & 196 \\
\hline ETE13T & 797 & $<15$ & 65 & 24 & 23 & 110 & 180 & 208 \\
\hline
\end{tabular}

<15: Abaixo do limite de detecçăo do aparelho para este metal. 
TABEla 27 - Elementos menores detectados nas amostras de Sedimento ARGILOSO (SUBAMOSTRA DO TOPO - T) DO PERIODO SECO.

\begin{tabular}{|c|c|c|c|c|c|c|c|c|}
\hline 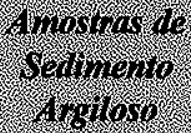 & 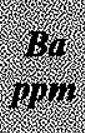 & 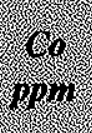 & 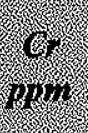 & 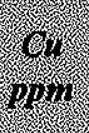 & 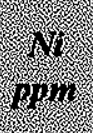 & op & trov. & ppon \\
\hline ETEO2T & 610 & 18 & 76 & 48 & 94 & 170 & 172 & 80 \\
\hline ETE03T & 612 & 24 & 73 & 43 & 62 & 173 & 159 & 174 \\
\hline ETE04T & 634 & 58 & 76 & 115 & 67 & 115 & 117 & 366 \\
\hline ETE0ST & 813 & 24 & 77 & 38 & 95 & 161 & 169 & 242 \\
\hline ETE06T & 665 & 16 & 82 & 52 & 73 & 165 & 187 & 153 \\
\hline ETEOTT & 761 & 20 & 94 & 78 & 113 & 131 & 214 & 218 \\
\hline ETE08T & 601 & $<15$ & 75 & 50 & 74 & 178 & 155 & 125 \\
\hline ETE09T & 648 & 20 & 87 & 46 & 111 & 145 & 173 & 142 \\
\hline ETE10T & 583 & $<15$ & 67 & 41 & 18 & 145 & 137 & 165 \\
\hline ETEIIT & $n d$ & nd & nd & $n d$ & nd & $n d$ & $n d$ & $n d$ \\
\hline$E T E I 2 T$ & 606 & $<15$ & 57 & 34 & 115 & 158 & 143 & 230 \\
\hline ETE13T & $n d$ & nd & $n d$ & nd & $n d$ & $n d$ & $n d$ & $n d$ \\
\hline
\end{tabular}

Da análise dos dados obtidos nas Tabelas 26 e 27, pode-se observar que as concentrações de Bário $(\mathrm{Ba})$ foram mais elevadas nas amostras do período de alta pluviosidade. Neste mesmo período, os maiores valores para este elemento foram observados nas amostras ETE09T (915 ppm) e 05T (828 ppm) e os menores nas ETE08T (624ppm) e 03T( 626 ppm). Na estação climática de baixa pluviosidade, a concentração mais elevada de $\mathrm{Ba}$ foi observada na amostra ETE05T (813ppm) e a menor na ETE10T (583ppm).

A leitura para o Cobalto $(\mathrm{Co})$ nestes mesmos sedimentos, exibiu um quadro de concentrações com valores semelhantes à um pouco menores no período chuvoso se comparado com o seco (Tabelas 26 e 27), com exceção das amostras ETE02T (19ppm) e 10T (19ppm). Os valores observados estavam um pouco acima do limite de deteç̧ão deste elemento (menor que 15 ppm) e não ultrapassaram 20 ppm. A concentração de Co no período de menor pluviosidade ultrapassou estes valores em pelo menos três amostras, uma das quais com o maior valor observado (ETE04T com 58 ppm).

Os dados obtidos para o Cromo $(\mathrm{Cr})$ no período de coleta de maior pluviosidade, apresentaram-se inferiores ao do período de baixa pluviosidade, com exceção das amostras ETE10T e 12T. A maior concentração de $\mathrm{Cr}$ foi observada no período chuvoso (ETE04T com 73 ppm) e a menor na ETE08T 
(abaixo do limite de detecção do aparelho para este metal). No período seco, a maior concentração de $\mathrm{Cr}$, foi observada na amostra ETE07T (94 ppm) e a menor na ETE12T (57 ppm) (Tabela 27).

Para os teores de Cobre ( $\mathrm{Cu}$ ) obtidos neste sedimento no período de coleta chuvoso, notou-se que estes valores ou são similares ou ligeiramente superiores aos observados no período seco. Neste contexto, verificou-se que a maior concentração de Cobre ( $\mathrm{Cu}$ ) foi detectada na estação ETE07T (128 ppm) e a menor na ETE08T (menor que $15 \mathrm{ppm}$ ), conforme exibe a Tabela 26. Para o período seco, a maior concentração de Cu foi observada na amostra ETE04T (115 ppm) e a menor na ETE12T (34 ppm).

A mesma leitura aplicada para as concentrações de Níquel ( $\mathrm{Ni}$ ), exibiu maior enriquecido deste metal nas amostras do período seco se comparado com as do período chuvoso. Apenas as amostras ETE02T, 03T e 10T destoam deste comportamento. Para as amostras do período chuvoso, o maior valor observado sedia-se na ETE02T (103ppm) e o menor ETE08T (menor que 15 ppm). Como mencionado, nos sedimentos do periodo seco foram encontradas as maiores concentrações deste metal, sendo que o maior valor para este período sedia-se na amostra ETE12T(115 ppm) e o menor na ETE10T (18 ppm) (Tabela 27).

O comportamento observado para o elemento Estrôncio $(\mathrm{Sr})$ nestas duas coletas, demonstrou que os valores obtidos no período chuvoso são sempre inferiores aos do período seco, sem exceção. Neste caso, o maior valor observado para o Sr no período de alta pluviosidade foi de $135 \mathrm{ppm}$ na estação ETE12T e o menor foi de 74ppm na ETE 05T. No periodo seco a média dos valores encontra-se acima de $115 \mathrm{ppm}$, sendo o maior valor obtido encontrado na amostra ETE08T (178 ppm).

As concentrações de Zinco $(\mathrm{Zn})$ obtidas nas amostras coletadas no período chuvoso foram inferiores às obtidas no período seco, exceto para as amostras ETE04T e 10T. A média, no período chuvoso, ficou próxima a 150 ppm, tendo sido o maior valor encontrado na amostra ETE07 (192 ppm) e o menor na ETE08T $(70 \mathrm{ppm})$. Para o período seco a média deste elemento estava acima de $160 \mathrm{ppm}$, sendo o maior valor encontrado de $214 \mathrm{ppm}$ (ETE07T) e o menor entorno de 117ppm (ETE04T). 
A leitura dos teores obtidos para o Zircão $(\mathrm{Zr})$, denotou certa variabilidade entre os dois períodos de amostragem. No período chuvoso alguns valores apresentaram-se mais elevados que no período seco (quatro estações). Nas amostras do período chuvoso a média residiu na casa dos 238 ppm, sendo o maior valor obtido na amostra ETE08T (600ppm), este inclusive, pelo menos duas vezes superior a qualquer valor observado no período seco. No entanto é deste mesmo período o menor valor observado 60 ppm em ETE02T). Para o período seco a média atingiu 189 ppm (inferior ao do período chuvoso). O maior teor observado neste período de coleta foi de 366 ppm na estação ETE04T e o menor de 80 ppm na ETE02T.

Os valores obtidos nas Tabelas 26 e 27, para os metais $\mathrm{Cu}, \mathrm{Cr}, \mathrm{Zn}$ e $\mathrm{Ni}$ (metais de estudo) foram plotados em diagramas binários visando a delineação de suas assinaturas químicas. As Figuras 21 e 22 ilustram o resultado para estes metais nos Sedimentos Argilosos amostrados nos períodos chuvoso e seco.

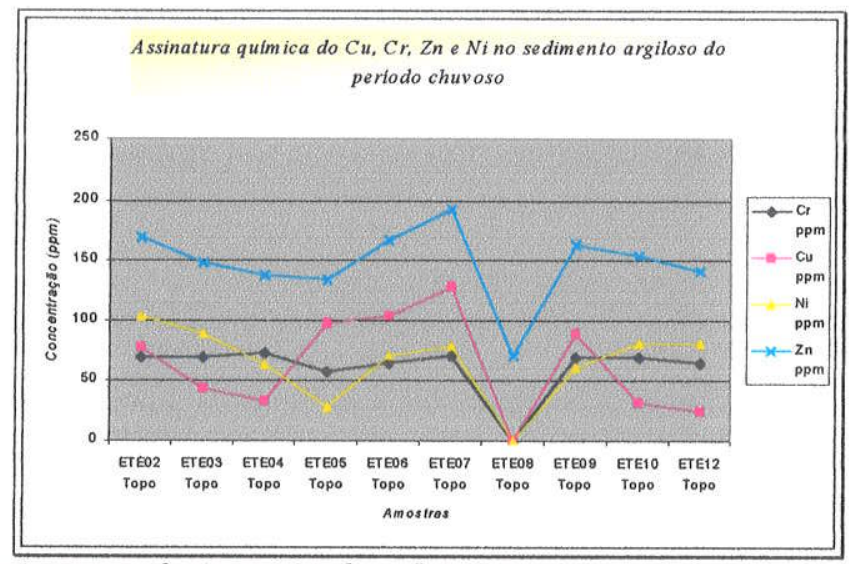

Figura 21 - Assinaturas químicas do $\mathrm{Cu}, \mathrm{Cr}, \mathrm{Zn}$ e Ni no Sedimento Argiloso, referente a coleta do período chuvoso.

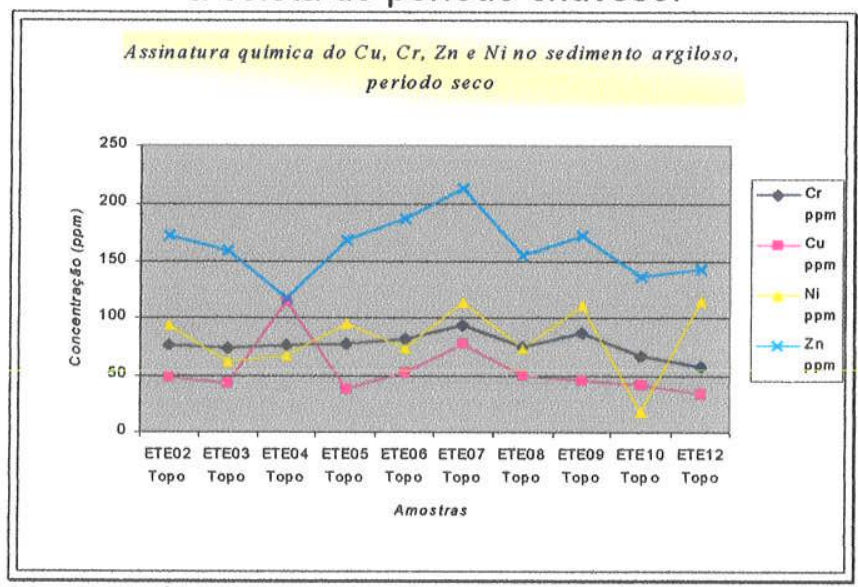

Figura 22 - Assinaturas químicas do $\mathrm{Cu}, \mathrm{Cr}, \mathrm{Zn}$ e Ni no Sedimento Argiloso, referente a coleta do período seco. 
As leituras das assinaturas químicas apresentadas pelo diagrama da Figura 21, indicaram forte caráter depletivo para os quatro metais de estudo na estação de amostragem ETE08. O Cu, $\mathrm{Zn}$ e $\mathrm{Ni}$ exibiram assinaturas de concentração química, nas estações de amostragem, que foram consideradas similares, exceto para as amostras ETE05T (neste ponto a concentração de $\mathrm{Cu}$ foi incrementada enquanto a de $\mathrm{Zn}$ foi diminuída); e 10T (neste ponto o $\mathrm{Ni}$ apresentou maior incremento de teor que o $\mathrm{Zn}$ e $\mathrm{Cu}$ ). $\mathrm{O} \mathrm{Cr}$, metal restante, demonstrou neste gráfico uma assinatura própria, tendendo a similaridade em alguns pontos com as concentrações químicas obtidas para o $\mathrm{Zn}$.

Nas amostras do período seco, observou-se que cada um dos metais analisados, apresentaram uma assinatura química própria (Figura 22). Nas amostras deste periodo climático, a assinatura química do $\mathrm{Cr}$ passou a ser mais expressiva que a do $\mathrm{Cu}$. As amostras coletadas na estação ETE07, neste mesmo período de coleta, exibiram as maiores concentrações químicas para os quatro metais de estudo.

Verificou-se assim que as assinaturas químicas do $\mathrm{Cu}, \mathrm{Cr}, \mathrm{Zn}$ e $\mathrm{Ni}$ diferem de um período climático para outro, considerando os resultados obtidos e esta forma de ilustração (Figuras 21 e 22). Nota-se ainda, que os quatro metais exibiram ligeiro acréscimo nas suas curvas de concentração química para as amostras coletadas no período seco. As curvas formadas pelos valores de $\mathrm{Zn}$ foram sempre superiores aos dos outros metais, nos dois períodos de coleta.

Além destes gráficos binários, foram confeccionados mapas de isoconcentrações químicas para $\circ \mathrm{Cu}, \mathrm{Cr}, \mathrm{Zn}$ e Ni , obtidos nas amostras de Sedimento Argiloso coletadas no verão e no inverno, objetivando analisar-se a variação espacial destes metais nas diferentes estações de amostragem, além de detectar a possível migração destes metais pesados para o lago a partir do lodo de esgoto que circunda parte deste ambiente. Para a construção destes mapas, não considerou-se as concentrações químicas obtidas na estação ETE01, por este material representar origem diferente dos outros, ou seja, trata-se de Sedimento Aluvionar e não de Sedimento Argiloso. Além disso, nas estações ETE11 e 13 as concentrações químicas foram obtidas pelo método 
da interpolação de pontos vizinhos, justificando a não consideração destes valores na leitura destas curvas (não são valores reais e sim calculados).

As distribuições das curvas de isoconcentração química obtidas para o $\mathrm{Cu}$ detectado nas amostras coletadas nos períodos climáticos chuvoso e seco (Figuras 23 e 24), confirmaram as anteriores considerações aqui mencionadas, de que as concentrações de $\mathrm{Cu}$ eram iguais e as vezes um pouco mais elevadas nas amostras coletadas no período climático de alta pluviosidade.

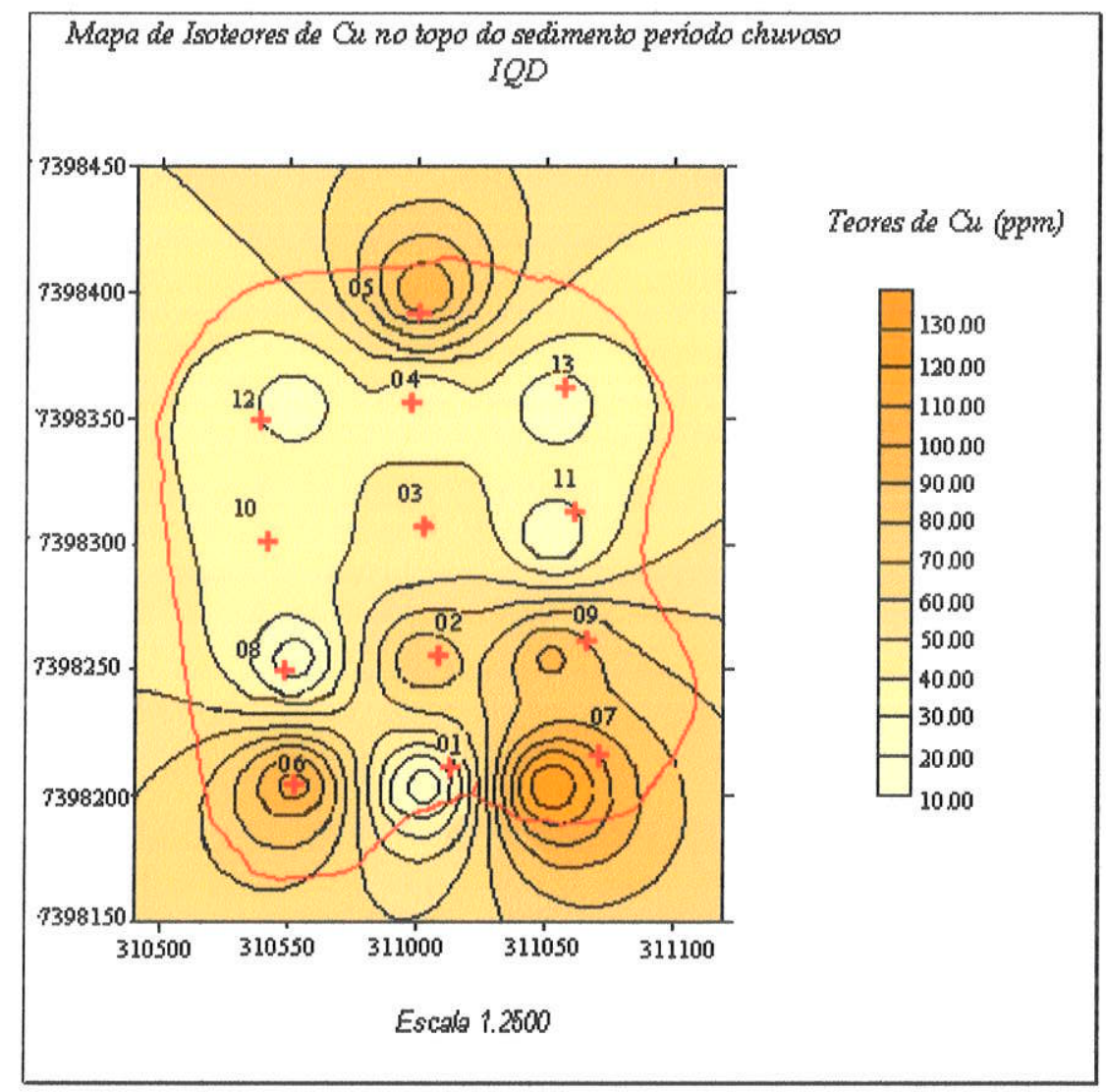

Figura 23 - Mapa de isoconcentração química do Cu para os Sedimentos Argilosos coletados nas diferentes estações de amostragem, no período chuvoso. 


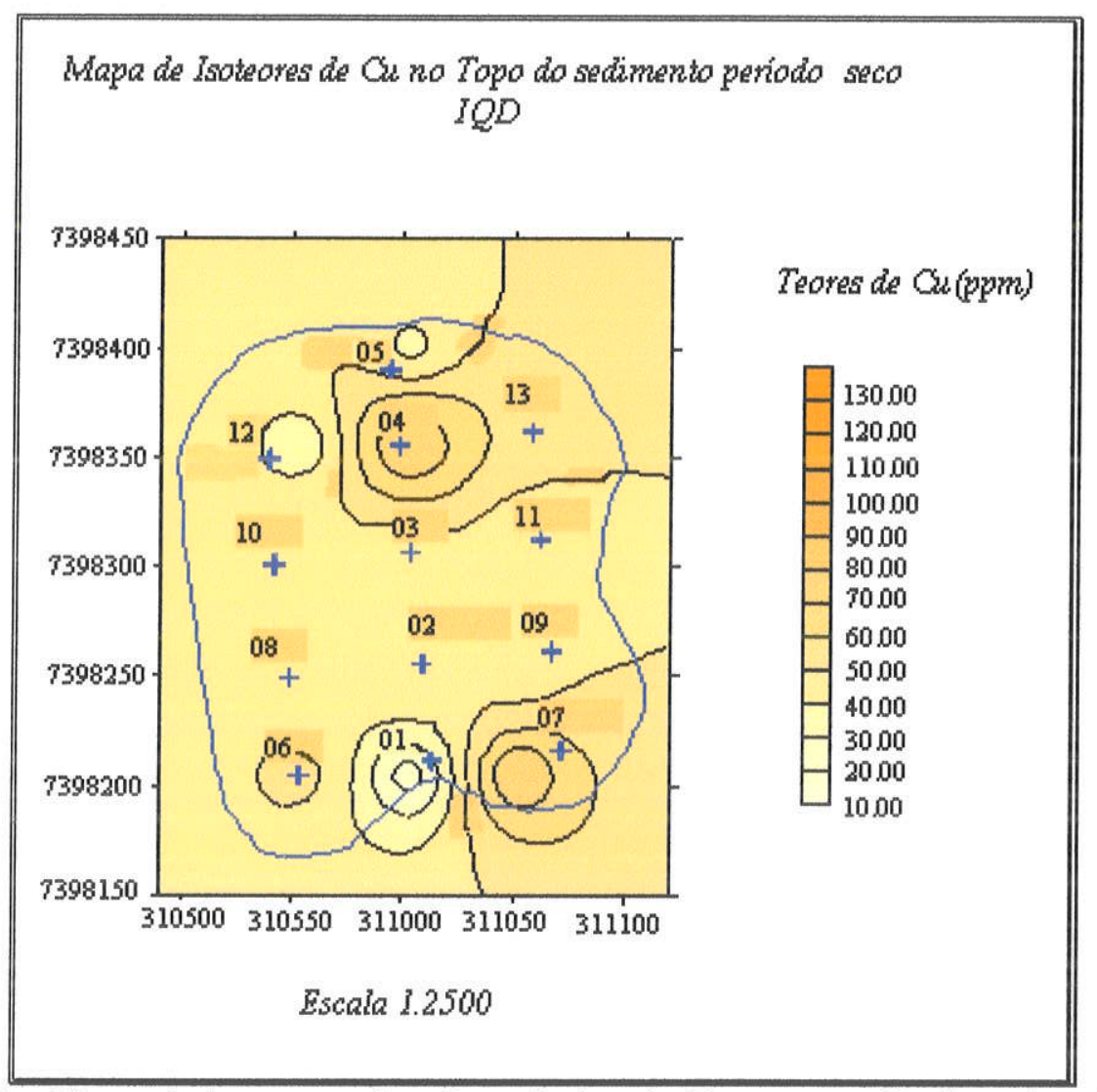

Figura 24 - Mapa de isoconcentração química do Cu para os Sedimentos Argilosos coletados nas diferentes estações de amostragem, no período seco.

Os sedimento coletadas tanto no período chuvoso como no seco nas estações de amostragem ETE 07 e 06, apresentaram-se mais enriquecidos em Cu que os outros.

A distribuição das curvas de isoconcentração química do $\mathrm{Cu}$ no período chuvoso, confirmou boa parte das observações já mencionadas, de que as maiores concentrações deste elemento foram detectadas nas estações de amostragem ETE05, 06 e 07 (amarelo escuro) e as menores nas estações ETE08, 11, 12 e 13 (amarelo claro). Por outro lado, a distribuição das curvas de isoconcentração para o período seco, apontou maiores concentrações deste elemento nas amostras coletadas nas ETE07, 04 e 06 (amarelo mais escuro), e a menor na ETE12 (amarelo esbranquiçado).

O mesmo tratamento aplicado para o Cr, exibido pelas Figuras 25 e 26, demonstrou de modo comparado que as concentrações química de Cr obtidas no período de maior pluviosidade são menores do que as obtidas no período seco. 


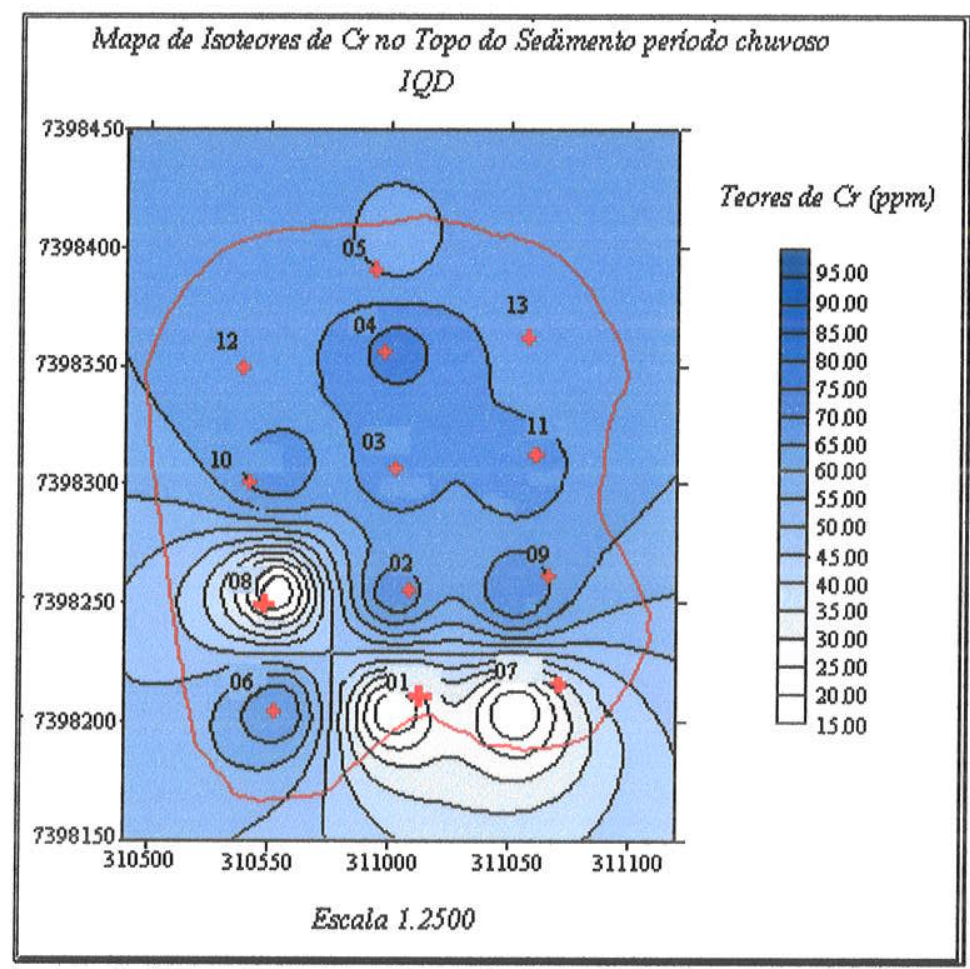

Figura 25 - Mapa de isoconcentração química do $\mathrm{Cr}$ para os Sedimentos Argilosos coletados nas diferentes estações de amostragem, no período chuvoso.

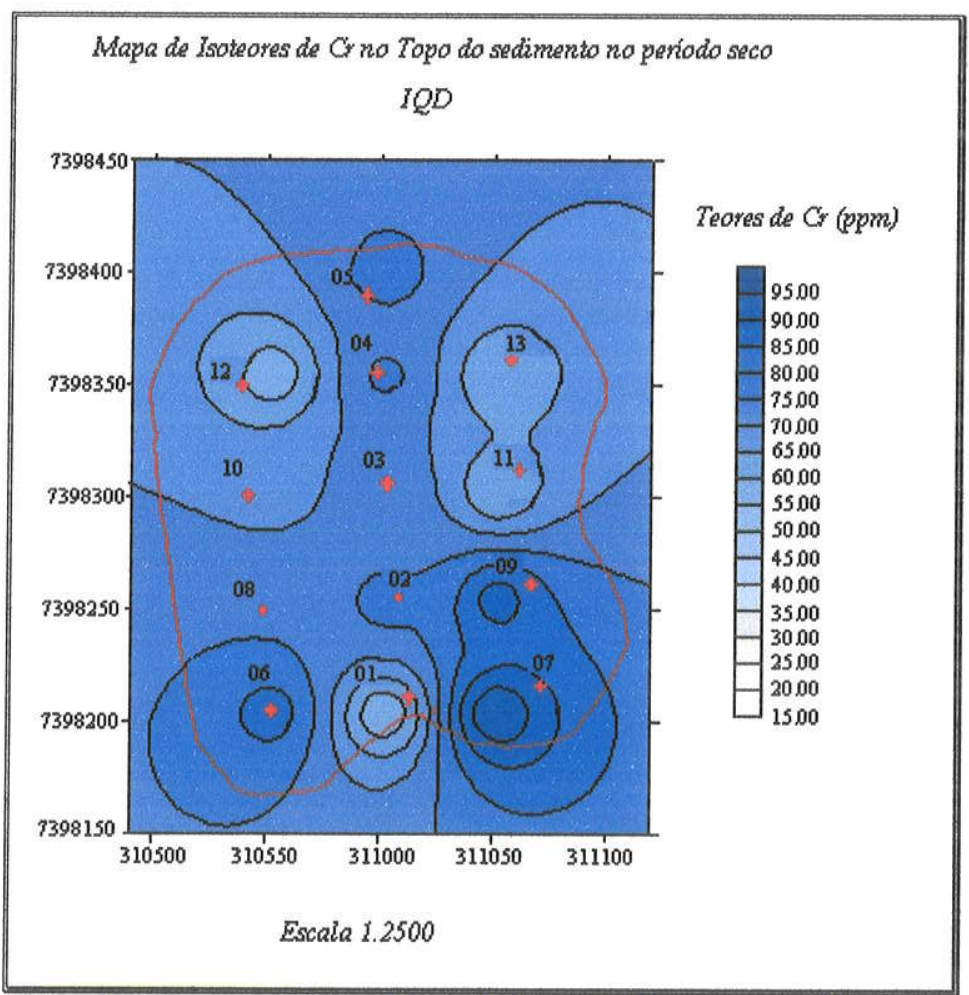

Figura 26 - Mapa de isoconcentração química do Cr para os Sedimentos Argilosos coletados nas diferentes estações de amostragem, no período seco.

As curvas de isoconcentração química delimitaram de forma clara na Figura 25, que as concentrações mais elevadas de $\mathrm{Cr}$ para o período climático chuvoso concentraram-se na porção superior do lago, compreendendo as 
estações ETE04, 03, 09, 10 e 11 (azul), enquanto que as curvas de menores concentração ocuparam a porção sul do lago, compreendida pelas estações ETE07 e 08 (branco). No período seco, a organização das curvas de isoconcentração química distinguiram-se das do período chuvoso como ilustra a Figura 26. Nesta, pode ser verificado que as maiores concentrações de $\mathrm{Cr}$ estavam ocupando a porção SE do ambiente lacustre (ETE07, 09) e SW (ETE06), enquanto que as curvas de menor teor ocuparam o setor NW deste mesmo ambiente, compreendido principalmente pela estação ETE12.

A distribuição das curvas de isoconcentração química obtidas para o $\mathrm{Ni}$ exibidas nas Figuras 27 e 28, coletados nos períodos de alta e baixa pluviosidade, demonstraram e confirmaram os anteriores comentários aqui mencionados, de que as amostras coletadas no período de menor pluviosidade estavam mais enriquecidas em $\mathrm{Ni}$.

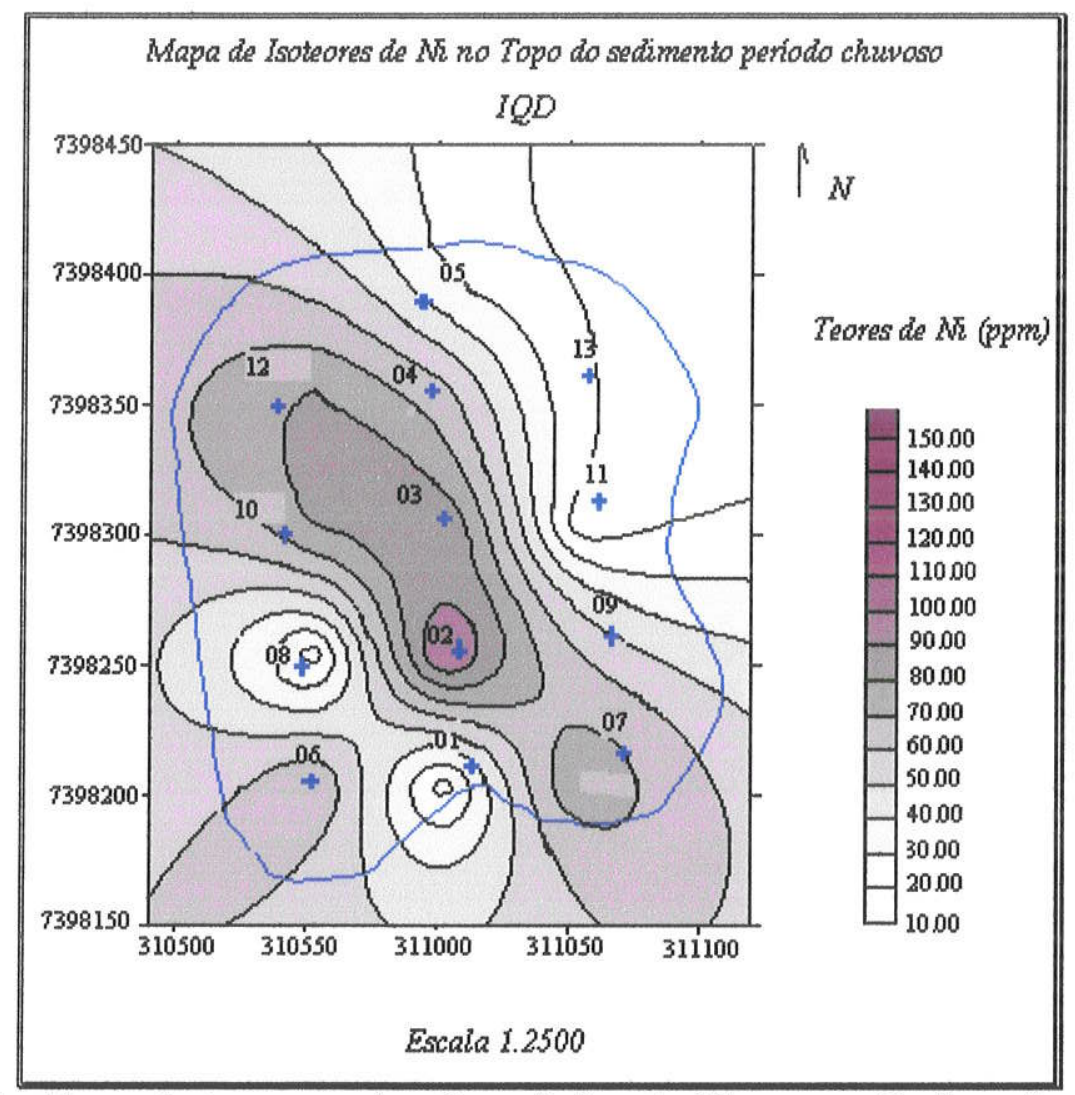

Figura 27 - Mapa de isoconcentração química do Ni para os Sedimentos Argilosos coletados nas diferentes estações de amostragem, no período chuvoso. 


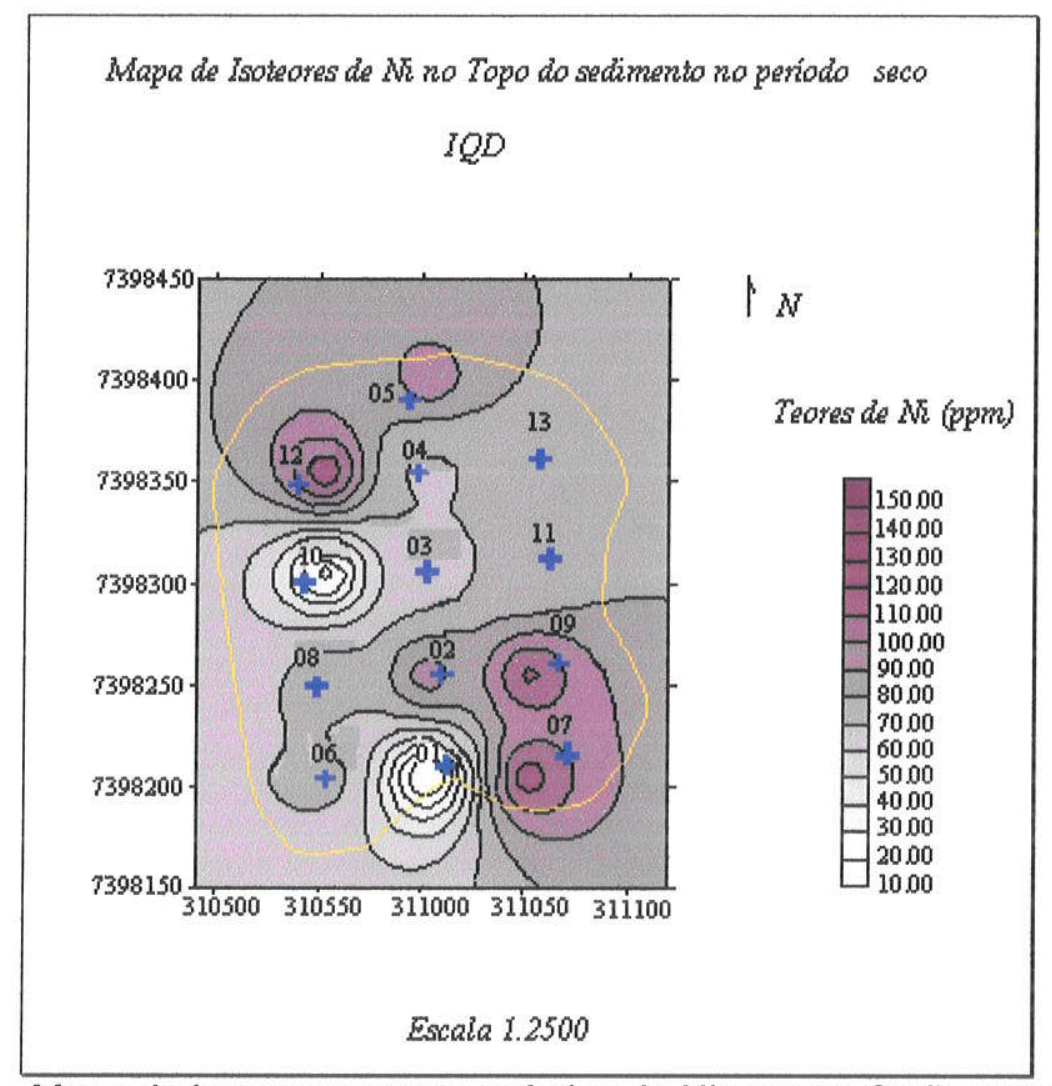

Figura 28 - Mapa de isoconcentração química do Ni para os Sedimentos Argilosos coletados nas diferentes estações de amostragem, no período seco.

A distribuição das curvas de isoconcentração química do Ni para o período chuvoso, exibiu uma área de concentração deste metal que ocupa a direção SE-NW do ambiente lacustre (lilás escuro), compreendido principalmente pelas amostras coletadas nas estações ETE02, 03, 07 e 12 desta orientação. No período seco, estas curvas desenharam dois pólos preferenciais de concentração, um a NW, compreendendo principalmente as estações de coleta ETE05 e 12, e o outro no polo SE incluindo as estações ETE07 e 09.

Este mesmo tipo de análise, efetuada para as curvas de isoconcentrações químicas de $\mathrm{Zn}$ nas amostras de Sedimento Argiloso, coletadas no verão e no inverno, demonstraram que este elemento no que diz respeito ao período climático chuvoso (Figura 29) concentra-se em dois pólos preferenciais no meio lacustre investigado. Um a SW e outro a SE, o primeiro representado pela estação ETE06 e, o segundo pela estação ETE07 preferencialmente. Esta distribuição espacial corrobora com as considerações anteriormente mencionadas quanto aos pontos de maiores concentrações de Zn observados neste ambiente. 


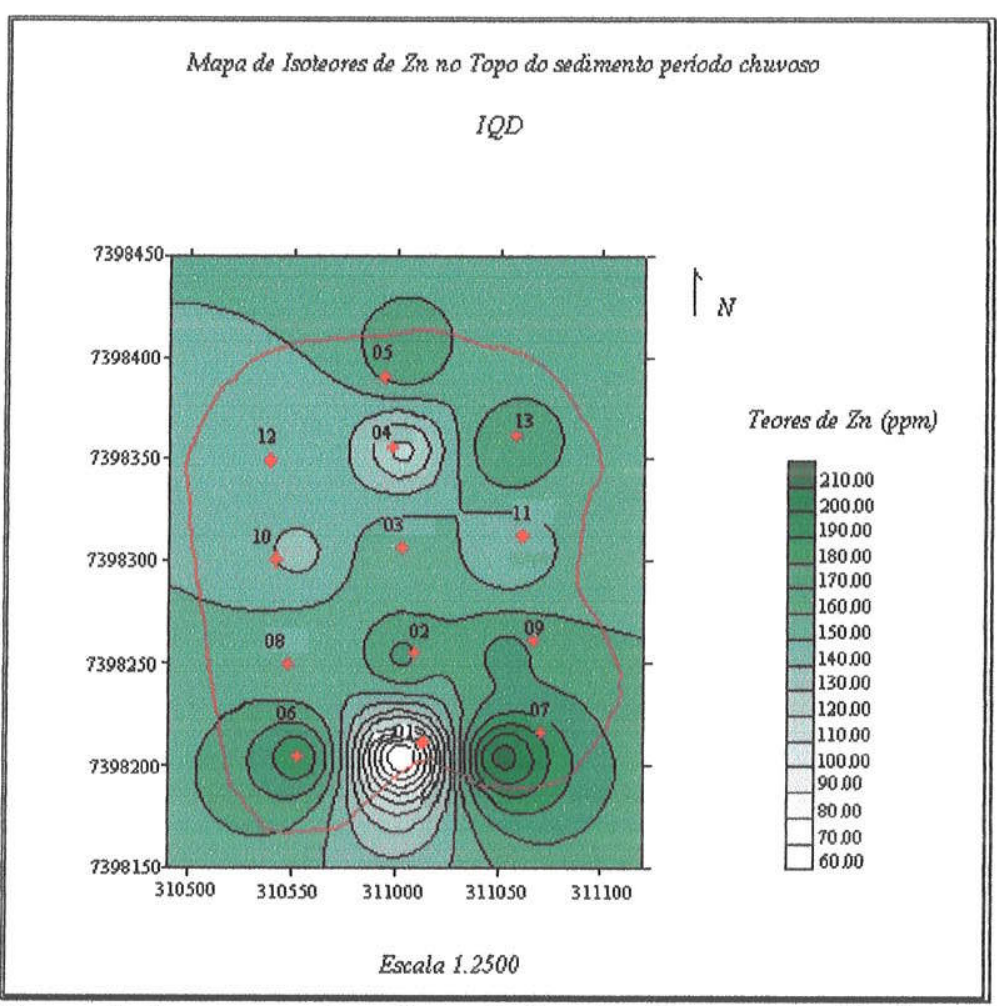

Figura 29 - Mapa de isoconcentração química do Zn para os Sedimentos Argilosos coletados nas diferentes estações de amostragem, no período chuvoso.

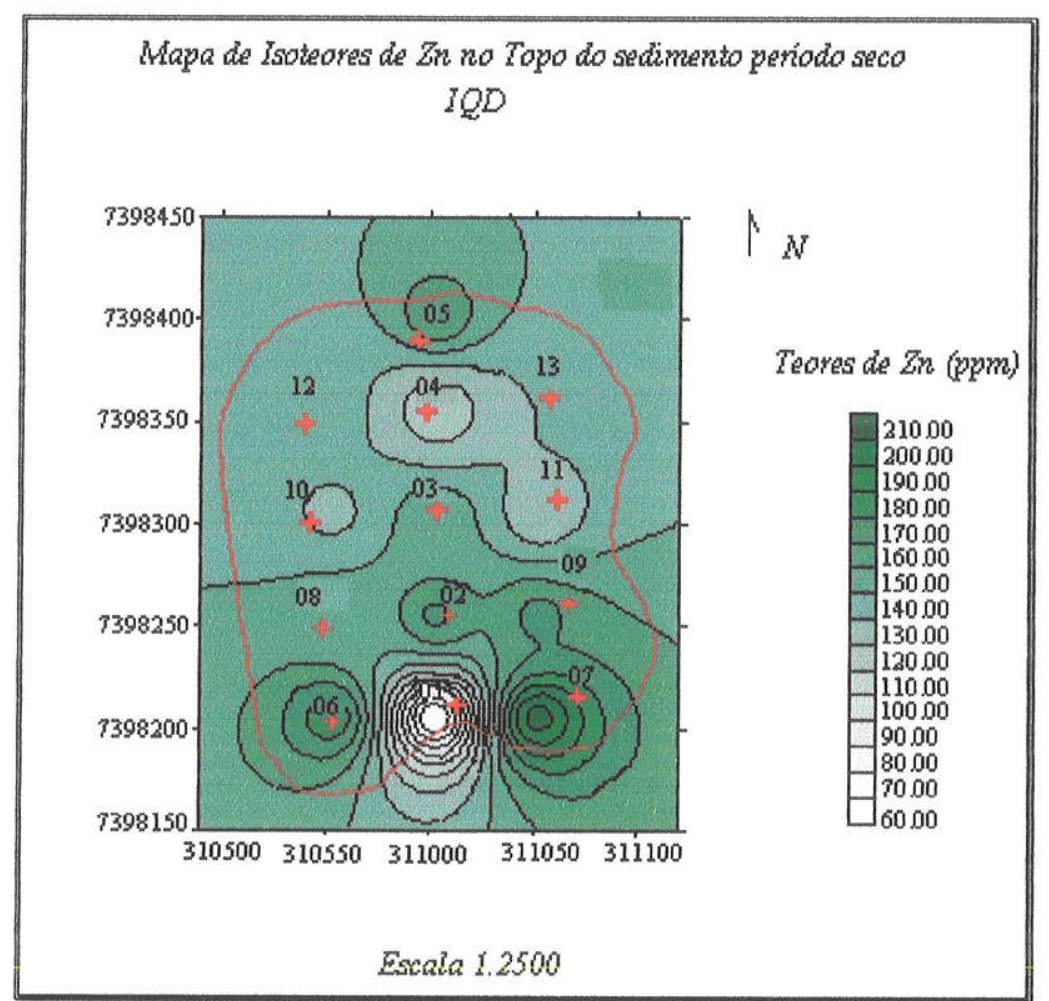

Figura 30 - Mapa de isoconcentração química do Zn para os Sedimentos Argilosos coletados nas diferentes estações de amostragem, no período seco.

O mesmo procedimento aplicado as curvas de isoconcentração deste elemento para as amostras analisadas no período seco (Figura 30), delineou 
coincidentemente os mesmos dois campos observados para o período chuvoso, ou seja, dois polos de concentração sediados um a SW e outro a SE deste ambiente lacustre. Este representa o único caso em que os valores de teores distribuem-se semelhantemente nos dois períodos de coleta quando comparados com os outros elementos metálicos aqui mencionados.

$\mathrm{Na}$ intenção de delimitar a provável contaminação ou não dos sedimentos aqui investigados pelos metais $\mathrm{Cu}, \mathrm{Cr}, \mathrm{Zn}$ e Ni , dois critérios foram empregados visando atingir tal finalidade. $O$ primeiro denomina-se Fator de Contaminação ou Enriquecimento e o segundo índice de Geoacumulação (Igeo). Os procedimentos metodológicos encontram-se explicitados no Capítulo 4, subcapítulo 4.3, itens 4.3.3.1 e 4.3.3.2 desta dissertação. Os valores obtidos nas amostras de Sedimento Argiloso para o $\mathrm{Cu}$, juntamente com os valores calculados pelo Fator de Contaminação e Igeo para este metal, encontram-se nas Tabelas 28 e 29.

TABela 28 - ComparaÇÃo dos VALORES de Cu OBtido nAS AMOSTRAS de SEDIMENTO ARGILOSO (SUBAMOSTRA DO TOPO - T) COM O FATOR DE CONTAMINAÇÃO E IGEO DESTE METAL PARA ESTAS AMOSTRAS, NO PERIODO CHUVOSO.

\begin{tabular}{|c|c|c|c|}
\hline $\begin{array}{l}\text { Amosrias de } \\
\text { Sedimeno Argilloso }\end{array}$ & cir & $\begin{array}{l}\text { Faror de } \\
\text { contaminagab }\end{array}$ & Tseo \\
\hline ETE02T & 77,00 & 1,71 & 0,09 \\
\hline ETE03T & 43,00 & 0,96 & 0,08 \\
\hline ETE04T & 33,00 & 0,73 & 0,07 \\
\hline ETE05T & 98,00 & 2,18 & 0,10 \\
\hline ETE06T & 103,00 & 2,29 & 0,10 \\
\hline ETE07T & 128,00 & 2,84 & 0,10 \\
\hline ETE08T & 10,00 & 0,22 & 0,05 \\
\hline ETE09T & 89,00 & 1,98 & 0,10 \\
\hline ETE10T & 32,00 & 0,71 & 0,07 \\
\hline ETE11T & 23,00 & 0,51 & 0,07 \\
\hline ETE12T & 25,00 & 0,56 & 0,07 \\
\hline ETE $13 T$ & 24,00 & 0,53 & 0,07 \\
\hline
\end{tabular}


TABELA 29 - COMPARAÇÃo dOS VALORES DE CU OBTIDO NAS AMOSTRAS DE SEDIMENTO ARGILOSO (SUBAMOSTRA DO TOPO - T) COM O FATOR DE CONTAMINAÇÃO E IGEO DESTE METAL PARA ESTAS AMOSTRAS, NO PERIODO SECO.

\begin{tabular}{|c|c|c|c|}
\hline 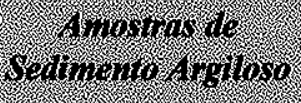 & 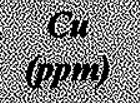 & 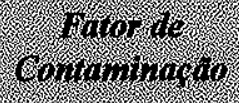 & 1800 \\
\hline ETE02T & 48,00 & 1,07 & 0,08 \\
\hline ETE03T & 43,00 & 0,96 & 0,08 \\
\hline ETE04T & 115,00 & 2,56 & 0,10 \\
\hline ETE05T & 38,00 & 0,84 & 0,08 \\
\hline ETE06T & 52,00 & 1,16 & 0,08 \\
\hline ETE07T & 78,00 & 1,73 & 0,09 \\
\hline ETE08T & 50,00 & 1,11 & 0,08 \\
\hline ETEO9T & 46,00 & 1,02 & 0,08 \\
\hline ETEIOT & 41,00 & 0,91 & 0,08 \\
\hline ETE11T & $n d$ & nd & $n d$ \\
\hline ETE $12 T$ & 34,00 & 0,76 & 0,08 \\
\hline ETE $13 T$ & $n d$ & nd & $n d$ \\
\hline
\end{tabular}

Nd: nâo detectado na amostra em questão.

Os resultados obtidos para Cu nestas amostras de Sedimento Argiloso, coletadas no período de alta e baixa pluviosidade, não indicaram possibilidade de contaminação por este metal, pelo critério lgeo, em decorrência dos resultados obtidos por tal método serem inferiores a zero em todas as amostras analisadas (Tabelas 28 e 29). Conforme MILLER (1979) apud CALMANO e FÖRSTNER (1996), estes sedimentos pertencem a classe zero do lgeo, caracterizando a não poluição destas amostras por este metal de estudo.

O Fator de Contaminação do $\mathrm{Cu}$, calculado para as mesmas amostras nas quais aplicou-se o lgeo, apontou a contaminação deste metal pesado para os Sedimentos Argilosos coletados nas estações de amostragem ETE02, 05, 06, 07 e 09 no período de maior precipitação pluviométrica (Tabela 28) e nas ETE02, 04, 06, 07, 08 e 09 no periodo de menor precipitação pluviométrica (Tabela 29). Segundo HAKANSON e JANSSON (1983), estes valores obtidos de Fatores de Contaminação foram considerados moderados, em decorrência destes terem resultados em valores numéricos superiores a um e inferiores a três. 
As Tabelas 30 e 31 expostas a seguir, exibem os valores numéricos obtidos para o Índice de Geoacumulação e o Fator de Contaminação do $\mathrm{Cr}$, obtidos nos Sedimentos Argilosos no período chuvoso e no seco.

TABELA 30 - Comparação dos VAloRes de Cr ObTido nas amostras de Sedimento ARGILOSO (SUBAMOSTRA DO TOPO - T) COM O FATOR DE CONTAMINAÇÃO E IGEO DESTE METAL PARA ESTAS AMOSTRAS, NO PERÍODO CHUVOSO.

\begin{tabular}{|c|c|c|c|}
\hline $\begin{array}{l}\text { Amostras de } \\
\text { Sedimento Argiloso }\end{array}$ & (ppm) & $\begin{array}{l}\text { Fator de } \\
\text { Contaminasto }\end{array}$ & lgen \\
\hline ETE02T & 69,00 & 0,77 & 0,05 \\
\hline ETE03T & 69,00 & 0,77 & 0,05 \\
\hline ETE04T & 73,00 & 0,81 & 0,05 \\
\hline ETE05T & 58,00 & 0,64 & 0,04 \\
\hline ETE06T & 65,00 & 0,72 & 0,04 \\
\hline ETE07T & 71,00 & 0,79 & 0,05 \\
\hline ETE08T & 10,00 & 0,11 & 0,02 \\
\hline ETE09T & 69,00 & 0,77 & 0,05 \\
\hline ETE1OT & 69,00 & 0,77 & 0,05 \\
\hline ETE 11T & 68,00 & 0,76 & 0,05 \\
\hline ETE12T & 65,00 & 0,72 & 0,04 \\
\hline ETE $13 T$ & 65,00 & 0,72 & 0,04 \\
\hline
\end{tabular}

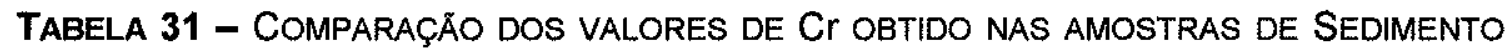
ARGILOSO (SUBAMOSTRA DO TOPO - T) COM O FATOR DE CONTAMINAÇÃO E IGEO DESTE METAL PARA ESTAS AMOSTRAS, NO PERIODO SECO.

\begin{tabular}{|c|c|c|c|}
\hline $\begin{array}{l}\text { Amostras de } \\
\text { Sedimento trgiloso }\end{array}$ & (or & $\begin{array}{l}\text { Turor de } \\
\text { Contaniriagdo }\end{array}$ & $18 e 0$ \\
\hline ETE02T & 76,00 & 0,84 & 0,05 \\
\hline ETE03T & 73,00 & 0,81 & 0,05 \\
\hline ETE04T & 76,00 & 0,84 & 0,05 \\
\hline ETE05T & 77,00 & 0,86 & 0,05 \\
\hline ETE06T & 82,00 & 0,91 & 0,05 \\
\hline ETE07T & 94,00 & 1,04 & 0,05 \\
\hline ETE08T & 75,00 & 0,83 & 0,05 \\
\hline ETEO9T & 87,00 & 0,97 & 0,05 \\
\hline ETE1OT & 67,00 & 0,74 & 0,04 \\
\hline ETEIIT & nd & nd & $n d$ \\
\hline ETE $12 T$ & 57,00 & 0,63 & 0,04 \\
\hline ETE $13 T$ & $n d$ & $n d$ & nd \\
\hline
\end{tabular}

Nd: não detectado na amostra em questão. 
Os valores numéricos calculados para o lgeo e o Fator de Contaminação do $\mathrm{Cr}$, apontaram a não contaminação dos sedimentos lacustres (Sedimentos Argilosos) por este metal pesado, com exceção da amostra ETE07T coletada no período seco, cujo valor numérico do Fator de Contaminação foi maior que um (Tabela 31). Conforme MILLER (1979) apud CALMANO e FÖRSTNER (1996), este valor numérico incluiria estes sedimentos na classe zero do lgeo, caracterizando a não poluição destas amostras por este metal de estudo. Os valores numéricos calculados para o Fator de Contaminação indicaram a não poluição destes sedimentos, em decorrência destes terem resultados em valores inferiores a um como indicam HAKANSON e JANSSON (1983) neste tipo de análise.

O Índice de Geoacumulação e o Fator de Contaminação para $\circ \mathrm{Ni}$, expostos nas Tabelas 32 e 33 para as amostras coletadas no período de maior pluviosidade e no de menor, indicaram que este metal não representa fonte de contaminação se considerado o critério lgeo, em decorrência dos valores numéricos obtidos serem inferiores a zero em todas as amostras analisadas. Segundo MILLER (1979) apud CALMANO e FÖRSTNER (1996), estes valores inseriram estes sedimentos na classe zero do lgeo, caracterizando assim que este elemento não representa fonte de poluição nestes sedimentos analisados.

TABELA 32 - CoMparaçÃo dos VAloRes de Ni OBTIDO NAS AMOSTRAS DE SEDIMENTO ARGILOSO (SUBAMOSTRA DO TOPO - T) COM O FATOR DE CONTAMINAÇÃO E IGEO DESTE METAL PARA ESTAS AMOSTRAS, NO PERÍODO CHUVOSO.

\begin{tabular}{|c|c|c|c|}
\hline 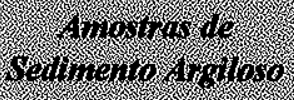 & $(p p i)$ & conominturato & $18 \mathrm{co}$ \\
\hline ETE02T & 103,00 & 1,51 & 0,07 \\
\hline ETE03T & 89,00 & 1,31 & 0,06 \\
\hline ETE04T & 63,00 & 0,93 & 0,06 \\
\hline ETE05T & 28,00 & 0,41 & 0,05 \\
\hline ETE06T & 71,00 & 1,04 & 0,06 \\
\hline ETE07T & 79,00 & 1,16 & 0,06 \\
\hline ETE08T & 10,00 & 0,15 & 0,03 \\
\hline ETE09T & 61,00 & 0,90 & 0,06 \\
\hline ETEIOT & 81,00 & 1,19 & 0,06 \\
\hline ETELIT & 15,00 & 0,22 & 0,04 \\
\hline ETE $12 T$ & 81,00 & 1,19 & 0,06 \\
\hline ETE13T & 23 & 0,34 & 0,04 \\
\hline
\end{tabular}


TABELA 33 - COMPARAÇÃO dOS VALORES DE NI OBTIDO NAS AMOSTRAS DE SEDIMENTO ARGILOSO (SUBAMOSTRA DO TOPO - T) COM O FATOR DE CONTAMINAÇÅO E IGEO DESTE METAL PARA ESTAS AMOSTRAS, NO PERIODO SECO.

\begin{tabular}{|c|c|c|c|}
\hline 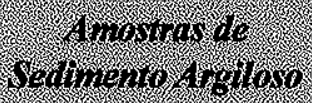 & (npri) & 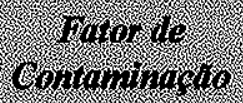 & foco. \\
\hline ETE02T & 94,00 & 1,38 & 0,06 \\
\hline ETE03T & 62,00 & 0,91 & 0,06 \\
\hline ETE04T & 67,00 & 0,99 & 0,06 \\
\hline ETE05T & 95,00 & 1,40 & 0,06 \\
\hline ETE06T & 73,00 & 1,07 & 0,06 \\
\hline ETE07T & 113,00 & 1,66 & 0,07 \\
\hline ETE08T & 74,00 & 1,09 & 0,06 \\
\hline ETE09T & 111,00 & 1,63 & 0,07 \\
\hline ETE $10 T$ & 18,00 & 0,26 & 0,04 \\
\hline ETE IIT & nd & nd & $n d$ \\
\hline ETE12T & 115,00 & 1,69 & 0,07 \\
\hline ETE $13 T$ & nd & $n d$ & $n d$ \\
\hline
\end{tabular}

Nd: não detectado na amostra em questão.

A aplicação do Fator de Contaminação do $\mathrm{Ni}$, calculado para as mesmas amostras nas quais aplicou-se o lgeo, apontou a contaminação deste metal pesado para os Sedimentos Argilosos coletados nas estações de amostragem ETE02, 03, 06, 07, 10 e 12 no período de maior pluviosidade (Tabela 32), e nas ETE02, 05, 06, 07, 08, 09 e 12 no período de menor pluviosidade (Tabela 33). De acordo com o proposto por HAKANSON e JANSSON (1983), estes valores de Fator de Contaminação, indicaram contaminação moderada, em função destes resultados atingirem valores numéricos superiores a um e inferiores a três.

Os valores calculados para o $\mathrm{Zn}$ segundo o critério lgeo para as amostras de sedimento lacustres (Sedimentos Argilosos) coletadas nos dois períodos climáticos e nas diferentes estações de amostragem (Tabelas $34 \mathrm{e}$ 35), demonstraram que estes não estão contaminados por $\mathrm{Zn}$, em decorrência dos valores numéricos obtidos serem inferiores a zero em todas as amostras analisadas. Tais materiais assim, pertenceriam a classe zero, pela classificação proposta por MILLER (1979) apud CALMANO e FÖRSTNER (1996). 
TABELA 34 - COMPARAÇÃO dOS VALORES DE Zn OBTIDO NAS AMOSTRAS DE SEDIMENTO ARGILOSO (SUBAMOSTRA DO TOPO - T) COM O FATOR DE CONTAMINAÇÄO E IGEO DESTE METAL PARA ESTAS AMOSTRAS, NO PERIODO CHUVOSO.

\begin{tabular}{|c|c|c|c|}
\hline 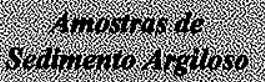 & 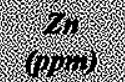 & 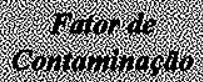 & He \\
\hline ETE02T & 169,00 & 1,78 & 0,05 \\
\hline ETE03T & 148,00 & 1,56 & 0,05 \\
\hline ETE04T & 137,00 & 1,44 & 0,05 \\
\hline ETE05T & 134,00 & 1,41 & 0,05 \\
\hline ETE06T & 167,00 & 1,76 & 0,05 \\
\hline ETE07T & 192,00 & 2,02 & 0,05 \\
\hline ETE08T & 70,00 & 0,74 & 0,04 \\
\hline ETE09T & 163,00 & 1,72 & 0,05 \\
\hline ETE $10 T$ & 154,00 & 1,62 & 0,05 \\
\hline ETEIIT & 138,00 & 1,45 & 0,05 \\
\hline ETE12T & 141,00 & 1,48 & 0,05 \\
\hline ETE $13 T$ & 180 & 1,89 & 0,05 \\
\hline
\end{tabular}

TABELA 35 - COMPARAÇÃO DOS VALORES DE Zn OBTIDO NAS AMOSTRAS DE SEDIMENTO ARGILOSO (SUBAMOSTRA DO TOPO - T) COM O FATOR DE CONTAMINAÇÃO E IGEO DESTE METAL PARA ESTAS AMOSTRAS, NO PERIODO SECO.

\begin{tabular}{|c|c|c|c|}
\hline 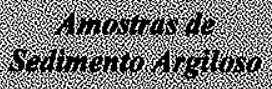 & $(6,1)$ & 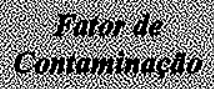 & 380 \\
\hline ETE02T & 172,00 & 1,81 & 0,05 \\
\hline ETE03T & 159,00 & 1,67 & 0,05 \\
\hline$E T E 04 T$ & 117,00 & 1,23 & 0,05 \\
\hline ETEOST & 169,00 & 1,78 & 0,05 \\
\hline ETE06T & 187,00 & 1,97 & 0,05 \\
\hline ETE07T & 214,00 & 2,25 & 0,05 \\
\hline ETE08T & 155,00 & 1,63 & 0,05 \\
\hline ETE09T & 173,00 & 1,82 & 0,05 \\
\hline ETE10T & 137,00 & 1,44 & 0,05 \\
\hline$E T E I I T$ & nd & nd & $n d$ \\
\hline ETE $12 T$ & 143,00 & 1,51 & 0,05 \\
\hline ETE13T & nd & nd & nd \\
\hline
\end{tabular}

Nd: não detectado na amostra em questẫo.

Por outro lado, os valores calculados com a aplicação do critério do Fator de Contaminação para o $\mathrm{Zn}$, nas mesmas amostras onde aplicou-se o Igeo, apontou a contaminação para quase todas as amostras de Sedimento Argiloso, nos dois períodos de coleta, com exceção da amostra ETE08 no período chuvoso. Os valores numéricos obtidos podem ser classificados como moderados, segundo a proposta de HAKANSON e JANSSON (1983), em decorrência destes valores orbitarem entre um e três. 


\section{B. Aterro}

A despeito dos sedimentos classificados como Aterro representarem sabidamente materiais de origem antrópica, estes também foram analisados quanto aos seus teores de elementos menores nas amostras coletadas nos períodos chuvoso e seco. Os resultados obtidos encontram-se nas Tabelas 36 e 37, e tem por finalidade a verificação de uma provável migração dos metais pesados contidos no sedimentos de origem lacustre para estes de origem antrópica.

TABELA 36 - Elementos MENORES DETECTADOS NAS AMOSTRAS DE ATERRO (SUBAMOSTRA DA BASE - B) DO PERIODO CHUVOSO.

\begin{tabular}{|c|c|c|c|c|c|c|c|c|}
\hline Whor & 86 & Shor & $r_{2}$ & S & 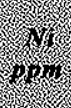 & r & 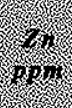 & rith \\
\hline ETEO3B & 441 & 20 & 81 & 22 & $<15$ & 39 & 59 & 385 \\
\hline ETEOSB & 1016 & 15 & 60 & 25 & 21 & 99 & 162 & 189 \\
\hline ETE06B & nd & nd & $n d$ & $n d$ & $n d$ & $n d$ & $n d$ & nd \\
\hline ETEO7B & 766 & $<15$ & $S 8$ & 24 & $<15$ & 72 & 128 & 191 \\
\hline ETEOSB & $n d$ & nd & $n d$ & $n d$ & nd & nd & nd & $n d$ \\
\hline ETEOSB & 723 & 28 & 49 & 17 & 23 & 51 & 85 & 409 \\
\hline ETE $10 B$ & 626 & 241 & 83 & 107 & 82 & 47 & 128 & 476 \\
\hline ETE IIB & 570 & 28 & 41 & $<15$ & $<15$ & 55 & 71 & 350 \\
\hline ETE $12 B$ & 577 & 28 & 81 & $<15$ & $<15$ & 66 & 51 & 467 \\
\hline$E T E \perp 3 B$ & 724 & 70 & 42 & 15 & $<15$ & 77 & 75 & 345 \\
\hline
\end{tabular}

nd: Elementos Menores não detectados nas amostras em questão.

$<15$ : Menor que o limite de deteção do aparelho.

TABELA 37 - ElemEntos MENORES DETECTADOS NAS AMOSTRAS DE ATERRO (SUBAMOSTRA DA BASE - B) DO PERIODO SECO.

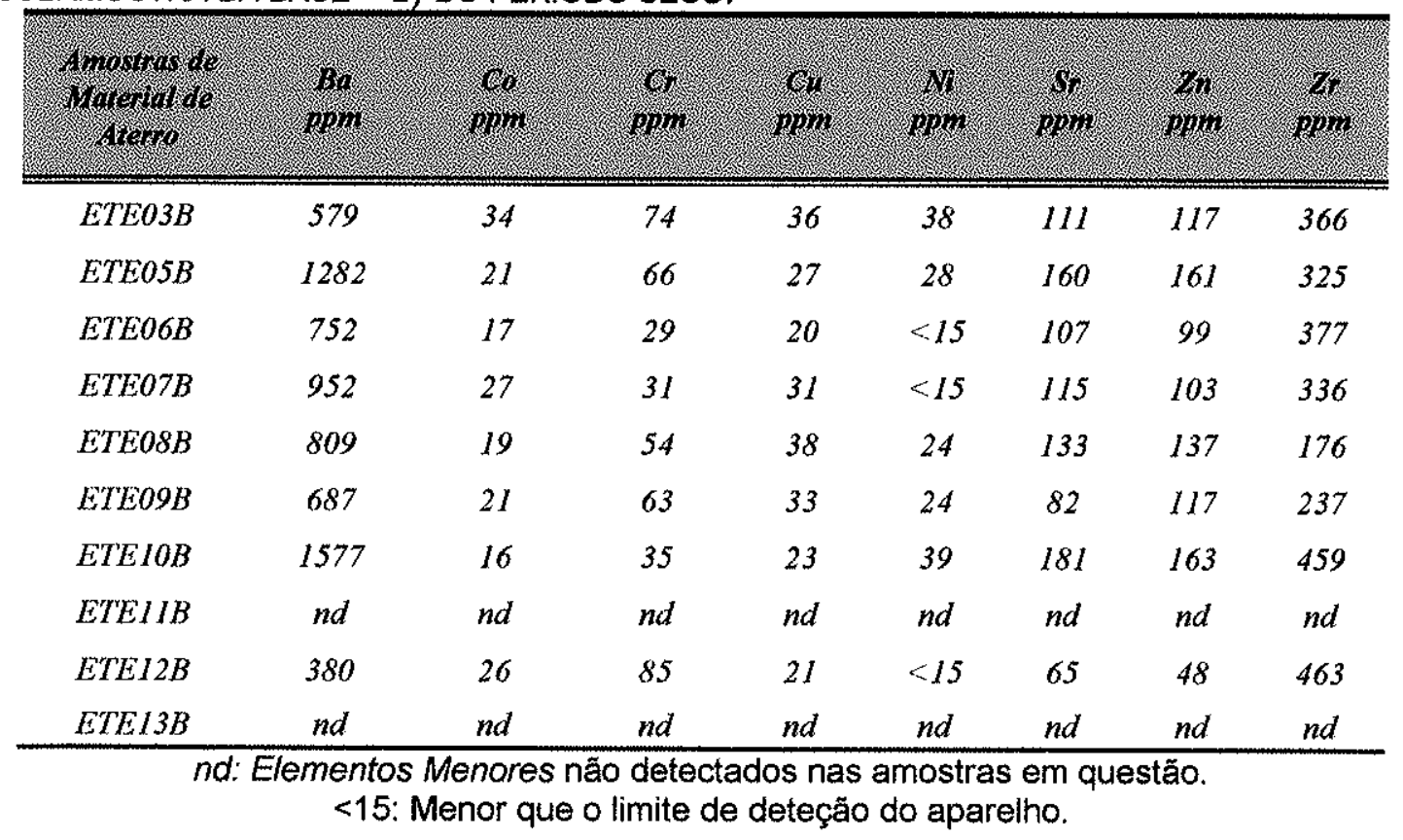


A comparação dos resultados obtidos para $\circ \mathrm{Ba}$, nos Aterros amostrados nos períodos climáticos chuvoso e seco, exibiu concentrações menores deste elemento nas amostras do período de alta pluviosidade, com exceção das ETE09B e 12B. A máxima (1577ppm) e a mínima concentração $(380 \mathrm{ppm})$ para este elemento foram determinadas nas amostras coletadas nas estações ETE09B e 12B respectivamente, no período climático de menor pluviosidade, conforme demonstrado nas Tabelas 36 e 37 .

Esta mesma análise comparativa aplicada para $\mathrm{Co}$, demonstrou que este elemento varia de um período climático para outro, sendo que em algumas amostras os maiores valores foram detectados no período chuvoso (ETE09B, $10 \mathrm{~B}$ e 12B) e em outras no seco (ETE03B, 05B e 07B). A máxima e a mínima concentração determinada no Aterro, foi encontrada nas amostras coletadas no período climático chuvoso na ETE10B (241 ppm) e ETEO7B (menor que 15 ppm), respectivamente.

Como ocorrido com as concentrações de Co, verificou-se que os valores obtidos para o $\mathrm{Cr}$ também variaram de um periodo de coleta para outro, de tal forma que as vezes os maiores valores foram detectados nas amostras do período chuvoso (ETE03B, 07B, 10B) e em outras no seco (ETE05B, 09B e 12B). A máxima e a mínima concentração de $\mathrm{Cr}$ no entanto residiram nas amostras ETE12B ( 85 ppm) e 06B (29 ppm) coletadas no período climático de baixa pluviosidade.

Comparando-se as concentrações de $\mathrm{Cu}$ obtidas nos dois períodos climáticos de estudo (Tabelas 36 e 37), verificou-se que os valores deste elemento são quase integralmente menores em todas as amostras referentes a coleta realizada no período chuvoso, com exceção da amostra ETE10B. No entanto, é a amostra ETE10B coletada no período de maior pluviosidade que exibiu a concentração máxima (107 ppm), e as ETE11B e 12B deste mesmo período, que exibiram as concentrações mínimas (menor que $15 \mathrm{ppm}$ ).

Para o Ni, os valores obtidos exibiram a mesma relação observada para - $\mathrm{Cu}$, ou seja, menores concentrações deste elemento nas amostras do período chuvoso. A máxima e a mínima concentração observadas nos Aterros residiram respectivamente, nas amostra ETE10B (82 ppm) e ETE03B, 07B, $11 \mathrm{~B}, 12 \mathrm{~B}$ e $13 \mathrm{~B}$ (menor que $15 \mathrm{ppm}$ ), ambos amostrados no período de alta 
pluviosidade. Cabe destacar que três valores mínimos também são observados no período seco (estações ETE06B, 07B e 12B).

Os resultados observados para o $\mathrm{Sr}$ nos períodos de alta e baixa pluviosidade, indicaram que as amostras coletadas no periodo chuvoso são mais empobrecidas em Sr que as do seco, exceto a amostra ETE12B. Neste período, o valor máximo obtido foi na ETE8B (133 ppm). O valor mínimo observado encontra-se no período de maior pluviosidade na amostra ETE03B (39ppm).

A análise comparativa das concentrações $\mathrm{Zn}$ para os dois períodos de coleta, exibiu valores ligeiramente mais elevados nas amostras de Aterro do período seco. O teor máximo deste elemento no Aterro foi detectado na amostra ETE10B e o mínimo na ETE12B, ambos coletados no período seco.

$A$ concentração de $Z r$, variou de um período climático para outro, da mesma maneira que foi observado para o Co e Cr. A maior concentração observada deste elemento residiu nos Aterros do período chuvoso (467 ppm na estação ETE12B). Em contrapartida, o menor valor também foi observado neste período (189 ppm na estação ETE05B).

\section{C.Sedimento Aluvionar}

No contexto desta dissertação, foram incluídos os resultados obtidos para as amostras descritas e caracterizadas como Sedimento Aluvionar, objetivando correlacionar os valores de metais encontrados neste material com os detectados nos Sedimentos Argiloso e Aterro. Tal procedimento deve-se à possibilidade de que este sedimento possa ser o responsável pela provável contaminação do meio lacustre, mesmo não representando de fato, sedimento desta origem. Os valores de teores obtidos para este caso encontram-se nas Tabelas 38 e 39 para os dois períodos de coleta. 
Tabela 38 - Elementos menores detectados nas amostras de Sedimento ALUVIONAR (SUBAMOSTRAS DO TOPO - TE BASE - B) DO PERIODO CHUVOSO.

\begin{tabular}{|c|c|c|c|c|c|c|c|c|}
\hline homingrito & Bot & 20 & pring & $2 p$ & $h_{p}$ & som & $\frac{7}{2}+2$ & 20 \\
\hline ETEOIT & 685 & $<15$ & $<15$ & $<15$ & $<15$ & 103 & 57 & 398 \\
\hline ETEOIB & 619 & 16 & 44 & $<15$ & 28 & 72 & 77 & 536 \\
\hline ETEO2B & 807 & 59 & 75 & 21 & 16 & 82 & 88 & 343 \\
\hline ETE04B & 789 & 21 & 76 & 22 & 24 & 67 & 99 & 431 \\
\hline
\end{tabular}

TABELA 39 - ELEMENTOS MENORES DETECTADOS NAS AMOSTRAS DE SEDIMENTO ALUVIONAR (SUBAMOSTRAS DE TOPO - T E BASE - B) DO PERIODO SECO.

\begin{tabular}{|c|c|c|c|c|c|c|c|c|}
\hline 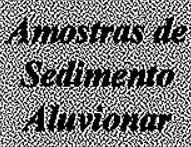 & bin & $c_{0}$ & 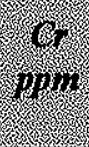 & rom & rit & S $p$ & 20 & in \\
\hline ETE01T & 600 & $<15$ & 56 & 17 & $<15$ & 99 & 60 & 191 \\
\hline ETEOIB & 317 & 18 & 25 & $<15$ & $<15$ & 52 & 48 & 620 \\
\hline ETEO2B & 1046 & 24 & 64 & 23 & 19 & 149 & 108 & 183 \\
\hline ETE04B & 595 & 41 & 82 & 23 & $<15$ & 86 & 54 & 497 \\
\hline
\end{tabular}

A análise comparativa entre os dois periodos de coleta para o elemento Ba no Sedimento Aluvionar, denotou maiores concentrações deste elemento no período chuvoso. A máxima observada foi detectada na amostra ETE02B (1046ppm) e a mínima na ETE01B (317ppm), ambas coletadas no período seco.

O Co neste material, concentrou-se mais nas amostras coletadas no período seco, com exceção da ETE02B. A concentração máxima obtida para este elemento foi observada na amostras ETE02B (59ppm) coletada no período chuvoso. Os valores mínimos de Co (menor que $15 \mathrm{ppm}$ ) foram obtidos tanto em um como no outro período climático, na mesma estações de coleta (ETE01B).

Os maiores e menores valores de $\mathrm{Cr}$ foram determinados tanto em um como no outro período climático de coleta (Tabelas 38 e 39). $O$ valor máximo observado neste caso, reside na coleta do período seco (82 ppm na estação ETE04B) e o mínimo (menor que $15 \mathrm{ppm}$ na estação ETE01T) na coleta do período chuvoso. 
A comparação dos teores de $\mathrm{Cu}$ em dois períodos climáticos distintos, demonstrou que este elemento concentra-se nas amostras de Sedimento Aluvionar coletadas no período seco. $\mathrm{O}$ valor máximo de $\mathrm{Cu}$ foi detectado nas amostras ETE02B e 04B (23 ppm) coletadas na estação climática seca. O valor mínimo de concentração de $\mathrm{Cu}$ observado foi encontrado tanto no período chuvoso (ETE01T e 01B) como no seco (ETE01B).

A mesma comparação de valores obtidas para o $\mathrm{Ni}$ neste caso, demonstrou serem os maiores teores detectados nas amostras do período de chuvoso. Nas amostras do período seco, a maioria das concentrações de $\mathrm{Ni}$ estavam abaixo do limite de deteç̧ão do aparelho. A concentração máxima obtida ficou na casa dos $28 \mathrm{ppm}$, sendo esta determinada na amostra ETE01B coletada no período chuvoso.

As concentrações de $\mathrm{Sr}$, variaram de um período de coleta para outro. A máxima observada foi de $149 \mathrm{ppm}$ na estação ETE02B e a mínima de $52 \mathrm{ppm}$ na estação ETE01B, ambas obtidas nas amostras coletadas no período seco.

Os resultados obtidos para o $\mathrm{Zn}$, refletiram o mesmo comportamento do $\mathrm{Sr}$ e $\mathrm{Cr}$, com distribuição aleatória de maiores e menores valores nos dois períodos de coleta. A máxima ficou na casa dos 108 ppm (Estação ETE02B) e a mínima em 48 ppm (ETE01B), ambas obtidas no período de coleta seco.

As concentrações obtidas para o $\mathrm{Zr}$, refletiram o mesmo comportamento que foi observado para $\circ \mathrm{Zn}, \mathrm{Sr}$ e $\mathrm{Cr}$, sendo a máxima concentração encontrada de 620 ppm (ETE01B) e a mínima de 183 ppm (ETE02B), ambas no período de coleta seco.

Os teores de $\mathrm{Cu}, \mathrm{Cr}, \mathrm{Zn}$ e $\mathrm{Ni}$ obtidos nos Aterros e Sedimentos Aluvionares não foram tratados no aplicativo "SURFER", bem como não foram calculados os valores numéricos para delimitação de contaminação pelos critérios de Fator de Contaminação e Igeo, pois estes não apresentaram as características necessárias para serem aplicados tais métodos. 


\section{2 - ÁGUA DA INTERFACE}

\subsection{1 pH e Eh}

A partir dos valores de $\mathrm{pH}$ obtidos no campo para a água da interface, nos dois períodos climáticos de coleta, elaborou-se a tabela abaixo.

TABELA 40 - Valores de PH obtidos nas amostras de AGUA DA INTERFACE, NOS PERIODOS CLIMATICOS CHUVOSO E SECO.

\begin{tabular}{|c|c|c|}
\hline rolomos & 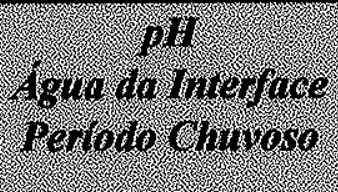 & 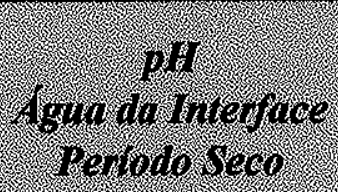 \\
\hline ETE OI & $n . d$ & 8,33 \\
\hline ETE 02 & 8,61 & 7,66 \\
\hline ETE 03 & $n . d$ & 7,76 \\
\hline ETE 04 & n.d & $n . d$ \\
\hline ETE 05 & 8,69 & 7,81 \\
\hline ETE 06 & 8,25 & 8,03 \\
\hline ETE 07 & 7,83 & 7,37 \\
\hline ETE 08 & 8,36 & 7,62 \\
\hline ETE 09 & 8,40 & 7,89 \\
\hline ETE 10 & 8,96 & 7,30 \\
\hline ETE 11 & 8,22 & n.d \\
\hline ETE 12 & 8,88 & 7,85 \\
\hline ETE 13 & 8,81 & n.d \\
\hline
\end{tabular}

n.d: Valores de pH não detectados para o período climático em questão.

Com base nesta tabela, aplicou-se o programa "SURFER" para obtenção dos mapas de isovalores deste parâmetro físico-químico em cada um dos períodos de coleta. Este procedimento visou a identificação da distribuição espacial deste parâmetro (Figuras 31 e 32 ). 


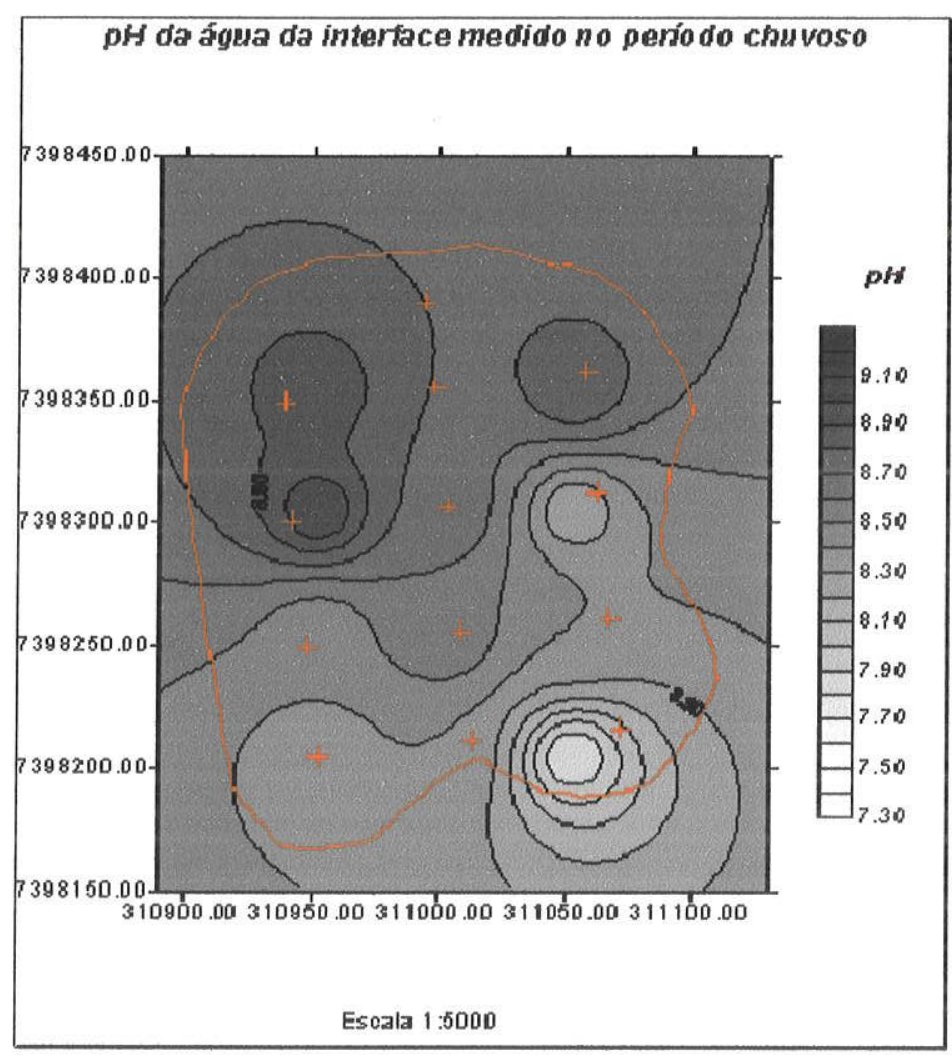

Figura 31 - Mapa de isovalores de pH para a água da interface coletada no período chuvoso.

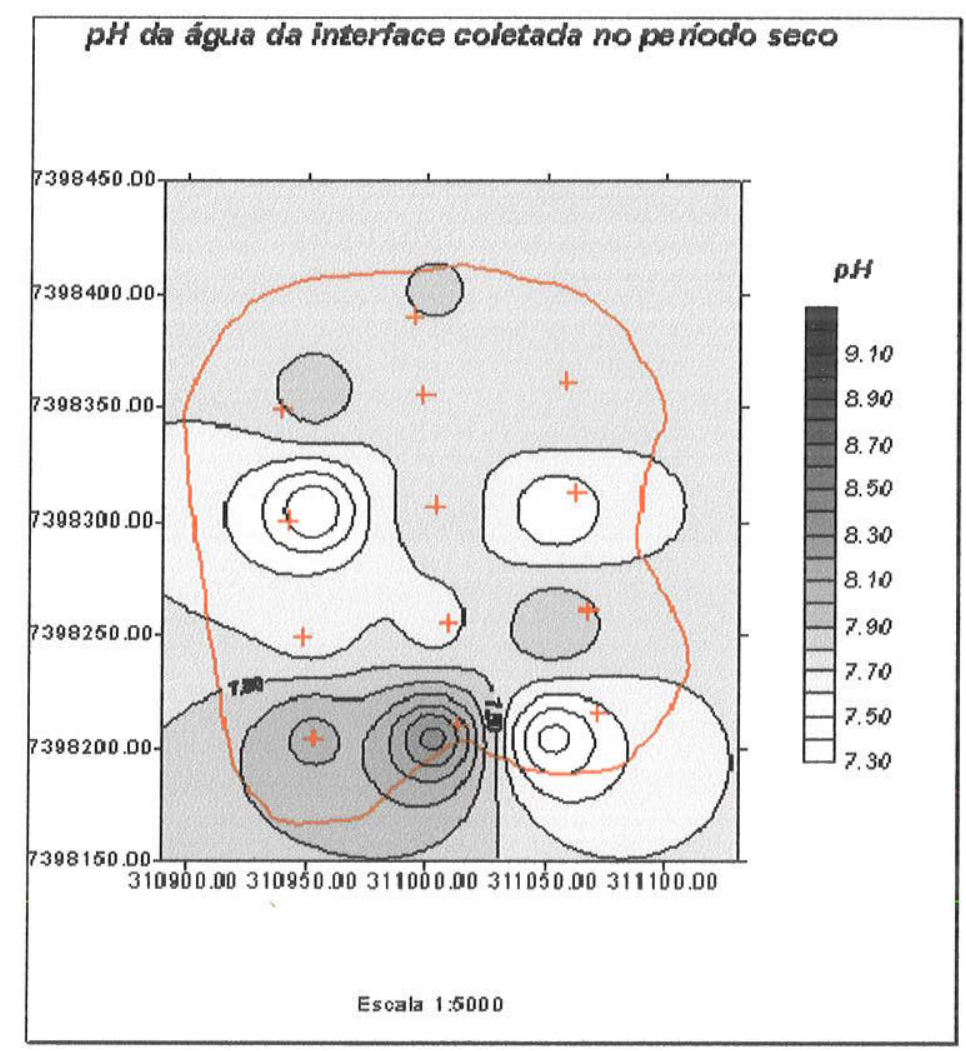

Figura 32 - Mapa de isovalores de pH obtidos na água da interface coletada no período seco. 
A partir dos resultados obtidos por este aplicativo, pode-se notar que os valores de $\mathrm{pH}$ da água da interface coletada no período climático chuvoso foram mais elevados que o do seco (Figuras 31 e 32). No período chuvoso, as amostras de água da interface foram classificadas como alcalinas $\mathrm{pH}$ maior que 8,20 , exceto para a amostra coletada na ETE 07), enquanto que as do período seco foram consideradas neutras tendendo a alcalinas $(\mathrm{pH}$ da ordem de 7,30 a 7,89, exceto para as amostras da ETE 01 e 06 que são mais alcalinas).

Com base ainda nestas mesmas figuras identificou-se que o valor mais baixo de $\mathrm{pH}$ para as águas coletadas nos dois períodos estava concentrado na estação de amostragem ETE07. O pH medido durante a estação chuvosa foi maior na porção noroeste do lago e menor na porção sudeste (Figura 31). $O$ pH da água da interface para o período seco é um pouco mais elevado na porção sudoeste do lago, sendo os menores valores observados nas amostras coletadas nas ETE07 e ETE10 (Figura 32).

No momento da obtenção do $\mathrm{pH}$, também o Eh foi determinado na água e os resultados encontram-se na Tabela 41.

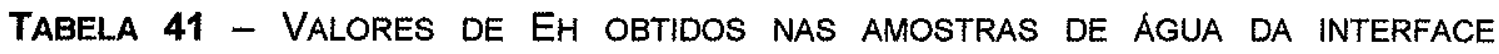
COLETADOS NOS PERIODOS CLIMATICOS CHUVOSO E SECO.

\begin{tabular}{|c|c|c|}
\hline horym & 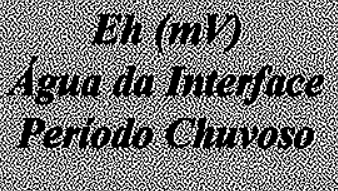 & 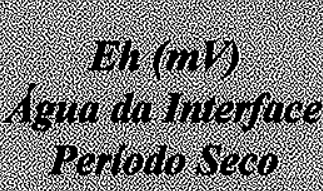 \\
\hline ETE 01 & n.d & 58,6 \\
\hline ETE 02 & 130,0 & 180,1 \\
\hline ETE 03 & n.d & 183,3 \\
\hline ETE 04 & n.d & n.d \\
\hline ETE 05 & 198,1 & 111,9 \\
\hline ETE 06 & 123,1 & 52,4 \\
\hline ETE 07 & 116,9 & 22,3 \\
\hline ETE 08 & 118,1 & 56,3 \\
\hline ETE 09 & 22,0 & 34,8 \\
\hline ETE 10 & 41,0 & 45,0 \\
\hline ETE II & 23,5 & $n . d$ \\
\hline ETE 12 & 41,4 & 70,5 \\
\hline ETE 13 & 38,8 & n.d \\
\hline
\end{tabular}


Com base nos dados obtidos na Tabela 41, foram construídos mapas de isovalores para Eh obtidos nas estações de coleta, visando a leitura da distribuição espacial neste meio lacustre deste parâmetro (Figuras 33 e 34).

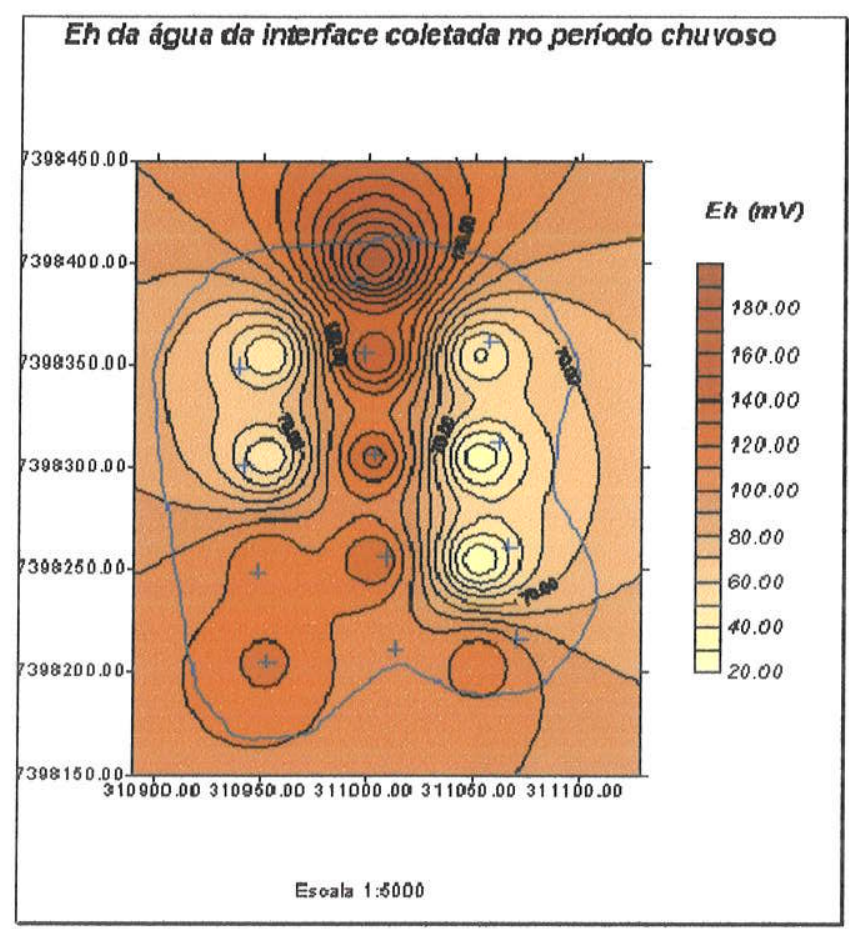

Figura 33 - Mapa de isovalores de Eh para água da interface do período chuvoso.

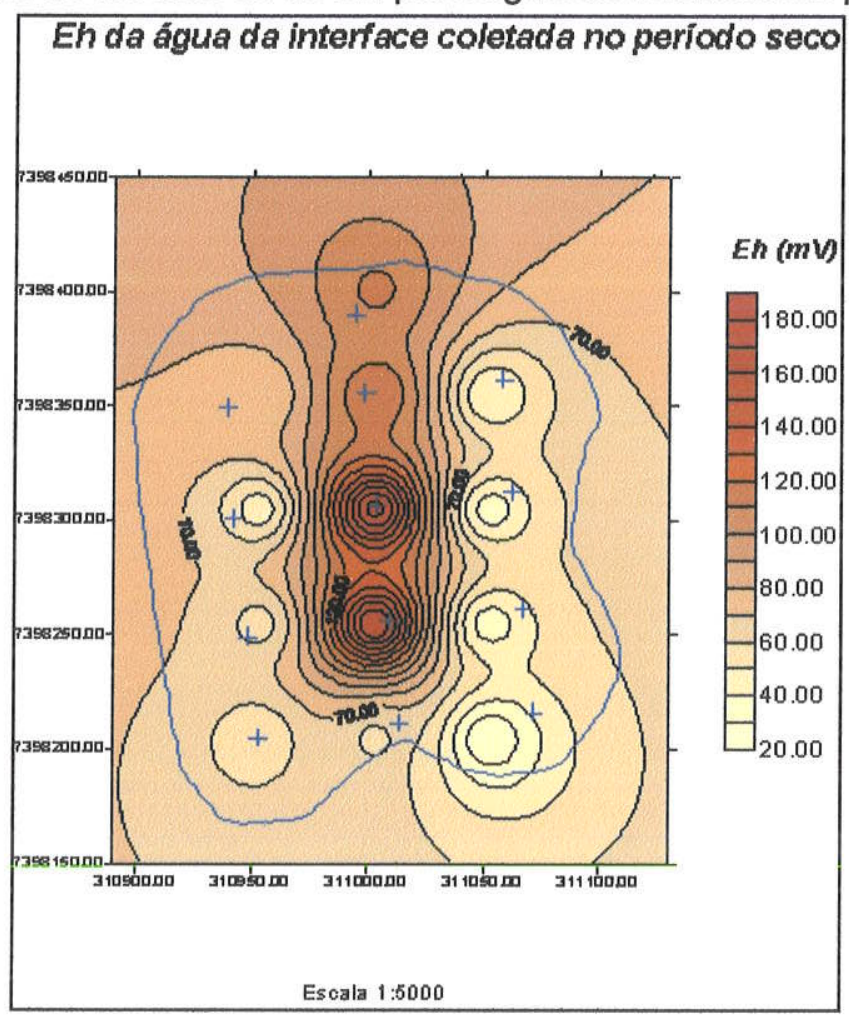

Figura 34 - Mapa de isovalores de Eh para água da interface do período seco. 
De um modo geral, a água da interface foi classificada como oxidante, para os dois períodos de análise (Tabela 41). No período chuvoso, verifica-se que os maiores valores encontram-se na porção $\mathbf{N}$ do lago (estações ETE05 e 04). Neste período, a máxima observada foi de $198 \mathrm{mV}$ na estação ETE05 e a mínima de $22 \mathrm{mV}$ (estação ETE09). No período seco, o campo de distribuição dos maiores valores sedia-se na parte central do lago (Estações ETE02 e 03), tendo o valor máximo compreendendo a casa do $180 \mathrm{mV}(180,1$ e $183,3 \mathrm{mV}$ em ETE02 e 03 respectivamente) e a mínima sediada na estação ETE07 com 22,3 mV (Figuras 33 e 34)

De maneira geral, os parâmetros físico-químicos medidos na água da interface indicaram que esta água apresentou-se alcalina e oxidante no período chuvoso, e neutra tendendo a alcalina e oxidante (Eh um pouco mais baixo que no chuvoso) no período seco.

\subsubsection{Análises Químicas Totais}

$\mathrm{Na}$ água de interface, foram também analisados os ânions $e$ os resultados encontram-se expostos nas Tabelas 42 e 43.

TABELA 42 - ANIONS DETECTADOS NAS AMOSTRAS DE AGUA DA INTERFACE COLETADA NO PERIODO CHUVOSO.

\begin{tabular}{|c|c|c|c|c|c|c|c|}
\hline 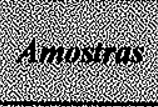 & 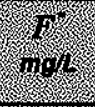 & $i_{2}$ & Not & $84 r_{2}$ & hos & 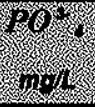 & rot \\
\hline \multicolumn{8}{|l|}{ Limite de } \\
\hline Deteç̧ão & 0,016 & 0,070 & 0,005 & 0,005 & 0,011 & 0,010 & 0,020 \\
\hline ETEOI & n.d & n.d & n.d & n.d & $n \cdot d$ & n.d & n.d \\
\hline ETE 02 & 0,04 & 74,73 & $n \cdot d$ & 0,04 & 1,00 & 0,65 & 125,25 \\
\hline ETE 03 & n.d & n.d & $n . d$ & $n . d$ & n.d & $n \cdot d$ & $n . d$ \\
\hline ETE 04 & 0,36 & 74,89 & $n \cdot d$ & 0,04 & 0,58 & 0,20 & 124,48 \\
\hline ETE 05 & 0,36 & 72,54 & $n . d$ & 0,05 & 0,93 & 0,37 & 124,13 \\
\hline ETE 06 & 0,36 & 71,48 & $n . d$ & 0,04 & 0,70 & 0,77 & 123,18 \\
\hline ETE 07 & 0,35 & 69,56 & $n . d$ & 0,05 & 0,04 & 0,04 & 118,08 \\
\hline ETE 08 & 0,36 & 70,97 & $n \cdot d$ & 0,05 & 0,88 & 0,17 & 122,62 \\
\hline ETE 09 & n.d & n.d & n.d & n.d & n.d & n.d & n.d \\
\hline ETE 10 & 0,37 & 72,45 & $n . d$ & 0,05 & 0,21 & 0,05 & 124,25 \\
\hline ETE II & 0,37 & 82,76 & $n . d$ & 0,04 & 0,87 & 0,23 & 122,75 \\
\hline ETE 12 & 0,40 & 72,01 & $n \cdot d$ & 0,05 & 1,25 & 0,15 & 124,05 \\
\hline ETE 13 & 0,35 & 73,45 & n.d & 0,05 & 0,19 & 0,02 & 123,49 \\
\hline
\end{tabular}


TABELA 43 - ÂNIONS DETECTADOS NAS AMOSTRAS DE AGUA DA INTERFACE COLETADA NO PERIODO SECO.

\begin{tabular}{|c|c|c|c|c|c|c|c|}
\hline Anorion & 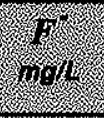 & 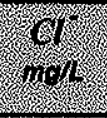 & 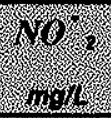 & 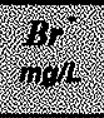 & not & por & rop \\
\hline \multicolumn{8}{|l|}{ Limite de } \\
\hline Detecção & 0,016 & 0,070 & 0,005 & 0,005 & 0,011 & 0,010 & 0,020 \\
\hline ETE OI & 0,41 & 79,96 & 0,00 & 0,00 & 0,18 & 0,03 & 139,22 \\
\hline ETE 02 & 0,43 & 83,92 & 0,00 & 0,00 & 0,74 & 0,03 & 134,59 \\
\hline ETE 03 & 0,40 & 78,75 & 0,00 & 0,03 & 0,31 & 0,00 & 136,52 \\
\hline ETE 04 & 0,43 & 79,51 & 0,00 & 0,00 & 1,35 & 0,45 & 132,52 \\
\hline ETE 05 & 0,39 & 82,88 & 0,00 & 0,00 & 0,27 & 0,01 & 138,41 \\
\hline ETE 06 & 0,46 & 95,51 & 0,00 & 0,00 & 0,92 & 0,03 & 168,22 \\
\hline ETE 07 & 0,69 & 81,69 & 0,00 & 0,00 & 0,28 & 0,02 & 130,49 \\
\hline ETE 08 & 0,44 & 78,42 & 0,00 & 0,03 & 0,31 & 0,02 & 132,97 \\
\hline ETE 09 & 0,45 & 75,92 & 0,00 & 0,03 & 0,38 & 0,01 & 132,87 \\
\hline ETE 10 & 0,49 & 78,12 & 0,00 & 0,03 & 0,76 & 0,02 & 130,66 \\
\hline ETE 11 & nd & $n d$ & nd & nd & nd & nd & $n d$ \\
\hline ETE 12 & nd & nd & nd & nd & $n d$ & $n d$ & nd \\
\hline ETE 13 & nd & nd & no & $n d$ & nd & nd & nd \\
\hline
\end{tabular}

As águas da interface, nos dois períodos de coleta, apresentaram os seguintes ânions em sua composição: $\mathrm{F}^{-}, \mathrm{Cl}^{-}, \mathrm{NO}_{3}^{-}, \mathrm{PO}_{4}^{3-}$ e $\mathrm{SO}^{2-}{ }_{4} . \mathrm{O} \mathrm{Br}^{-}$foi detectado em concentrações próximas ao limite de detecção do aparelho, sendo que no período seco este não foi detectado na maioria das estações de amostragem. Estas águas são mais enriquecidas em $\mathrm{Cl}^{-}$e $\mathrm{SO}^{2 .}{ }_{4}$, sendo os outros elementos considerados secundários ou traços. Verificou-se que os teores de $\mathrm{Cl}^{-}$e $\mathrm{SO}^{2-}{ }_{4}$ no período seco, apresentaram-se mais elevados que no chuvoso (Tabelas 42 e 43).

A determinação dos cátions nestas mesmas amostras de água, resultaram nos seguintes dados exibidos nas Tabelas 44 e 45 . 
TABELA 44 - CÁTIONS DETECTADOS NAS AMOSTRAS DE AGUA DA INTERFACE COLETADAS NO PERIODO CHUVOSO.

\begin{tabular}{|c|c|c|c|c|c|c|c|c|}
\hline Wovos & $x^{2}$ & 48 & $\frac{6}{6}$ & 46 & 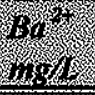 & 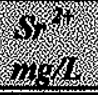 & 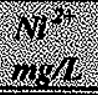 & 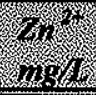 \\
\hline \multicolumn{9}{|l|}{ Limite de } \\
\hline Deteç̧ão & 0,200 & 0,003 & 0,050 & 0,020 & 0,180 & 0,050 & 0,040 & 0,008 \\
\hline ETE OI & n.d & $n . d$ & $n . d$ & n.d & $n . d$ & n.d & n.d & $n . d$ \\
\hline ETE 02 & 84,200 & 15,900 & 0,040 & 0,010 & 0,110 & 0,850 & 0,030 & 0,110 \\
\hline ETE O3 & n.d & n.d & n.d & n.d & n.d & $n . d$ & n.d & n.d \\
\hline ETE 04 & $n d$ & $n . d$ & $n . d$ & $n . d$ & n.d & n.d & $n . d$ & $n . d$ \\
\hline ETE 05 & 84,600 & 15,900 & 0,020 & 0,030 & 0,100 & 0,810 & 0,030 & 0,190 \\
\hline ETE 06 & 85,000 & 15,450 & 0,040 & 0,030 & 0,100 & 0,830 & 0,020 & 0,580 \\
\hline ETE 07 & 84,400 & 15,850 & 0.050 & 0,240 & 0,110 & 0,840 & 0,020 & 0,260 \\
\hline ETE 08 & 85,800 & 15,750 & 0,040 & 0,000 & 0,110 & 0,850 & 0,020 & 0,460 \\
\hline ETE 09 & n.d & $n . d$ & n.d & n.d & n.d & n.d & n.d & $n . d$ \\
\hline ETE 10 & 82,600 & 16,100 & 0,040 & 0,010 & 0,140 & 0,860 & 0,020 & 0,400 \\
\hline ETE 11 & 83,800 & 15,850 & 0,190 & 0,090 & 0,150 & 0,850 & 0,030 & 0,090 \\
\hline ETE 12 & 85,800 & 16,150 & 0,040 & 0,010 & 0,110 & 0,860 & 0,020 & 0,520 \\
\hline ETE 13 & 88,800 & 15,900 & 0,130 & 0,030 & 0,130 & 0,880 & 0,020 & 0,400 \\
\hline
\end{tabular}

${ }^{*}$ n.d: Valores de pH não detectados para o período climático em questão.

TABELA 45 - CÁtIONS DETECTADOS NAS AMOSTRAS de ÁGUA DA INTERFACE COLETADAS NO PERIODO SECO.

\begin{tabular}{|c|c|c|c|c|c|c|c|c|c|}
\hline mosinos & mgh & 28 & $77^{2}$ & 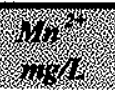 & 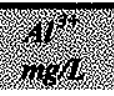 & 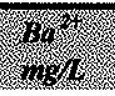 & (s) & Nor & ro \\
\hline \multicolumn{10}{|l|}{ Limite de } \\
\hline Detecção & 0,200 & 0,003 & 0,050 & 0,020 & 0,550 & 0,180 & 0,050 & 0,040 & 0,050 \\
\hline ETE 01 & 95,100 & 17,850 & 0,040 & 0,050 & 0,110 & 0,110 & 0,930 & 0,020 & 0,010 \\
\hline ETE 02 & 96,300 & 17,600 & 0,050 & 0,060 & 0,150 & 0,200 & 0,930 & 0,010 & 0,000 \\
\hline ETE 03 & 94,350 & 17,550 & 0,030 & 0,010 & 0,110 & 0,190 & 0,910 & 0,020 & 0,000 \\
\hline ETE 04 & 92,000 & 16,950 & 0,050 & 0,170 & 0,130 & 0,110 & 0,810 & 0,010 & 0,000 \\
\hline ETE 05 & 92,750 & 16,950 & 0,030 & 0,010 & 0,110 & 0,180 & 0,900 & 0,010 & 0,010 \\
\hline ETE 06 & 92,000 & 16,950 & 0,030 & 0,020 & 0,130 & 0,190 & 0,940 & 0,010 & 0,000 \\
\hline ETE 07 & 92,400 & 15,850 & 0,140 & 0,560 & 0,180 & 0,440 & 0,760 & 0,010 & 0,000 \\
\hline ETE 08 & 91,400 & 16,900 & 0,040 & 0,060 & 0,090 & 0,210 & 0,890 & 0,010 & 0,020 \\
\hline ETE 09 & 94,920 & 17,200 & 0,050 & 0,020 & 0,150 & 0,200 & 0,900 & 0,010 & 0,000 \\
\hline ETE 10 & 91,850 & 16,600 & 0,520 & 0,500 & 0,110 & 0,210 & 0,880 & 0,010 & 0,000 \\
\hline ETE 11 & nd & nd & nd & $n d$ & nd & nd & nd & nd & nd \\
\hline ETE 12 & nd & nd & nd & $n d$ & nd & nd & $n d$ & nd & nd \\
\hline ETE 13 & nd & $n d$ & $n d$ & nd & $n d$ & nd & nd & nd & nd \\
\hline
\end{tabular}

${ }^{\star} n$.d: Valores de $\mathrm{pH}$ não detectados para o periodo climático em questão.

Os cátions detectados na água da interface, para os dois períodos de amostragem foram: $\mathrm{Ca}^{2+}, \mathrm{Mg}^{2+}, \mathrm{Fe}$ Total $\mathrm{Mn}^{2+}, \mathrm{Sr}^{2+}, \mathrm{Ba}^{2+}$ e $\mathrm{Ni}^{2+}$. As concentrações de $\mathrm{Ca}^{2+}$ e $\mathrm{Mg}^{2+}$ foram mais expressivas, enquanto que as dos outros cátions foram consideradas traços (Tabelas 44 e 45 ). Estes dois elementos foram detectados em maiores concentrações nas águas referentes 
ao período seco. $\mathrm{O} \mathrm{Zn}^{2+}$ foi detectado apenas na água coletada no período chuvoso, este estava um pouco acima do limite de detecção do aparelho.

De um modo geral, apenas o $\mathrm{Zn}$ foi detectado nas amostras de água, visto que os outros $(\mathrm{Cu}, \mathrm{Cr}$ e $\mathrm{Ni})$, encontram-se abaixo do limite de deteç̧ão do aparelho. Nesta água, não foram calculados os valores de Fator de Contaminação e do Índice de Geoacumulação dos metais pesados de interesse, pois conforme os resultados expostos, esta água não contém tais metais em sua composição ou estes quando presentes estão em baixas concentraçöes. 


\section{3 - SEDIMENTO PARTICULADO EM SUSPENSÃO}

Nesta dissertação houve possibilidade de serem obtidos os sedimentos particulados em suspensão a partir dos filtros millipore de $0,8 \mu \mathrm{m}$ e neles foram executadas análises químicas qualitativas com MEV/EDS dos metais pesados, detectados nas amostras deste sedimento. Os metais pesados analisados ( $\mathrm{Ni}$, $\mathrm{Cr}, \mathrm{Zn}$ e eventualmente $\mathrm{Cu}$ ) foram encontrados, na maioria das vezes, no interior de cavidades geradas na filtragem das amostras (Figura 35), dificultando, em parte, a obtenção de imagens e a qualidade dos dados químicos qualitativos. Nos espectros obtidos, verifica-se que $\mathrm{Ni}, \mathrm{Cr}$ e $\mathrm{Zn}$, no geral, encontram-se associados à presença de $\mathrm{Fe}, \mathrm{Al}, \mathrm{Si}, \mathrm{S}$ (Figuras 36 e 37) e em alguns casos aos elementos terras raras (ETR). Por outro lado o $\mathrm{Cu}$, quando presente, é encontrado preferencialmente em associação com os elementos terras raras (Figura 38). $\mathrm{O} \mathrm{Cr}$ e $\mathrm{Ni}$ são os metais pesados mais freqüentes, aparecendo em todas as amostras analisadas de sedimento particulado em suspensão.

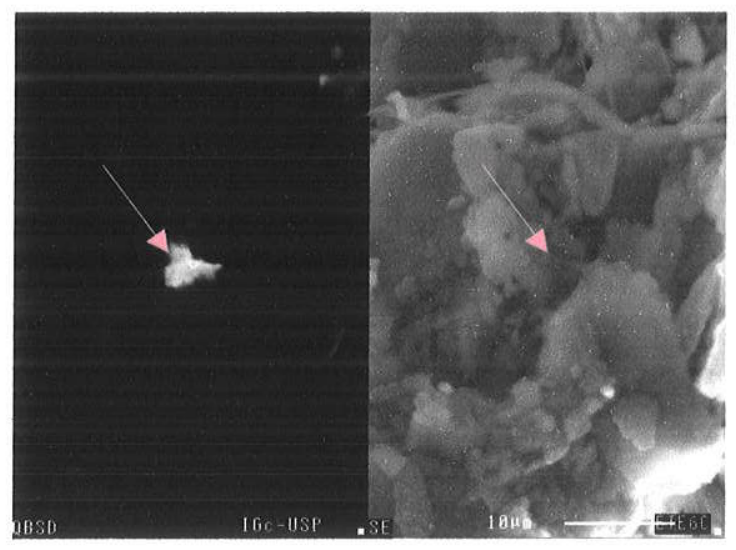

Figura 35 - Imagem de partícula metálica (partícula brilhante, imagem do lado esquerdo) detectada no interior de uma cavidade. Imagem Split, obtida com Eletroretroespalhados e Secundários.

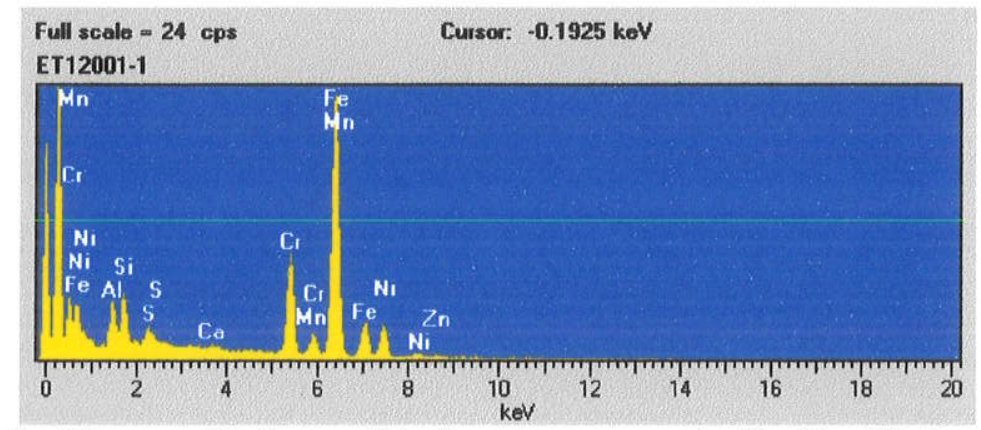

Figura 36 - Análise qualitativa exibindo a presença de $\mathrm{Cr}, \mathrm{Zn}, \mathrm{Ni}, \mathrm{Fe}, \mathrm{S}$, Si e Al no ponto analisado na figura 35 . 


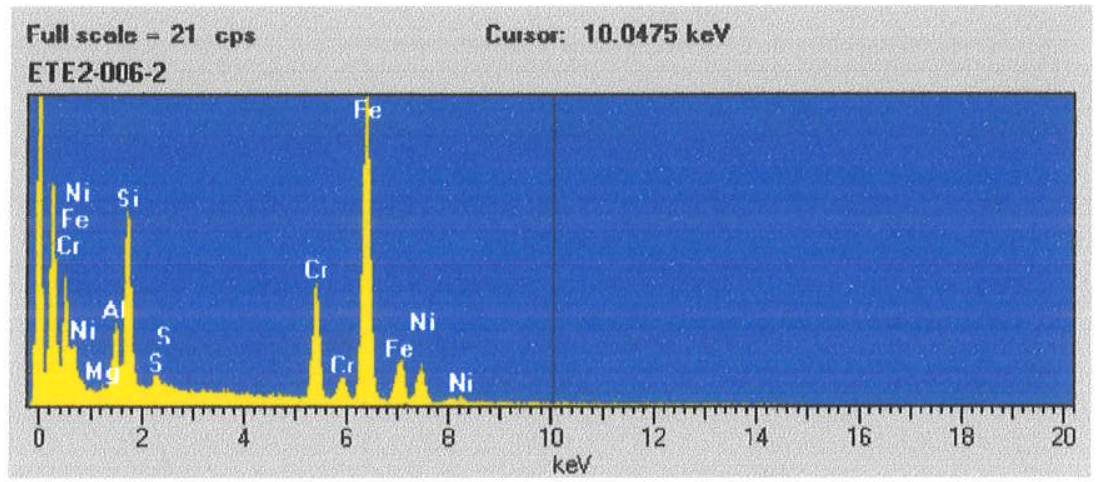

Figura 37 - Análise qualitativa realizada no ponto brilhante localizado na porção sudeste da figura 35 (imagem à direita), indicando a presença de $\mathrm{Cr}, \mathrm{Ni}, \mathrm{Fe}, \mathrm{Al}, \mathrm{Si}$ e $\mathrm{S}$.

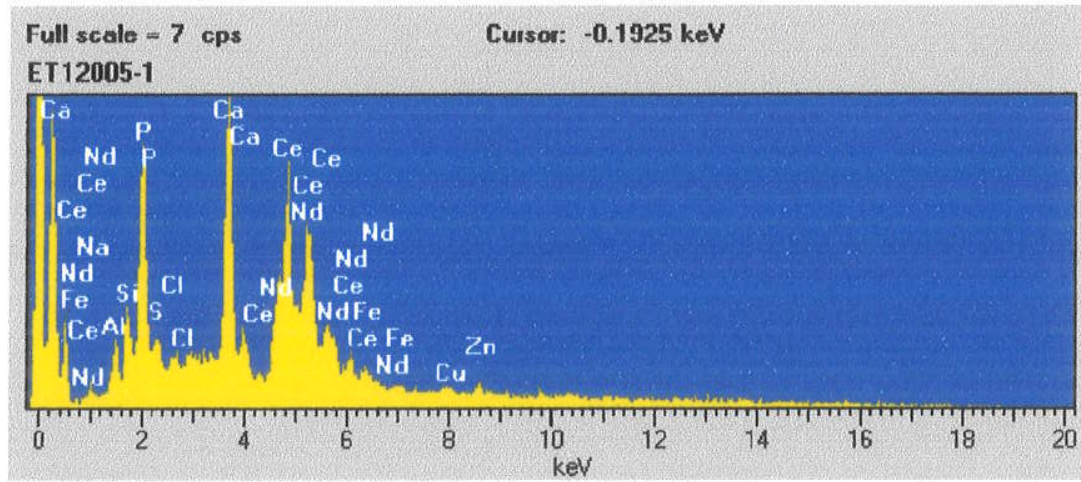

Figura 38 - Análise qualitativa de outro ponto localizado na porção sudoeste da figura 35 (imagem do lado direito), indicando a presença de $\mathrm{Ce}, \mathrm{Nd}, \mathrm{Cu}, \mathrm{Zn}$ e Ni.

A matriz que compõem o sedimento particulado em suspensão, contém principalmente $\mathrm{Fe}, \mathrm{Si}, \mathrm{Al}$ e $\mathrm{S}$, como pode ser observado na Figura 39. Em algumas amostras neste mesmo sedimento, identifica-se a presença de Mg, $\mathrm{Mn}, \mathrm{K}$ e Ca, na matriz.

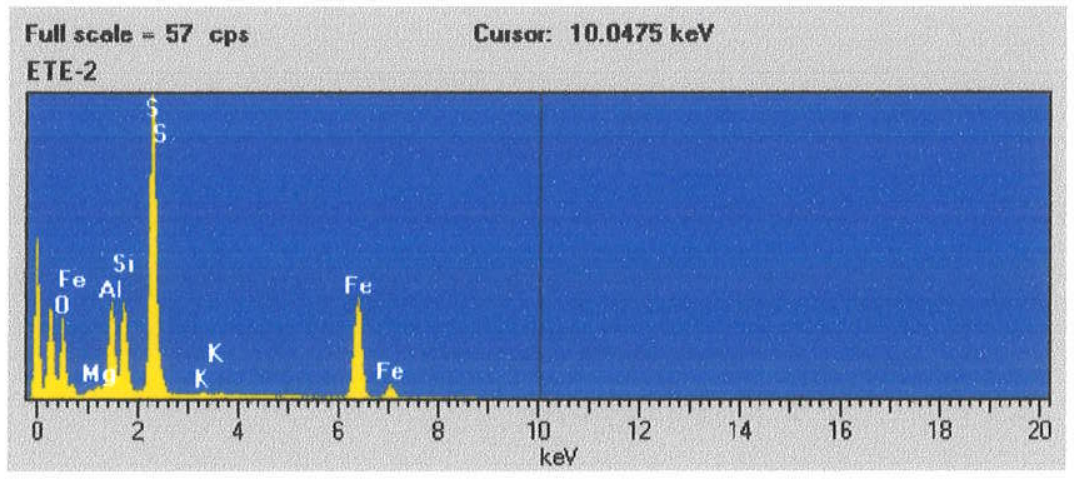

Figura 39 - Análise qualitativa de um ponto localizado na porção sudoeste da figura 35 , indicando a presença de $\mathrm{K}, \mathrm{S}, \mathrm{Al}, \mathrm{Ni}$ e Fe.

Em boa parte das amostras de sedimento particulado em suspensão analisadas em EMVIEDS, foi identificada a presença de Elementos Terras Raras (ETR), estando estes representados principalmente por Cério (Ce) e 
Neodímio (Ne) (Figura 40). Em alguns amostras de sedimento particulado em suspensão encontrou-se Tório (Th) (Figura 40).

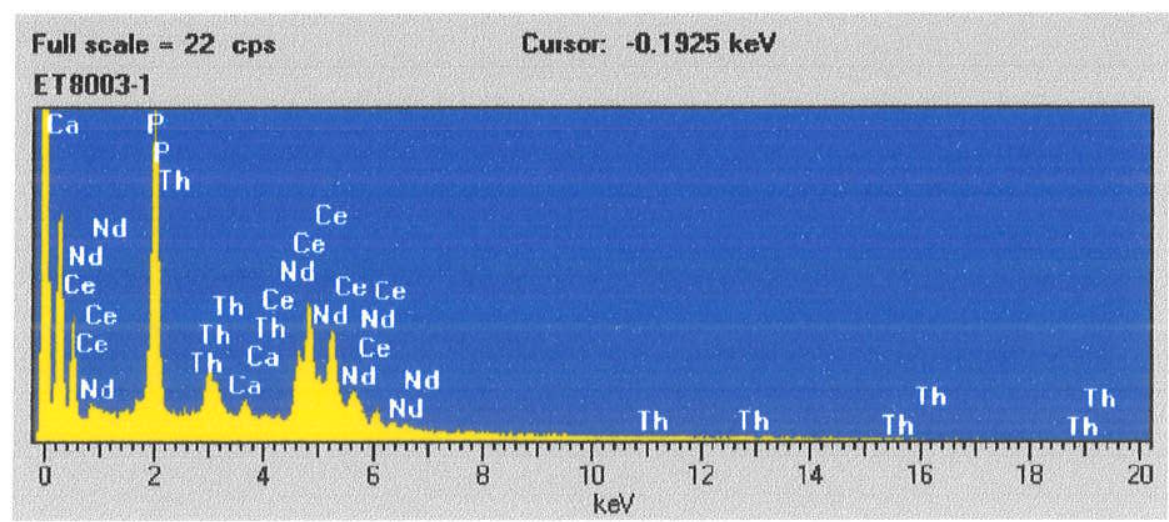

Figura 40 - Análise qualitativa indicando a presença de Ce e Nd, Th, Cu, Ca e Mn. Outro ponto analisado na amostra da figura 35.

Nas amostras de sedimento particulado em suspensão foram observadas extensas colônias planctônicas (Figura 41), entretanto estas não foram classificadas (sistematizadas), uma vez que tal procedimento não enseja a proposta de trabalho desta dissertação. Algumas análises químicas qualitativas com Eletroretrodifusos sobre estes organismos foram realizadas, visando detectar a presença dos metais pesados, não logrando êxito neste aspecto.

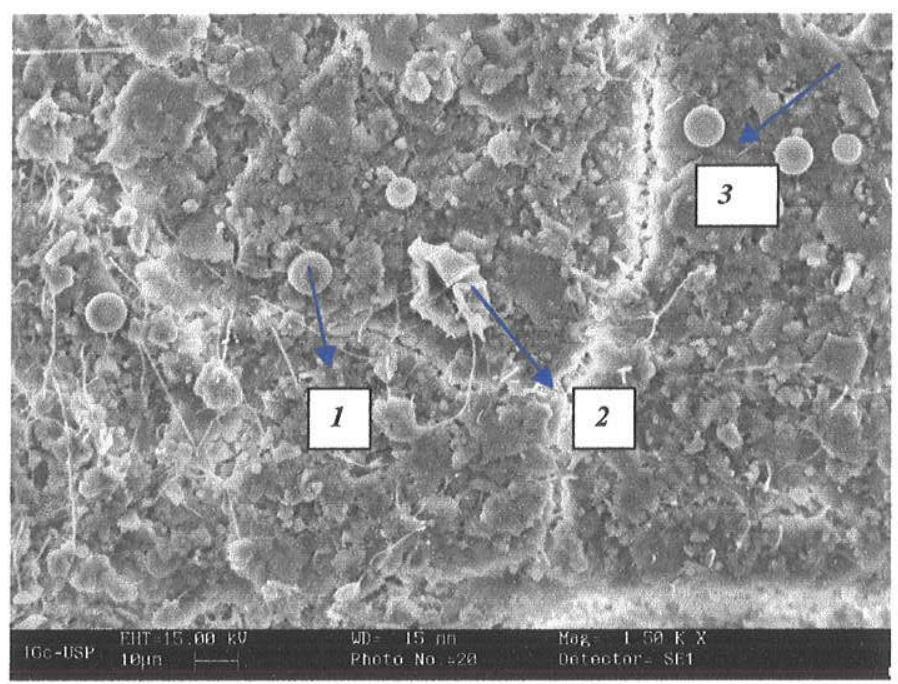

Figura 41 - Comunidade de fitoplânctons detectados no sedimento particulado, representadas por três grupos distintos. 


\section{6 - DISCUSSÕES}

Pretende-se neste capitulo estabelecer alguns esclarecimentos de ordem interpretativa, bem como alguns aspectos discutíveis obtidos com os dados do capítulo Resultados. Esta abordagem restringe-se aos resultados das amostras de sedimento de fundo (principalmente os Sedimentos Argilosos), água da interface e sedimento particulado em suspensão.

\section{1 - SEDIMENTO DE FUNDO}

Surpreendentemente, constatou-se a existência de três materiais distintos compondo o compartimento referente ao sedimento de fundo, ao contrário do que se era esperado, pois acreditava-se apenas na existência de sedimentos de origem lacustres, produtos da atual sedimentação. Neste lago, além dos sedimentos lacustres (Sedimentos Argilosos), foram detectados materiais de origem antrópica (Aterro) e de origem fluvial (Sedimentos Aluvionares), os primeiros originados a partir do aterramento da área que compreende a ETE e o segundo resultado da antiga sedimentação do rio Tietê uma vez que esta área representa antiga faixa de várzea deste rio. RIBEIRO et al. (2001), demonstraram a existência de Materiais de Aterro e de Sedimentos Aluvionares; mesmos materiais detectados no lago estudado; a partir de uma tradagem compondo um perfil de solo localizado próximo a borda oeste deste ambiente lacustre, confirmando assim nas margens, a existência destes mesmos materiais observados nos sedimentos de fundo do ambiente lacustre analisado.

A partir das análises realizadas sobre os sedimentos de origem lacustres (Sedimentos Argilosos), verificou-se com certa surpresa que estes sedimentos coletados durante a estação climática seca apresentaram maiores teores de umidade que as do chuvoso, ao contrário do que se esperava. Tal fato, possivelmente pode ser explicado, devido ao sedimento coletado no período climático chuvoso ter permanecido mais tempo na estufa que os do seco, o que deve ter contribuído para maior perda da água. 
Nas determinações dos teores de matéria orgânica, ficou constatado que os Sedimentos Argilosos, de maneira geral, são mais ricos em matéria orgânica se comparados com os Aterros e Sedimentos Aluvionares, conforme exibem as Tabelas 8, 9 e 10, como era de se esperar. A presença desta maior quantidade de matéria orgânica em tais sedimentos, deve-se ao fato de que estes materiais interagem de modo mais efetivo com os sedimentos em suspensão e com o fitoplâncton, permitindo assim maior acúmulo no sedimento a ser precipitado no fundo do lago acompanhado da matéria orgânica.

Dos três materiais detectados no lago, os Sedimentos Argilosos foram os únicos a exibirem características granulométricas capazes de reterem os metais pesados, pois estes apresentaram fração silte-argilosa a silte, enquanto os outros dois exibiram frações mais grossas. Estas características se coadunam com as observações de GIBBS (1977); JURASIC apud SINGH et al., (1999) para contaminações em sedimentos lacustres. Este resultado, justifica o tratamento dos dados diferenciados para o Sedimento Argiloso, no SURFER e na verificação da sua provável contaminação.

Nos períodos de coleta chuvoso e seco, verificou-se que há pequena mudanças no comportamento geral dos valores obtidos de $\mathrm{pH}$ nos sedimentos lacustres. Os resultados obtidos no período chuvoso tendem a maior alcalinidade que os do seco, sendo estes últimos mais neutros. O maior aporte de materiais provenientes do lodo para o lago, no período chuvoso, possivelmente explica o aumento de $\mathrm{pH}$ neste período. Tal fato pode ser confirmado pelos valores observados no $\mathrm{pH}$ do lodo o qual, quando fresco atinge 12 e descresce gradativamente a neutralidade em função do tempo, como demonstrou ASSUNÇÃO (1996). Desta forma, provavelmente no período seco, não há influência do lodo sobre a sedimentação no meio lacustre, permitindo assim que ocorra estabilização do pH em direção a neutralidade. Esta explicação não se aplica ao ponto ETE08, que apresentou valores sempre ácidos de $\mathrm{pH}$, comportamento este que não se encontrou explicação adequada.

Os valores obtidos para Eh não coincidem com o hipoteticamente esperado, aguardava-se encontrar valores de maior oxidação nas estações de amostragem mais rasas e de maior redução nas estações mais profundas. 
Segundo as análises dos elementos maiores, ficou demonstrado que as concentrações de Silício, Alumínio e Ferro são maiores nas amostras coletadas durante o período de alta pluviosidade. Provavelmente a explicação para este fato esteja ligada ao maior aporte de sedimentos clásticos em direção a sedimentação do lago neste período. A similaridade do comportamento do Potássio e Manganês com o Alumínio, Silício e Ferro, possivelmente deve-se ao fato de que estes são produtos da decomposição das rochas que circundam a ETE de Barueri, ou seja, granitos, gnaisses e migmatitos, milonitizados ou não. Por outro lado, o Manganês não se coaduna com esta explicação e pode provir de outra fonte, provavelmente do lodo de esgoto circunscrito a parte do ambiente lacustre. O Cálcio e o Sódio, apresentaram comportamento inverso aos dos outros elementos maiores já mencionados, tal fato pode possivelmente estar ligado ao comportamento geoquímico destes elementos que são de muita mobilidade em ambientes tropicais, com isso, no período mais chuvoso, estes são lixiviados e dissolvidos enquanto que, no período seco, estes aumentam sua concentração face a evaporação do meio lagunar podendo até a virem se depositar na forma de sais.

Os quatro metais pesados analisados $(\mathrm{Cu}, \mathrm{Cr}, \mathrm{Zn}$ e $\mathrm{Ni})$, apresentaram forte caráter depletivo na amostra de Sedimento Argiloso coletada na ETE08, tal aspecto pode ser explicado pelos valores de $\mathrm{pH}$ obtidos nesta estação, ou seja, sempre ácido, conforme já mencionado por SÍGOLO e GUIMARÃES (2001). Este valor de pH possivelmente deve estar contribuindo para maior mobilidade dos metais neste ponto em virtude destes sempre terem apresentado menor concentrações que o restante. Considerando que estes metais sempre apresentam maior mobilidade quando os valores de $\mathrm{pH}$ apresentam-se ácidos (SALOMONS e STIGLIANI, 1995), acredita-se que esta seja a razão dos teores exibirem sempre valores depletivos neste ponto. Somase a este aspecto, o fato de que o Aterro subamostrado na base do "core" coletado na ETE08, exibiu teores de $\mathrm{Cu}, \mathrm{Cr}, \mathrm{Zn}$ e $\mathrm{Ni}$ mais elevados que as outras amostras (Tabelas 26, 27, 36 e 37). Confirmando assim o caracter de maior mobilidade destes quatro metais nesta estação de amostragem. Acredita-se que dadas as condições deste local, esteja ocorrendo migração 
dos metais pesados do Sedimento Argiloso para a base (Aterro) e com conseqüente retenção neste ponto.

Os valores elevados de Bário, Cobalto, Estrôncio e Zircão no Aterro, aparentemente são provenientes do transporte de solos de alteração das rochas circunvizinhas ao lago.

A partir da análise das curvas de concentração do $\mathrm{Cu}$, no período chuvoso e seco, e das curvas de isovalores de $\mathrm{pH}$ e $\mathrm{Eh}$, verifica-se provável correlação do Eh com a concentração dos metais, pois os maiores valores observados foram detectados nas mesmas estações onde o Eh era mais redutor.

A mesma consideração pode ser apontada para as curvas do $\mathrm{Cr}$ obtidas para as amostras do período chuvoso, pois estas também exibiram certa correlação com as curvas de Eh ou seja, quanto mais redutor é o Eh, maiores concentrações de $\mathrm{Cr}$ são observadas.

Comparando-se as curvas de isovalores de $\mathrm{pH}$ e Eh com as de concentração de $\mathrm{Ni}$, verifica-se que este encontra-se influenciado diretamente pelos dois parâmetros, $\mathrm{pH}$ e Eh, pois quando o pH é alcalino, ocorre diminuição das concentrações de $\mathrm{Ni}$. Por outro lado, quanto mais redutor o sedimento maior é a concentração de $\mathrm{Ni}$.

A construção e comparação das curvas de isovalores para o Eh com as curvas de isoteores para o $\mathrm{Zn}$, tanto em um como no outro período de coleta, exibe similaridade, sugerindo assim que este metal esteja sendo influenciado diretamente pelos valores deste parâmetro.

As curvas de isoconcentração química para $\mathrm{Cu}, \mathrm{Cr}, \mathrm{Zn}$ e Ni, exibiram maiores valores de isoconcentração na estação ETE06 e 07. No caso da ETE06 estes maiores valores devem-se a influência do lodo sobre este ponto, uma vez que o lodo está depositado nas margens sul e oeste deste lago, muito próximos desta estação. Para a ETE07, este aumento de valores pode ser explicado possivelmente pela direção preferencial dos ventos que devem estar colocando os sedimentos de fundo em resuspensão e consequentemente transportando-os na direção da estação. Tal influência dos ventos na resuspensão de sedimentos encontram apoio em SALOMONS e BACCINI, (1986). 
A comprovação ou não de contaminação dos Sedimentos Argilosos, depende do critério de deteç̧ão a ser utilizado. Quando aplicou-se o Igeo, verificou-se que a totalidade dos sedimentos analisados compreendiam o campo da não contaminação da amostra nos dois períodos de coleta para os quatro metais investigados. Quando aplicou-se o Fator de Contaminação para os teores obtidos destes metais, nota-se que em algumas estações de amostragem os sedimentos passam a ser considerados contaminados. Segundo CALMANO \& FÖRSTNER (1996), o emprego indiscriminado do Índice de Geoacumulação como forma de análise de meios contaminados ou não, tende a minimizar o impacto de contaminação devido ao fator de correção 1,5 (esse fator é artificial não condizendo como a realidade do lugar contaminado), como comprovado nesta pesquisa, pois nas amostras que foram comparados enriquecimentos de metais pelo Fator de Correção o Igeo continuou sendo zero.

O Cromo foi o único dos quatro metais que, segundo os métodos aplicados para verificar a possivel contaminação, exibiu resultados que não implicavam na contaminação do ambiente lacustre investigado.

\section{2 - AGUA DA INTERFACE}

Dos quatro metais de interesse, na água da interface só foi detectado o $\mathrm{Zn}$, e este foi encontrado em concentrações próximas ao limite de detecção do aparelho utilizado. Tal fato possivelmente está ligado a maior estabilidade dos metais, pois estes como citado anteriormente, estão sofrendo precipitação e retenção no compartimento representado pelo sedimento de fundo (Sedimento Argiloso). A presença de $\mathrm{SO}_{4} \mathrm{e} \mathrm{Cl}$ na composição da água da interface, sugere que $\circ \mathrm{Zn}$ pode estar formando composto com estes ânions, em uma ou em ambas formas, explicando possivelmente o porque de sua presença na forma solúvel.

\section{3 - SEDIMENTO PARTICULADO EM SUSPENSÃO}

A presença dos metais pesados $\mathrm{Cr}, \mathrm{Zn}$ e $\mathrm{Ni}$ e eventualmente $\mathrm{Cu}$ no sedimento particulado em suspensão pode estar indicando um aporte de metais pesados do resíduo localizado na borda oeste deste ambiente lacustre, ou a intercomunicação entre as diferentes fases deste lago (fase sólida e 
líquida) em decorrência da ação de ventos causadores da remobilização dos metais de uma fase para outra.

A ausência de $\mathrm{Cu}$ em quase todas as amostras de sedimento particulado em suspensão, provavelmente está ligada a formação de compostos estáveis de $\mathrm{Cu}$ no sedimento de fundo. Segundo REIMANN e CARITAT (1998), há a formação de compostos estáveis de $\mathrm{Cu}$ quando da presença de sulfetos, $\mathrm{pH}$ elevado e adsorção, neste caso o pH deve estar contribuindo para a formação desta barreira geoquímica.

O $\mathrm{Cr}$ e Ni, como abordado no capítulo 5, são os metais pesados mais constantemente detectados nos sedimentos particulados em suspensão, nos dois períodos climáticos estudados. Tal fato pode estar relacionado a formação de sulfetos metálicos, onde foi detectado qualitativamente a presença de enxofre (S) nos mesmos grãos que foram encontrados estes metais, sendo esta hipótese comprovada apenas por análises químicas quantitativas e especiação química não realizadas nesta dissertação.

Como comprovado pelas análises químicas pontuais qualitativas realizadas sobre as colônias planctônicas, os metais pesados estão associados as partículas minerais e não ao material orgânico como era de se esperar. 


\section{7- CONCLUSÕES}

A apresentação dos resultados e discussões nesta dissertação permitem o estabelecimento de algumas conclusões acerca dos Sedimentos de Fundo, Sedimentos Particulados em Suspensão e Água de Interface, no ambiente lacustre investigado da Estação de Esgotos de Barueri:

1. Ficou demonstrado que os materiais obtidos nos sedimentos de fundo, diferentemente do que poderia ser esperado, exibiram distinções que permitiram classificá-los em três grupos: Sedimentos Argilosos, Sedimentos Aluvionares e Aterro.

2. Por se tratar de ambiente lacustre artificial e moderno, a deposição de sedimentos genuinamente lagunares é de pequena monta e não exibe grandes espessuras. No entanto, identifica-se claramente haver deposição sedimentar na forma de extratos, e que a contribuição dos materiais que constituem estes sedimentos advém de processos de carreamento de sedimentos que bordejam este lago (embasamento metamórfico e granitos principalmente), incluindo-se ai materiais de origem antropogênica (lodo de esgoto).

3. Verifica-se também claramente que, dependendo do tipo de critério empregado na determinação de processo de contaminação ou não do meio investigado, seja no emprego do Índice de Geoacumulação, ou do Fator de Contaminação, o resultado pode ser completamente diferente. Os valores em teores obtidos para os metais analisados neste trabalho mostraram que com o emprego de determinado critério, 0 ambiente pode ser considerado não contaminado e com o emprego de outro, este passa a ser considerado contaminado e sujeito e intervenção. 
4. Ficou demonstrado também que os ambiente lacustres, mesmo sendo a área investigada de origem artificial, representam meios extremamente sensiveis as modificações climáticas no que tange aos seus parâmetros físico-químicos. Tal afirmação é endossada com os valores de Eh e pH obtidos nas coletas do período seco e do período chuvoso. A alteração destas condições promovem a redistribuição dos elementos (inclusive os metais poluentes), tanto nos sedimentos de fundo, como nos particulados em suspensão e na própria coluna de água. Tal afirmação encontra apoio no fato de que os valores de $\mathrm{pH}$ e Eh obtidos no sedimento (básico e redutor), assemelham-se aos apresentados por HAKANSON e JANSSON (1983), para os valores ideais para retenção e concentração de metais pesados, principalmente pela possibilidade de formação de sulfetos metálicos. Adicione-se ainda que, nestes casos, a movimentação de águas de meios lacustres sofrem forte influência da direção preferencial dos ventos (SALOMONS e BACCINI, 1986) em cada uma das estações do ano em função de sua pequena lâmina de água, e assim, promovem a resuspensão de sedimentos de fundo. Deste modo, boa parte dos materiais poluentes que encontram-se sedimentados no ambiente lacustre estudado, podem ter sido retransportados para outros pontos.

5. Torna-se claro que os Sedimentos Argilosos são os maiores receptores dos metais investigados nesta dissertação pelas características apresentadas e discutidas nos diferentes capítulos desta dissertação. As análises químicas comprovaram a presença de metais pesados $(\mathrm{Cu}, \mathrm{Cr}, \mathrm{Ni}, \mathrm{Zn}$ e outros) nesse sedimento e permitiram concluir preliminarmente que $\mathrm{Cu}, \mathrm{Zn}$ e $\mathrm{Ni}$ exibem Fatores de Contaminação que os colocam como elementos poluentes nos sedimentos analisados. 
6.

Evidencia-se também que há intensa atividade biológica ditada pela existência de colônias de fitoplânctons, os quais interagem com os particulados em suspensão. Estes particulados em suspensão, como demonstrado, contem parte dos metais tidos como tóxicos investigados neste trabalho e acredita-se que este grupamento de origem biológica deve também interagir com os metais envolvidos neste meio.

7. Nesse estudo, verificou-se que $\circ \mathrm{Cu}$ e $\mathrm{Ni}$ apresentam curvas de isoconcentração similares, indicando que esses provavelmente apresentam mesmo comportamento químico no sedimento de fundo.

8. As análises realizadas sobre a água da interface demonstraram não contaminação desta, sendo necessário maior monitoramento para a verificação de provável liberação dos metais do sedimento para a coluna d'água. Por outro lado, verificou-se a presença dos metais de interesse no sedimento particulado em suspensão, indicando prováveis trocas destes metais com as diferentes fases que compõem o ambiente lacustre.

Entende-se assim, que o lodo de esgoto depositado na borda do ambiente lacustre analisado pode estar contribuído de forma efetiva na entrada de metais neste lago. Seja de modo dissolvido, seja como transporte de partículas por arrasto mecânico quando dos períodos de maior precipitação pluviométrica. Esta consideração encontra apoio na identificação através dos mapas de isoteores para os metais analisados que exibem concentrações elevadas dos quatro metais na estação de amostragem mais próxima da borda onde encontra-se depositado o Lodo de esgoto em superfície. 


\section{8 - REFERÊNCIAS BIBLIOGRÁFICAS}

ADRIANO, D. C. (1986) Trace Elements in the Terrestrial Environment. New York, Springer Verlag, $533 p$.

ALLOWAY, B. J. (1995) Heavy Metals in Soils. Second Edition, London, Blackie Academic \& Professional, $368 \mathrm{p}$.

ALMEIDA, F. F. M. (1964) Fundamentos Geológicos do Relevo Paulista In: Boletim do Instituto Geológico, São Paulo, 41, p.169-263.

ALMEIDA, F. F. M.; HASUI, Y. (1984) O Pré-Cambriano do Brasil. São Paulo, Edgard Blücher, p.308-344.

AMAZARRAY, M. T. R. (1992) Origem, Distribuição e Formas de Transferência de Elementos-Traços na Lagoa Emboaba - Uma Lagoa Costeira do Estado do Rio Grande do Sul. São Carlos, 291p. Tese de Doutorado, Instituto de Química, Universidade Federal de São Carlos.

ANDERSON, B. S.; HUNT, J. W.; PHILLIPS, B. M.; FAIREY, R.; ROBERTS, C. A.; OAKDEN, J. M.; PUCKETT, $H$. M.; STEPHENSON, M.; TJEERDEMA, R. S.; LONG, E. R.; WILSON, C. J.; LYONS, M. (2001) Sediment Quality in Los Angeles Harbor, USA: A Triad Assessment. Environmental Toxicology and Chemistry, v.20, 2, p.359-370.

ANKLEY, G. T. (1996) Evaluation of Metal/Acid-Volatile Sulfide Relationships in the Prediction of Metal Bioaccumulation by Benthic Macroinvertebrates. Environmental Toxicology and Chemistry, v.15, 12, p.2056-2066.

ASSUNÇÃO, J. C. B. (1996) Análise Mineralógica, Geoquímica e Textural de Lodos Gerados e Dispostos pela ETE de Barueri - SP: Associações com Metais Pesados e seus Efeitos no Solo. São Paulo, 120p. Dissertação de Mestrado, Instituto de Geociências, Universidade de São Paulo.

ASSUNÇÃO, J. C. B.; SÍGOLO, J. B. (1997) Influência do Ambiente Tropical em Lodos Gerados na Estação de Tratamento de Esgoto de Barueri SP: Comportamento dos Metais Pesados. Revista Brasileira de Geociências, v.27, p355-364.

ASSUNÇÃO, J. C. B.; SíGOLO, J. B. (1998) Evolução Geoquímica de Lodos Gerados na ETE de Barueri, SP: Efeitos de sua Exposição ao Clima Tropical. Revista Geochima Brasiliensis, v.12, p001-016.

ASSUNÇÃO, J. C. B.; SíGOLO, J. B. (2000) Heavy Metal Behavior in Sawage Sludge in Tropical Conditions. $31^{\text {st }}$ International Geological Congress. CD Room Abstracts and Poster Geociências Presentation, Session 14-5, Booth C55. Rio de Janeiro. 
BAUDO, R; GIESY, J. P.; MUNTAU, H. (1990) Sediments: Chemistry and Toxicity of in Place Pollutants. Lewis Publishers, Boston, Inc. Boca Raton, 405p.

BOURG, A. C. M. (1995) Speciation of Heavy Metals in Soils and Groundwater and Implications for their Natural and Provoked Mobility. In: SALOMONS, W.; FÖRSTNER, U. MADER, P. (eds.) Heavy Metals: Problems and Solutions, New York, Springer Verlag. p.19-31.

CALMANO, W.; FÖRSTNER, U. (1996) Sediments and Toxic Substances: Environment Effects and Ecotoxicity. Berlin, Springer Verlag, Heidelberg, p.01-29.

COMPANHIA DE TECNOLOGIA DE SANEAMENTO AMBIENTAL - CETESB (1994) Relatório de Qualidade Ambiental no Estado de São Paulo, 1993. Série de Relatórios/CETESB. São Paulo, 59p.

COVELLI, S.; FONTOLAN, G. (1997) Application of a Normalization Procedure in Determining Regional Geochemical Baselines. Environmental Geology, Springer Verlag, 30, p.34-45.

DEPARTAMENTO DE ÁGUAS E ENERGIA ELÉTRICA - DAEE (1975) Estudos de Águas Subterrâneas - Região Administrativa 1 - Grande São Paulo, São Paulo, v 1, Textos, 220p.

DEPARTAMENTO NACIONAL DE PESQUISA MINERAL - DNPM/CPRM (1991) Projeto Integração Geológica da Região Metropolitana de São Paulo. São Paulo. DNPM/CPRM. 65p e 28 mapas.

EMPRESA BRASILEIRA DE PESQUISA AGROPECUÁRIA - EMBRAPA (1999) Sistema Brasileiro de Classificação de Solos. Centro Nacional de Pesquisa de Solos, Ministério da Agricultura e Abastecimento. Brasília, $412 p$.

EMPRESA METROPOLITANA DO PLANEJAMENTO DE SÃO PAULO EMPLASA (2001) Sumário de Dados da Grande São Paulo. Metrópoles em Dados - Região Metropolitana de São Paulo. (http://www.emplasa.sp.gov.br). 16/10/01.

ESTEVES, F. A. (1988) Fundamentos de Limnologia. Rio de Janeiro, Interciência/FINEP, 575p.

FÖRSTNER, U.; WITTMANN, G. T. W. (1981) Metal Pollution in the Aquatic Environment. First Edition, Heidelberg, Springer Verlag, 486p.

FÖRSTNER, U. (1983) Metal Transfer Between Solid and Aqueous Phases in: Metal Pollution in the Aquatic Environment. New York, Spring Verlag, p.197-269.

FÖRSTNER, U. (1990) Inorganic Sediment Chemistry and Elemental Speciation. In: BAUDO, R.; GIESY, J.; MUNTAU, H. (eds.) Sediments: 
Chemistry and Toxicity of in-place Pollutants. Boston, Lewis Publisher, p.61-105.

FÖRSTNER, U.; WOLFGANG, A.; WOLFGANG, C.; KERSTEN, M. (1990) Sediment Criteria Development from Environmental Geochemistry to Water Quality Management In: HELING, D.; ROTHE, P.; FÖRSTNER, U.; STOFFERS, P. (eds.). Sediments and Environmental Geochemistry: Selected Aspects and Case Histories. Springer Verlag, p.312-338.

GIBBS, R. J. (1977) Transport Phases of Transition Metals in the Amazon and Tukon Rivers. Geol. Soc. Am. Bull, v.88, p.829-843.

HAKANSON, L., JANSSON, M. (1983) Principles of Lake Sedimentology. Berlin, Springer Verlag, Heidelberg, 316p.

INSTITUTO AGRÓNOMICO DE CAMPINAS - IAC (1999) Mapa Pedológico do Estado de São Paulo, Escala 1:500 000, EMBRAPA/IAC, 64p.

INSTITUTO DE PESQUISAS TECNOLÓGICAS - IPT (1981a) Mapa Geológico do Estado de São Paulo, Escala 1:500.000. PRÓ MINÉRIO/PROMOCET, 1981, v.1, 126p.

JANASI, V. A.; ANDRADE, S.; ULBRICH, H. H. G. J. (1995) A Correção do "Drift" Instrumental em ICP.AES com Espectrômetro Seqüêncial e Análise de Elementos Maiores, Menores e Traços em Rochas. Bol. IGUSP, Série Científica, 26, p.45-58.

LERMAN, A.; IMBODEN, D. M.; GAT, J. R. (1995) Physics and Chemistry of Lakes. Berlin, Springer Verlag, Heidelberg, p.217-258.

MERIAN, E. (1991) Metals and Their Compounds in the Enverionment. Occurrence, Analysis and Biological Relevance. VHC, Verlagsgesellschaft, Weinheim, 1373p.

MOORE, J. W.; RAMAMOORTHY, S. (1984) Heavy Metals in Natural Waters. First Edition. New York, Springer Verlag, 267p.

MOORE, J. W.; (1991) Inorganic Contaminants of Surface Water: Research and Monitoring Priorities, Springer Verlag, New York, p.334.

MOZETO, A. A. (1997) Como Avaliar a Qualidade da Água de Mananciais. Rev. Ciência Hoje, v.22, 127, p.16-19.

MOZETO, A. A.; JARDIM, W. F; VALENT, G. U. (1998) Projeto QUALISED: Bases Técnico-Científicas para o Desenvolvimento de Critérios de Qualidade de Sedimentos (CSQ): Experimentos de Campo e Laboratório. Projeto Temático de Pesquisa FAPESP, 61p.

MUDROCH, A.; MACKNIGHT, S. D., (1994) Techniques for Aquatic Sediments Sampling. Second Edition. Lewis Publishers, Boca Raton, 236p. 
MUDROCH, A.; AZCUE, J. M. (1995). Manual of Aquatic Sediment Sampling, Lewis Publishers, Boca Raton, Florida, $219 \mathrm{p}$.

NAVARRA, C. T.; FURTADO, V. V.; EICHLER, B. B.; PRADO, O. R. (1980) Distribuição da Matéria Orgânica nos Sedimentos Costeiros e nos Solos Hidromórficos do Estado de São Paulo. Boletim do Instituto Oceonográfico, IO/USP, v.29, p.267-270.

NIMER (1989) Climatologia do Brasil . Segunda Edição, BGE-DERNA, Rio de Janeiro, 422p.

NOVOTNY, V. (1995) Diffuse Sources of Pollution by Toxic Metals and Impact on Receiving Waters. In: SALOMONS, W.; FÖRSTNER, U.; MADER, P. (eds). Heavy Metals: Problems and Solutions. Germany, Springer Verlag, p.33-52.

PENALOZA, A. (2001) Avaliação do Impacto Causado na Zona Saturada Pelos Metais Pesados Provenientes da Deposição de Lodo Residual na ETE de Barueri - SP. São Paulo, 90p. Dissertação de Mestrado, Instituto de Geociências, Universidade de São Paulo.

RAMAMOORTHY, S.; RUST, B. R. (1978) Heavy Metal Exchange Process in Sediment Water Systems. Environmental Geology, v.2, 3, p. 165-172.

REIMANN, C.; CARITAT, P. (1998) Chemical Elements in the Environment: Factsheets for the Geochemist and Environmental ScientistGermany. Springer Verlag, Berlin. Heidelberg, p.96-381.

RIBEIRO, A. P.; FIGUEIREDO, A. M. G.; SÍGOLO, J. B. (2001) Ativação Neutrônica Aplicada a Análise de Sedimentos Lacustres da Estação de Tratamento de Esgotos de Barueri - São Paulo. In: Actas do VI Cong. Geoq. Países de Língua Portuguesa e XII Sem. Geoquímica. Univiversidade do Algarve, Faro, Portugual, p.670-674.

RUDD, T. (1987) Scope of the Problem in Heavy Metals in Wastewater and Sludge Treatment Processes. Florida, Press, Inc. Boca Raton, v.1, CRC, p.1-29.

SALOMONS, W.; BACCINI, P. (1986) Chemical Species and Metal Transport in Lakes. In: BERNHARD, M.; BRINCKMAN, F. E. \& SADLER, P. J. The Importance of Chemical Speciation in Environmental Processes. Berlin, Springer Verlag, p.193-216.

SALOMONS, W.; FÖRSTNER, U. MADER, P. (1995). Heavy Metals: Problems and Solutions. Springer Verlag, Berlin, Heidelberg, New York, 412p.

SALOMONS, W.; STIGLIANI, W. M. (1995) Biogeodynamics of Pollutants in Soils and Sediments. Berlin, Springer Verlag, Heidelberg, p.87-100.

SíGOLO, J. B. (1998) Aplicação da Geoquímica de Superfície na Análise da Mobilidade e Concentração de Metais Pesados em Ambiente Tropical. 
São Paulo, 216 p. Tese de Livre-Docência, Instituto de Geociências, Universidade de São Paulo.

SIGOLO, J. B.; GUIMARÃES, V. (2001) Distribuição do Conteúdo de $\mathrm{Cu}, \mathrm{Cr}, \mathrm{Zn}$ e Ni em Sedimentos Lacustres da ETE de Barueri - SP. In: Actas do VI Cong. Geoq. Países de Língua Portuguesa e XII Sem. Geoquímica. Universidade do Algarve, Faro. Portugual, p.316-320.

SINGH, A. K.; HASNAIN, S. I.; BANERJEE, D. K. (1999) Grain Size and Geochemical Partitioning of Heavy Metals in Sediments of the Damodar River - A Tributary of the Lower Ganga, India. Environmental Geology, v. 39,1, p.90-98.

STUMM, W.; MORGAN, J. J. (1996) Aquatic Chemistry. A Wiley-Interscience Publication, USA, Limnological Research Center, University of Minnesota, 1022p.

SUGUIO K. (1973) Introdução à Sedimentologia. Editora Edgard Blücher, EDUSP, São Paulo, 317p.

SUTHERLAND, R. A. (2000) A Comparison of Geochemical Information Obtained from two Fluvial bed Sediment Fractions. Environmental Geology. Springer Verlag, v.39, p.330-341.

TESSIER, A.; CAMPBELL, P. G. C.; BISSON, M. (1979) Sequential Extraction Procedure for the Speciation of Particulate Trace Metals. An. Chem., 51, p.844-851.

TESSIER, A.; RAPIN, F.; CARIGNAN, R. (1985) Trace Metals in Oxic Lake Sediments: Possible Adsorption Onto Iron Oxyhydroxides. Geochimica et Cosmochimica Acta, 49, p.183-194.

TUREKIAN, K. K.; WEDEPOHL, K. H. (1961) Distribution of the Elements in Some Major Units of the Earth's Crust. Geological Society of America Bulletin, v.72, p.175-192.

TURCQ, B; MELO, M. S. (1989) O Quaternário na Área da Grande São Paulo. In: Workshop Geologia da Bacia de São Paulo. São Paulo. IGUSP/SBG, p.64-70. 